U.S. DEPARTMENT OF

(2.) ENERGY

Prepared for the U.S. Department of Energy under Contract DE-AC05-76RL01830

\title{
Uranium Metal Reaction Behavior in Water, Sludge, and Grout Matrices
}

\author{
$\mathrm{CH}$ Delegard
}

AJ Schmidt

September 2008

\section{Pacific Northwest}




\section{Uranium Metal Reaction Behavior in Water, Sludge, and Grout Matrices}

$\mathrm{CH}$ Delegard

AJ Schmidt

September 2008

Prepared for

the U.S. Department of Energy

under Contract DE-AC05-76RL01830

Pacific Northwest National Laboratory

Richland, Washington 99352 


\section{Summary}

This report summarizes information and data on the reaction behavior of uranium metal in water, in water-saturated simulated and genuine $\mathrm{K}$ Basin sludge, and in grout matrices. This information and data are used to establish the technical basis for metallic uranium reaction behavior for the K Basin Sludge Treatment Project (STP). The specific objective of this report is to consolidate the various sources of information into a concise document to serve as a high-level reference and road map for customers, regulators, and interested parties outside the STP (e.g., external reviewers, other DOE sites) to clearly understand the current basis for the corrosion of uranium metal in water, sludge, and grout.

The generation of hydrogen gas through oxidation/corrosion of uranium metal by its reaction with water can potentially create a flammable atmosphere during sludge handling, grouting, or subsequent transport and storage operations. Consequently, a thorough understanding of the uranium metal content and its reaction behavior, both in sludge and in grouted sludge matrices, is essential to the process designs and for management of sludge. Results of studies of this reaction and its characteristics have been reported in the technical literature for over 60 years. More focused studies of the reaction in simulated and genuine $\mathrm{K}$ Basin sludge and in grout matrices have been conducted in the past 10 years. The outcomes of these studies, provided in the present review, show that:

- The reaction of uranium metal with anoxic liquid water is highly exothermic and produces stoichiometric uranium dioxide $\left(\mathrm{UO}_{2}\right)$ and hydrogen.

- The reaction apparently proceeds through a uranium hydride intermediate that can sequester part of the hydrogen during the initial reaction.

- The corrosion reaction occurs isotropically such that the uranium particle size decreases at a constant rate at a given temperature.

- Based on a survey of 32 studies giving 128 data points, the corrosion rate follows an Arrhenius dependence on temperature (i.e., the logarithm of the rate is proportional to the inverse absolute temperature) from at least $24^{\circ} \mathrm{C}$ to $350^{\circ} \mathrm{C}$. The rate law was adopted for the STP. A $95 \%$ confidence level on the predicted rate is plus/minus about a factor of three.

- The STP rate law is essentially the same as used in the application to license the Yucca Mountain repository.

- Dissolved oxygen inhibits the reaction of uranium metal with liquid water, but the more rapid anoxic reaction can follow the lower oxic rates at times that are difficult to predict but which decrease with increased temperature.

- The corrosion rates of non-irradiated uranium metal, with and without simulated sludge, and irradiated metallic N Reactor fuel particles, with and without $\mathrm{K}$ Basin sludge, were measured at temperatures ranging from about $40^{\circ} \mathrm{C}$ to $95^{\circ} \mathrm{C}$. The rates correspond well with the rates observed for uranium metal in anoxic water. However, the corrosion rates for $\mathrm{N}$ Reactor fuel particles irradiated to $\sim 2,800 \mathrm{MWD} / \mathrm{MTU}$ (megawatts per day per metric ton of uranium) were lower than the regression line by about a factor of three.

- Uranium metal concentrations in K Basin sludge were found to be more reliable when based on the release of fission product gases (krypton and, with more sensitivity, xenon) than when based 
on hydrogen generation. Hydrogen was not necessarily completely distributed to the gas phase, particularly for low uranium metal concentrations in sludge, suggesting that trace hydrogen likely reacted with sludge constituent(s). Evidence for sequestration of hydrogen to uranium metal hydride also was observed. Uranium metal concentrations as low as about $0.004 \mathrm{wt} \%$ were determined by xenon gas release measurements.

- The size of irradiated uranium metal particles in sludge can be determined by analyzing the rate of fission product gas release. A self-consistent uranium metal particle-size distribution for a composite of canister sludge from 11 locations (KC-2/3 P250) was found with a Sauter mean diameter of about $560 \mu \mathrm{m}$.

- Tests of the effects of grouting on the rate of hydrogen generation from simulated $\mathrm{K}$ Basin sludge described by two independent laboratories showed that the corrosion rate of uranium metal in grout is consistent with the rate observed in water. At best, the rate was decreased by a factor of 2 to 3 as a result of specific grout formulation. Even with this decrease, the corrosion rate results lie within the $95 \%$ confidence level of the STP rate law. 


\section{Acronyms}

BNFL British Nuclear Fuels, Limited

DOE U.S. Department of Energy

EBR Experimental Breeder Reactor

FH Fluor Hanford

MTU metric ton of uranium

MWD megawatts per day

PNNL Pacific Northwest National Laboratory

$\mathrm{RH} \quad$ remote handled

SAIC Science Applications International Corporation

SNF spent nuclear fuel

STP Sludge Treatment Project

TRU transuranic (waste)

WIPP Waste Isolation Pilot Plant

XRD X-ray diffraction 



\section{Contents}

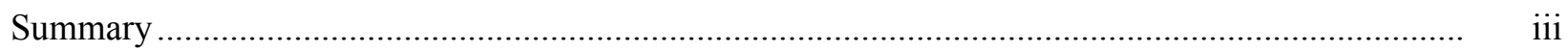

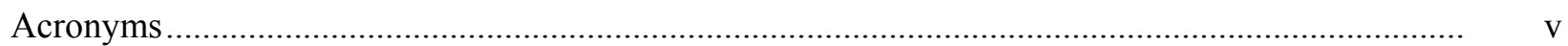

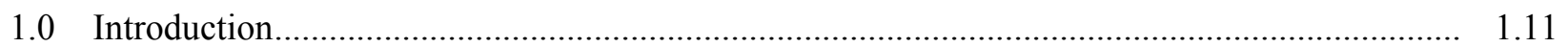

2.0 Reaction of Uranium Metal with Water............................................................................ 2.1

2.1 Reaction Mechanism, Thermodynamics, Stoichiometry, and Product Characteristics ...... 2.1

2.2 Uranium Metal Corrosion Rates in Anoxic Liquid Water................................................ 2.3

2.3 Review of the Reaction Rate Data from the Technical Literature and the STP Rate Law . $\quad 2.6$

2.4 Uranium Metal Corrosion Rates in Oxic Liquid Water.................................................. 2.9

3.0 STP Testing-Uranium Metal Corrosion Rate, Concentration, and Particle Size

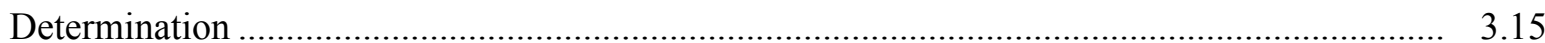

3.1 Correspondence of Non-Irradiated Uranium Metal Corrosion Rates in Water and in Simulated Sludge with Predicted Rates .................................................................... 3.15

3.2 Correspondence of Irradiated Uranium Metal Corrosion Rates in Water and in Sludge with Predicted Rates ............................................................................................ 3.16

3.3 Crumbling of Uranium Metal During Corrosion .......................................................... 3.19

3.4 Determination of Uranium Metal Concentration in K Basin Sludge ................................. 3.20

3.4.1 Uranium Metal Concentration by Reaction Calorimetry .................................... 3.21

3.4.2 Uranium Metal Concentration by Gas Generation and Release .......................... 3.21

3.4.3 Uranium Metal Concentration by Selective Dissolution ...................................... 3.23

3.5 Modeling Corrosion Rates in K Basin Sludge by Gas Generation Analysis to Determine Uranium Metal Particle-Size Distribution .................................................................. 3.26

4.0 Uranium Metal Oxidation in Grouted Simulated Sludge.........................................................

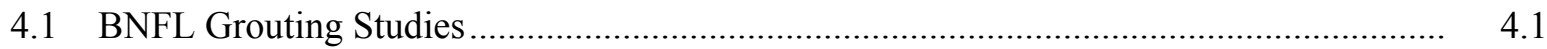

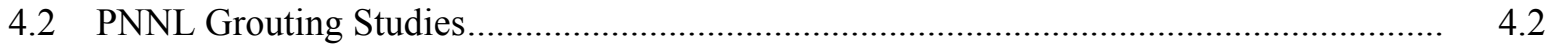

4.3 Results of BNFL and PNNL Testing .........................................................................

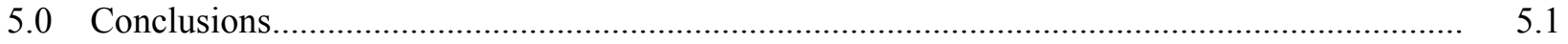

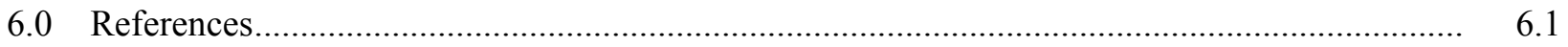




\section{Figures}

2.1. Manhattan Project Arrhenius Plot of Uranium Metal-Corrosion Rate Temperature Dependence in Anoxic Liquid Water

2.2. Arrhenius Plot of Published Rate Data for Uranium Metal Corrosion in Anoxic Liquid Water and Comparison with Regression of Data.

2.3. Comparison of Uranium Metal Oxidation-Rate Data for Anoxic Water from the Technical Literature with Uranium Metal Oxidation Rate in Aerated Water .

2.4. Uranium Metal-Corrosion Weight Loss in Aerated Distilled Water as a Function of Temperature and Time

3.1. Gas Generation Test Apparatus

3.2. Comparison of Uranium Metal Oxidation Rate Data from the Technical Literature with Data from Tests of Non-Irradiated Uranium Metal Beads with and Without Simulated Sludge Based on $\mathrm{H}_{2}$ Generation.

3.3. Comparison of Anoxic Uranium Metal Oxidation-Rate Data from the Technical Literature with Data from Tests of Irradiated Uranium with and Without K Basin Sludge Based on Xe Release

3.4. Uranium Concentrations in Settled K Basin Sludge as Determined by Chemical Gas Compared with Xe Fission Product Gas Release

3.5. Uranium Metal-Concentration Analysis by Selective Dissolution....

3.6. Progress of the Uranium Metal-Corrosion Reaction in KC-2/3 P250 Sludge as Measured by $\mathrm{H}_{2}$ Generation and Xe Release.

3.7. Rate of Uranium Oxidation by Water Expressed by the Shrinking Core Model.....

3.8. Model Shrinking Core Corrosion of Uranium Metal Versus Corrosion Observed Based on Xe Release Data.

4.1. Comparison of Uranium Metal Oxidation-Rate Data from the Technical Literature with BNFL Maximum Rate Grouts, BNFL Minimum Rate Grouts, and PNNL Grouts Based on $\mathrm{H}_{2}$ Generation

4.2. Comparison of Uranium Metal Oxidation-Rate Data from the Technical Literature with Data from BNFL Tests of Grouted Uranium Metal Pennies and Cylinders, BNFL Tests of Grouted Uranium Metal Pennies in Dry Blends, and PNNL Tests of Grouted Uranium Metal Beads in Simulated Sludge Based on $\mathrm{H}_{2}$ Generation.

5.1. Summary of Non-Irradiated and Irradiated Uranium Metal Corrosion-Rate Data in Anoxic Water, Sludge, and Grout Matrices 


\section{Tables}

2.1. Predicted Corrosion Rate Parameters and High/Low Values at the $95 \%$ Confidence Limits

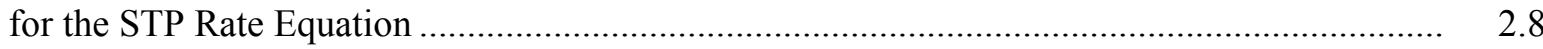

3.1. Uranium Metal Concentrations in K Basin Sludge Based on Gas Generation Testing .............. 3.24

3.2. Induction Times for Uranium Metal Corrosion in KC-2/3 P250 Sludge as Measured by $\mathrm{H}_{2}$

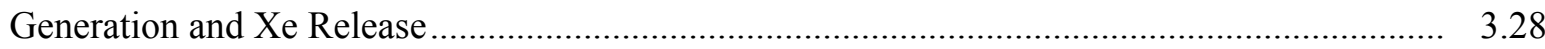

3.3. Uranium Metal-Particle Size Calculation for KC-2/3 P250 Sludge ....................................... 3.29

3.4. Initial Uranium Metal Particle-Size Distribution............................................................... 3.30

4.1. Grouted Simulated Sludge Test Matrix …............................................................................ 4.3 



\subsection{Introduction}

The generation of hydrogen gas through oxidation/corrosion of uranium metal by its reaction with water can potentially create a flammable atmosphere during sludge handling, grouting, or subsequent transport and storage operations. Consequently, a thorough understanding of the uranium metal content and its reaction behavior, both in sludge and in grouted sludge matrices, is essential to the process designs and for management of sludge. This report consolidates the various sources of information into a concise document to serve as a high-level reference and road map for customers, regulators, and interested parties outside the Sludge Treatment Project (STP) (e.g., external reviewers, other U.S. Department of Energy [DOE] sites, etc.) to clearly understand the current basis for the corrosion of uranium metal in water, sludge, and grout. This report was prepared at the specific request of Fluor Hanford (FH) in accordance with the Statement of Work associated with Contract 27647-38. ${ }^{\text {(a) }}$

$\mathrm{K}$ Basin sludge was generated in two water-filled concrete pools (K East and $\mathrm{K}$ West Basins) during the storage and packaging of irradiated uranium metal fuel elements irradiated in the Hanford Site N Reactor. The elements were stored in aluminum or stainless steel canisters at the pool bottoms. By Project definition, sludge is composed of any $\mathrm{K}$ Basin particulate that can pass through a 0.25 -inch screen. Sludge has been characterized and categorized based on its location of origin (i.e., basin floors, fuel canisters, basin pits, and sludge associated with fuel cleaning and packaging operations). Each type of sludge is a unique mixture containing irradiated uranium metal nuclear fuel corrosion products (i.e., uranium oxides, oxide hydrates, hydride), uranium metal fuel particles, Zircaloy cladding pieces, debris such as windblown soil minerals or insects, rack and canister corrosion products (aluminum and iron hydroxides), depth filter silica sands, organic ion exchange resin beads, inorganic ion exchange granules, Grafoil gasket material, and accompanying fission and activation products in various combinations and concentrations. The sludge from the K Basin floors, canisters, and pits has been consolidated from its original locations and currently resides in five large "Engineered Containers" located underwater in the KW Basin pool. Sludge associated with fuel cleaning/packaging operations (Settler Tank Sludge and Knockout Pot Sludge) is also currently stored in the KW Basin.

The STP is currently designing a process to solidify the sludge in a grout matrix and package it for ultimate disposition to the Waste Isolation Pilot Plant (WIPP) as remote handled transuranic waste (RH TRU). The generation of hydrogen gas through oxidation/corrosion of uranium metal by its reaction with water can potentially create a flammable atmosphere during sludge handling, grouting, or subsequent transport and storage operations. Consequently, a thorough understanding of the uranium metal content and its reaction behavior, both in sludge and in grouted sludge matrices, is essential to the process designs and for management of sludge.

This report describes background in the chemistry of the uranium metal reaction with water, generally based on historical studies and reviews (Section 2). The testing done under the STP and prior related projects on the behaviors and qualities of uranium in sludge are described in Section 3. Tests of uranium metal corrosion in grouts with and without simulated sludge are addressed in Section 4. Section 5 summarizes the conclusions from these evaluations, and Section 6 provides the references.

(a) Statement of Work, "PNNL Technical Support for Sludge Treatment Engineering," accompanying the transmittal of Contract 27647-38, Amendment 3, on September 25, 2006. 


\subsection{Reaction of Uranium Metal with Water}

A general introduction to the chemistry of the uranium metal reactions in sludge and a discussion of the reaction rate are provided in this section.

\subsection{Reaction Mechanism, Thermodynamics, Stoichiometry, and Product Characteristics}

The reaction of uranium metal with anoxic liquid water (i.e., free of dissolved oxygen) below $350^{\circ} \mathrm{C}$ proceeds according to the following reaction to form uranium dioxide $\left(\mathrm{UO}_{2}\right)$ and $\mathrm{H}_{2}$ :

$$
\mathrm{U}+2 \mathrm{H}_{2} \mathrm{O} \rightarrow \mathrm{UO}_{2}+2 \mathrm{H}_{2}
$$

The reaction is highly exothermic. The enthalpy of reaction, $\Delta \mathrm{H}_{298}$, is $-513.2 \mathrm{kcal} / \mathrm{mole}$ of uranium (based on thermodynamic data given by Wagman et al. 1982). In comparison, the $\Delta \mathrm{H}_{298}$ for the reaction of $\mathrm{H}_{2}$ with oxygen gas, $\mathrm{O}_{2}$, to form water $\left(\mathrm{H}_{2}+0.5 \mathrm{O}_{2} \rightarrow \mathrm{H}_{2} \mathrm{O}\right)$ is $-285.8 \mathrm{kcal} / \mathrm{mole}$ of hydrogen.

Once a small amount of $\mathrm{H}_{2}$ is generated, it can react directly with uranium metal to form uranium hydride $\left(\mathrm{UH}_{3}\right)$. Because of the high diffusivity of $\mathrm{H}_{2}$, the $\mathrm{UH}_{3}$ often is found along cracks, grain boundaries, or in crevices (such as beneath cladding) in uranium metal corrosion. The $\mathrm{UH}_{3}$ then can function as an intermediate by its reaction with water to form $\mathrm{UO}_{2}$. The $\mathrm{H}_{2}$ released by the reaction of $\mathrm{UH}_{3}$ with water becomes available to react with more uranium metal, if present, or escape into solution and the gas phase. The reaction of uranium metal with water thus occurs by the following reaction sequence which, if summed, is equivalent to the reaction of uranium metal with water to form $\mathrm{UO}_{2}$ and $\mathrm{H}_{2}$ :

$$
\begin{gathered}
\mathrm{U}+1.5 \mathrm{H}_{2} \rightarrow \mathrm{UH}_{3} \\
\mathrm{UH}_{3}+2 \mathrm{H}_{2} \mathrm{O} \rightarrow \mathrm{UO}_{2}+3.5 \mathrm{H}_{2}
\end{gathered}
$$

Reactions of uranium metal with dissolved $\mathrm{O}_{2}$ and nitrogen $\left(\mathrm{N}_{2}\right)$ gases with uranium metal potentially also can occur, although the evidence for the latter reaction is speculative under aqueous sludge temperatures and conditions:

$$
\begin{gathered}
\mathrm{U}+\mathrm{O}_{2} \rightarrow \mathrm{UO}_{2} \\
\mathrm{U}+0.875 \mathrm{~N}_{2} \rightarrow \mathrm{UN}_{1.75}
\end{gathered}
$$

The production of $\mathrm{H}_{2}$ or consumption of $\mathrm{O}_{2}$ and $\mathrm{N}_{2}$ are not, however, unique or quantitative indicators of the presence of uranium metal in sludge, especially at low concentrations. For example, $\mathrm{H}_{2}$ might also arise from the radiolysis of water or the corrosion of aluminum and mild steel or be consumed in secondary reactions with other phases. Similarly, $\mathrm{N}_{2}$ and particularly $\mathrm{O}_{2}$ (as will be seen) also may be consumed by other reactions or, in the case of $\mathrm{O}_{2}$, produced by water radiolysis.

According to most technical literature on the subject, the net anoxic reaction of uranium metal with water is hyperstoichiometric, forming $\mathrm{UO}_{2+\mathrm{x}}$, with $\mathrm{x}$ being less than 0.1 (Hilton 2000, p. 21). The technical literature also notes that the uranium oxide formed on the metal surface is not protective and periodically spalls from the surface. In anoxic water vapor, uranium oxide laminae about $0.1 \mu \mathrm{m}$ thick are formed 
under the surface-adsorbed water. When the uranium oxide product thickness reaches about $0.1 \mu \mathrm{m}$, the oxide spalls off as sheets (Hilton 2000, p. 17). The product oxide layers formed in liquid anoxic water are similar to those observed in anoxic water vapor (Baker et al. 1966a; Kaminski 2001) and likely reflect their similar reaction kinetics and mechanisms.

Recent X-ray diffraction (XRD) characterization of the reaction product of irradiated $\mathrm{N}$ Reactor fuel with $90^{\circ} \mathrm{C}$ anoxic water showed that the uranium oxide product formula was $\mathrm{UO}_{2.08 \pm 0.03}$. According to transmission electron microscopy, the reaction product particle size was $<10 \mathrm{~nm}$ within $\sim 150$-nm agglomerates (Kaminski et al. 2005).

In separate later experiments, the oxidation state of the uranium oxide produced by the $60^{\circ} \mathrm{C}$ reaction of uranium metal in anoxic water was analyzed by spectrophotometry of the solution produced by dissolving the uranium oxide in concentrated phosphoric acid containing $0.14 \mathrm{M} \mathrm{Na}_{2} \mathrm{SO}_{4}$ (Sinkov et al. 2008). The product was found to have the formula $\mathrm{UO}_{2.004 \pm 0.007}$. In the same study, particle-size analysis was performed by XRD and by analyzing the reaction rate of the uranium oxide with dissolved $\mathrm{O}_{2}$. These techniques showed that most particles to have $\sim 6-\mathrm{nm}$ diameter with the presence of smaller particles and larger agglomerates.

Based on these findings, the uranium oxide product formed by anoxic aqueous corrosion of uranium metal is taken to be stoichiometric $\mathrm{UO}_{2}$. The hyperstoichiometric uranium oxide compounds may have been observed in prior studies because of the marked susceptibility of the nascent and finely particulate $\mathrm{UO}_{2}$ to oxidation by atmospheric $\mathrm{O}_{2}$. Uranium dioxide, $\mathrm{UO}_{2}$, freshly prepared by anoxic uranium metal corrosion in water, reacts readily with gaseous or dissolved atmospheric $\mathrm{O}_{2}$ to become hyperstoichiometric (gaining oxygen) $\mathrm{UO}_{2+\mathrm{x}}$ and is further oxidized to form metaschoepite, $\mathrm{UO}_{3} \cdot 2 \mathrm{H}_{2} \mathrm{O}$ (Sinkov et al. 2008):

$$
\begin{gathered}
\mathrm{UO}_{2}+0.5 \mathrm{x} \mathrm{O}_{2} \rightarrow \mathrm{UO}_{2+\mathrm{x}} \\
\mathrm{UO}_{2}+0.5 \mathrm{O}_{2}+2 \mathrm{H}_{2} \mathrm{O} \rightarrow \mathrm{UO}_{3} \cdot 2 \mathrm{H}_{2} \mathrm{O}
\end{gathered}
$$

Sludge characterization by XRD techniques shows the progression of phases arising from the corrosion of uranium metal and subsequent uranium oxidation and mineralization reactions. The phases include $\mathrm{UH}_{3}$, uraninites $\left(\mathrm{UO}_{2}, \mathrm{U}_{4} \mathrm{O}_{9}, \mathrm{U}_{3} \mathrm{O}_{7}\right)$, triuranium octaoxide $\left(\mathrm{U}_{3} \mathrm{O}_{8}\right)$, various schoepites and metaschoepites (e.g., $\mathrm{UO}_{3} \cdot 2.25 \mathrm{H}_{2} \mathrm{O}, \mathrm{UO}_{3} \cdot 2 \mathrm{H}_{2} \mathrm{O}$ ), uranyl peroxides (studtite and metastudtite; $\mathrm{UO}_{4} \cdot 4 \mathrm{H}_{2} \mathrm{O}$ and $\mathrm{UO}_{4} \cdot 2 \mathrm{H}_{2} \mathrm{O}$, respectively), and hexavalent sodium, potassium, and calcium uranium compounds, such as becquerelite $\left[\mathrm{Ca}\left(\mathrm{UO}_{2}\right)_{6} \mathrm{O}_{4}(\mathrm{OH})_{6}\left(\mathrm{H}_{2} \mathrm{O}\right)_{8}\right]$ and compreignecite $\left[\mathrm{K}_{2}\left(\mathrm{UO}_{2}\right)_{6} \mathrm{O}_{2}(\mathrm{OH})_{6} \cdot 8 \mathrm{H}_{2} \mathrm{O}\right]$, but no uranium metal itself (Makenas et al. 1996, 1997, 1998, and 1999; Delegard et al. 2007). The high uranium concentrations in the solids and the variety of uranium phases present in most sludges complicate the interpretation of the XRD information and the understanding of the sludge qualities. The following remark attests to the difficulties faced in understanding the uranium oxide compositions (Katz and Seaborg 1957, p. 138):

The uranium-oxygen system is the most complex of the actinide element-oxygen systems and if not actually the most complex oxide system of any element in the Periodic Table, it comes close to achieving this dubious distinction. 


\subsection{Uranium Metal Corrosion Rates in Anoxic Liquid Water}

Understanding the reaction of uranium metal with water has been of great technical importance since the Manhattan Project. The initial interest was rooted in the design and operation of the original aluminum metal-clad, uranium metal-fueled, and light water-cooled nuclear reactors for operation at the Hanford Site. Interest in the reaction of uranium metal with liquid water at the Hanford Site continued in the design and operation of zirconium metal-clad and water-cooled uranium metal fuel used in the N Reactor and, worldwide, in the plutonium production reactors in the United Kingdom, France, and the Soviet Union, the NRX reactor in Canada, the CIRUS reactor in India, and other uranium metal-fueled reactors. The topic continues to be of technical interest in the geologic storage of uranium metal fuel (Bechtel 2004), in technological uses of uranium metal, including radiological shielding, counterweights, and armor-penetrating projectiles (e.g., Buck et al. 2004) and in treating the K Basin sludge and related streams that contain uranium metal particles and fragments.

As noted, the $\mathrm{UO}_{2}$ layer that forms on the surface of uranium metal is not protective and does not inhibit further corrosion. Therefore, the corrosion rate is linear (proportional to time) or specifically paralinear (initially parabolic but becoming linear following cyclic spallation and re-generation of the non-adherent uranium oxide layer). Protective corrosion layers generally exhibit parabolic (proportional to $\sqrt{\text { time }}$ ) reaction kinetics characteristic of diffusion-controlling protective corrosion product layers. Protective corrosion layers are found, for example, for stainless steel or zirconium in nitric acid applications or zirconium cladding in reactor coolant water.

Uranium metal corrosion in anoxic liquid water generally is uniform (i.e., occurs smoothly over the entire exposed surface) and shows little pitting. ${ }^{\text {(a) }}$ Thus, corrosion rates are expressed in units dependent on surface area, such as weight gain of solids to form $\mathrm{UO}_{2}, \mathrm{mg} / \mathrm{cm}^{2} \cdot \mathrm{h}$, or weight loss of uranium metal, $\mathrm{mg} / \mathrm{cm}^{2} \cdot$ day.

The uniform corrosion of uranium metal also may be expressed as a linear penetration rate by dividing the surface area-dependent rates by the density of uranium metal $\left(19.1 \mathrm{~g} / \mathrm{cm}^{3}\right)$. For example, a rate of $0.0253-\mathrm{mg}$ uranium-solids weight gain per $\mathrm{cm}^{2} \cdot$ day (as will be seen, the rate expected at $60^{\circ}$ ) may be converted to linear penetration rate of uranium metal, in $\mu \mathrm{m} /$ hour, by the following calculation:

$$
\frac{0.0253 \mathrm{mg} \text { gain }}{\mathrm{cm}^{2} \cdot \text { day }} \times \frac{238.03 \mathrm{mg} \mathrm{U} \text { metal loss }}{2 \times 15.9997 \mathrm{mg} \text { oxide gain }} \times \frac{\mathrm{g} \mathrm{U}}{10^{3} \mathrm{mg} \mathrm{U}} \times \frac{\mathrm{cm}^{3}}{19.1 \mathrm{~g} \mathrm{U}} \times \frac{\text { day }}{24 \text { hour }} \times \frac{10^{4} \mu \mathrm{m}}{\mathrm{cm}}=\frac{0.0986 \mu \mathrm{m} \mathrm{H}}{\text { hour }}
$$

Expressions in terms of linear penetration rates allow times to complete the reaction (extinction) of a uranium metal particle to be determined. For example, a 500- $\mu$ m-diameter spherical uranium metal particle corroding under anoxic conditions at $0.0986 \mu \mathrm{m} / \mathrm{h}$ would be predicted to be corroded to the center after $(250-\mu \mathrm{m}$ radius $/ 0.0986 \mu \mathrm{m} / \mathrm{h}=) \sim 2,540$ hours. Because most studies express uranium corrosion rates in units of $\mathrm{mg} \mathrm{U}(\mathrm{loss}) / \mathrm{cm}^{2} \cdot \mathrm{h}$, but prediction of metal particle extinction times are readily calculated by penetration rates, the present review will adopt both types of measurement units.

(a) Instances of non-uniform uranium metal corrosion by fragmentation or other phenomena are discussed in Section 3.3 and in more detail in Sections G4.2 and G4.3 of Appendix G of Plys and Schmidt (2006). 
The reaction rate of uranium metal with water has been measured by determining various reaction phenomena as functions of time:

- Weight loss of the uranium metal coupon after removing the $\mathrm{UO}_{2}$ corrosion layer (generally done by wiping followed by dissolving the product oxide in dilute nitric or sulfuric acid)

- Weight gain of the uranium based on formation of $\mathrm{UO}_{2}$

- Decrease in size of the uranium metal coupon

- Quantity of product hydrogen gas

- Quantity of released fission product gas (e.g., krypton, Kr, or xenon, Xe) from irradiated uranium metal

- Quantity of released fission product cesium-137 $\left({ }^{137} \mathrm{Cs}\right)$ from irradiated uranium metal

- Electrochemical (current/potential) measurements of corrosion.

Most of the investigations reported in the technical literature were conducted using distilled or deionized water and bare uranium metal coupons or clad subsections with one or more exposed surfaces. Nearly all studies described in the technical literature used either weight loss or a decrease in metal size to determine corrosion rate. Measuring weight gain is more difficult because water must be removed from the product $\mathrm{UO}_{2}$ while avoiding air oxidation and conversion of the $\mathrm{UO}_{2}$ to, for example, metaschoepite.

Determining the corrosion rate by measuring evolved $\mathrm{H}_{2}$ can be compromised by the indeterminate sequestration of hydrogen as the $\mathrm{UH}_{3}$ intermediate product in the metal. This phenomenon has been credited with as much as $15 \%$ shortfall in the amount of $\mathrm{H}_{2}$ observed and uranium reacted (Hilton 2000). The measurement of released fission products ( $\mathrm{Kr}$ or Xe gases, ${ }^{137} \mathrm{Cs}$ ) is only applicable to irradiated samples and requires knowledge of the fission product content and the extent of release of the contained fission product from the corrosion products. The electrochemical measurements are sensitive but require special equipment.

The uranium metal-corrosion reaction rate in anoxic water increases with increasing temperature. The dependence of the rate increase follows the Arrhenius equation. The Arrhenius equation has the form:

$$
\text { rate }=B^{\prime} e^{\frac{-E_{a}}{R T}}
$$

$$
\text { where } \quad \begin{aligned}
\mathrm{B}^{\prime} & =\text { pre-exponential factor } \\
\mathrm{E}_{\mathrm{a}} & =\text { reaction activation energy } \\
\mathrm{R} & =\text { gas constant } \\
\mathrm{T} & =\text { absolute temperature. }
\end{aligned}
$$

Therefore, the logarithm of the reaction rate is proportional to the inverse absolute temperature as shown in the following equation:

$$
\log _{10} \text { rate }=-\frac{\mathrm{E}_{\mathrm{a}}}{2.303 \mathrm{RT}}+\log \mathrm{B}^{\prime}=\frac{\mathrm{A}}{\mathrm{T}}+\mathrm{B}
$$

The slope of the plot of the $\log _{10}$ rate versus inverse absolute temperature is $-E_{a} / 2.303 R(=A)$. 
As seen in Figure 2.1, it was recognized as early as the Manhattan Project that the corrosion of uranium metal in anoxic liquid water follows the Arrhenius rate law over a broad temperature range (in this case, from $50^{\circ} \mathrm{C}$ to $183^{\circ} \mathrm{C}$ ). The activation energy, $\mathrm{E}_{\mathrm{a}}$, derived from the data used in this plot is $16.4 \mathrm{kcal} / \mathrm{mole}$ $(68.4 \mathrm{~kJ} / \mathrm{mole})$, and the correlation coefficient, $\mathrm{R}^{2}$, of the regressed data is 0.985 , meaning that $98.5 \%$ of the data variability is accounted for by the Arrhenius equation. The rate equations, expressed as areal corrosion and as linear penetration, are:

$$
\begin{gathered}
\log _{10} \text { rate, } \mathrm{mg} \mathrm{U} / \mathrm{cm}^{2} \cdot \mathrm{hr}=9.9489-3574.1 / \mathrm{T} \\
\log _{10} \text { rate, } \mu \mathrm{m} / \mathrm{hr}=9.6679-3574.1 / \mathrm{T}
\end{gathered}
$$

Because of the usefulness of the Arrhenius relationship, much of the comparative rate data will be presented in Arrhenius coordinates in the present paper.

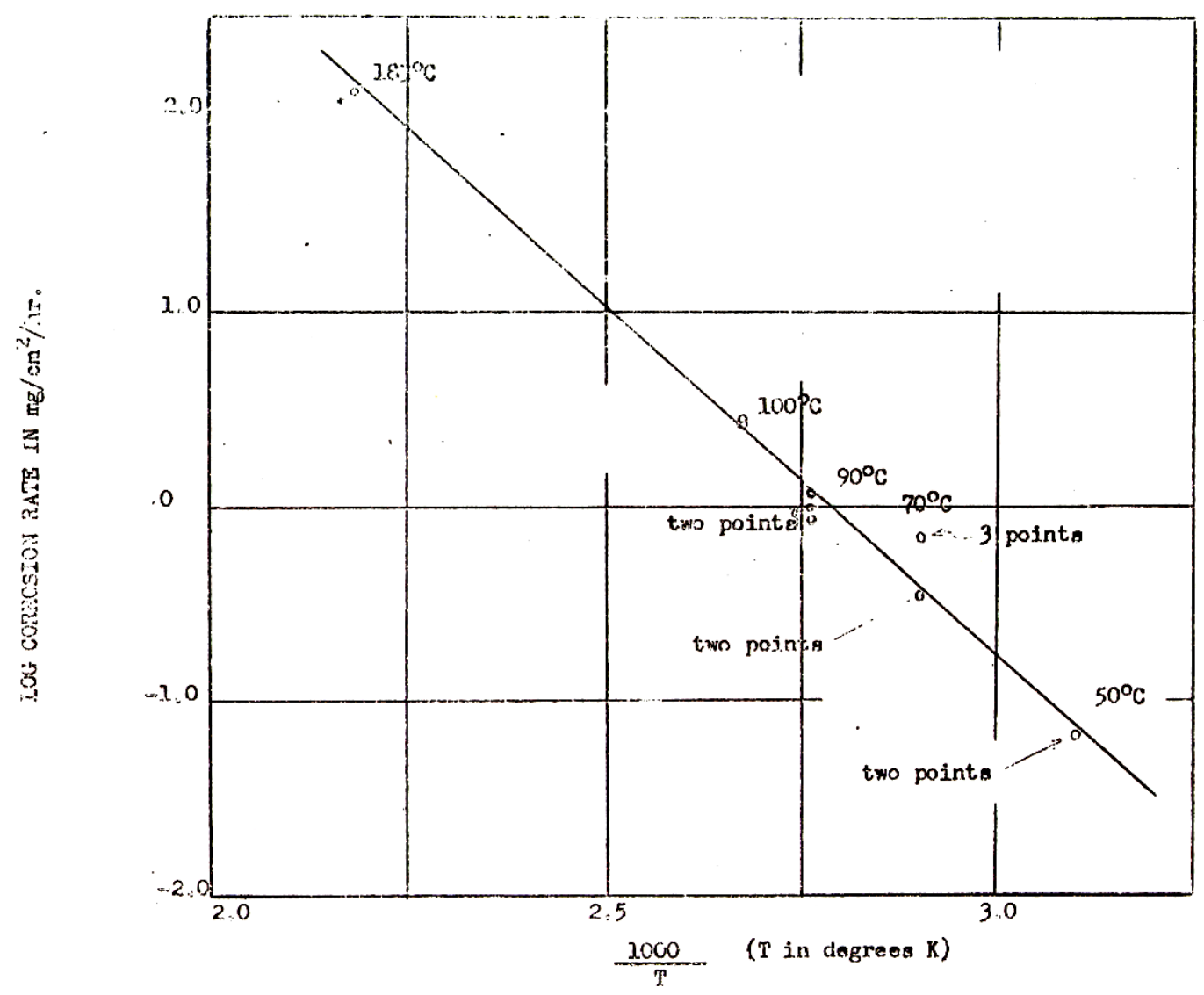

Figure 2.1. Manhattan Project Arrhenius Plot of Uranium Metal-Corrosion Rate Temperature Dependence in Anoxic Liquid Water (Mollison et al. 1945) 


\subsection{Review of the Reaction Rate Data from the Technical Literature and the STP Rate Law}

The oxidation rates of metallic uranium in oxygen, water vapor, and liquid water were reviewed by Hilton (2000) "to provide a baseline for comparison with release rate data and technical rationale for predicting general corrosion behavior of DOE SNF" (spent nuclear fuel). Hilton found that "linear kinetics adequately described the oxidation rates of metallic fuels in long-term corrosion. Temperature-dependent oxidation rates were determined by linear regression analysis of the literature data."

Hilton (2000) derived a rate law for uranium metal corrosion in anoxic liquid water based on a critical reevaluation of the 75-point data set from 11 separate studies collected and analyzed by Trimble (1998) for the K Basin Project. Hilton further expanded the dataset by evaluating the original publications and by including some points not included by Trimble. The rate law Hilton derived for the corrosion of uranium metal in anoxic liquid water forms the basis of the best-estimate SNF release-rate model for the license application for the Yucca Mountain Repository (Bechtel 2004). Of the DOE metal SNF destined for the Yucca Mountain Repository, 95\% is from the N Reactor. The rate equations based on the review by Hilton (2000), expressed in terms of areal corrosion and as linear penetration, indicate an activation energy of $15.9 \mathrm{kcal} / \mathrm{mole}$ or $66.4 \mathrm{~kJ} / \mathrm{mole}$ :

$$
\begin{gathered}
\log _{10} \text { rate, } \mathrm{mg} \mathrm{U} / \mathrm{cm}^{2} \cdot \mathrm{hr}=9.7016-3469.6 / \mathrm{T} \\
\log _{10} \text { rate, } \mu \mathrm{m} / \mathrm{hr}=9.4206-3469.6 / \mathrm{T}
\end{gathered}
$$

The technical literature identified by Trimble (1998) was carefully re-examined for the STP. ${ }^{(a)}$ In those investigations, it was discovered that not all data used by Trimble (1998) were for tests conducted under anoxic conditions. Furthermore, in checking the original source documents, it was found that some of the data were reported incorrectly or incompletely. Based on a critical review of the Trimble dataset, 56 data points from 9 studies were found to be relevant to the corrosion of uranium metal in anoxic liquid water.

The technical literature was critically reviewed further to gather additional data in support of possible $100^{\circ} \mathrm{C}$ to $200^{\circ} \mathrm{C}$ hydrothermal processing of $\mathrm{K}$ Basin sludge. The data were found in journals and in Manhattan Project, Argonne National Laboratory, Los Alamos Scientific Laboratory, Hanford, and other technical institution reports. The review revealed 72 additional data points from another 23 studies for uranium metal corrosion in anoxic liquid water. The data included four additional data points between $100^{\circ} \mathrm{C}$ and $200^{\circ} \mathrm{C}$ and 10 additional data points at $200^{\circ} \mathrm{C}$. At the completion of the review, 128 data points from 32 separate studies (including the data selected from the Trimble dataset) were found. The detailed results of the data collection and review are presented in Appendix G of Plys and Schmidt (2006).

The entire 128-point dataset is plotted in Arrhenius coordinates in Figure 2.2. The rate data are seen to follow the Arrhenius rate law remarkably well over the studied temperature range of $\sim 24^{\circ} \mathrm{C}$ to $350^{\circ} \mathrm{C}$ and reaction rates spanning a factor of 4 million. The goodness of fit to the Arrhenius equation of the combined diverse rate data is excellent with $\mathrm{R}^{2}=0.980$. The $95 \%$ confidence limits on the regression line

(a) The data selected for use in Hilton's technical report (2000) were plotted but not enumerated and, therefore, could not be further evaluated. 
also are presented in Figure 2.2. These limits are factors of 3.04 to 3.10 greater or smaller than the regressed line $\left(3.04\right.$ in the middle of the regression span between about $100^{\circ} \mathrm{C}$ and $180^{\circ} \mathrm{C}$ with factors increasing at temperatures above and below these temperatures).

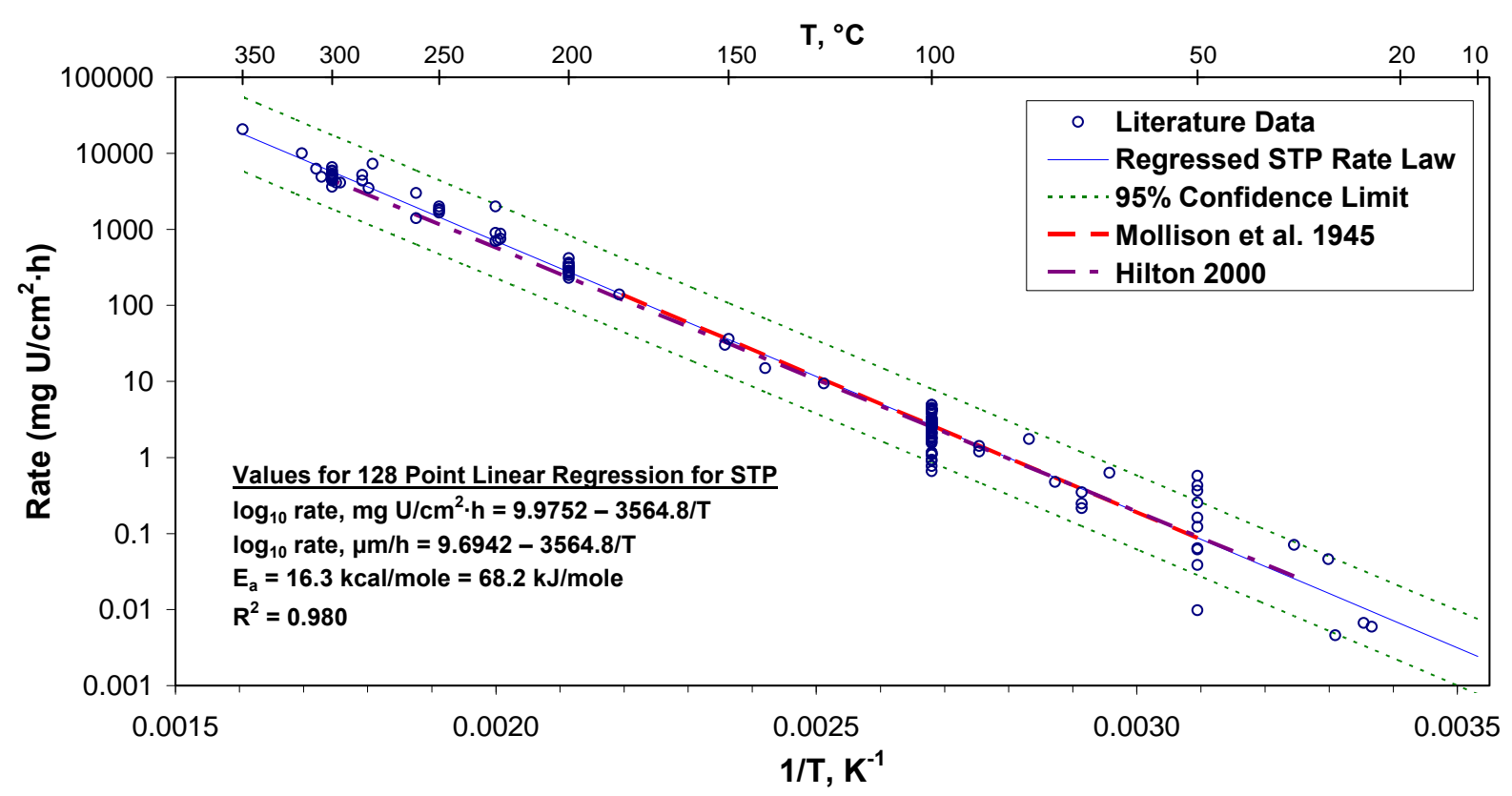

Figure 2.2. Arrhenius Plot of Published Rate Data for Uranium Metal Corrosion in Anoxic Liquid Water and Comparison with Regression of Data Reported by Mollison et al. (1945) and by Hilton (2000)

The rate equations for the entire 128-point dataset are presented as areal corrosion and as linear penetration by the following expressions:

$$
\begin{gathered}
\log _{10} \text { rate, } \mathrm{mg} \mathrm{U} / \mathrm{cm}^{2} \cdot \mathrm{hr}=9.9752-3564.8 / \mathrm{T} \\
\log _{10} \text { rate, } \mu \mathrm{m} / \mathrm{hr}=9.6942-3564.8 / \mathrm{T}
\end{gathered}
$$

Because of its extensive set of data points and critical review of the included data, the rate equations derived for the 128-point dataset as shown above and in Figure 2.2 have been adopted for use by the STP. ${ }^{(a)}$

The STP rate equations are seen to be very near the rate equations that were derived based on the early data reported in the Manhattan Project shown in Figure 2.1. Thus, as seen in Figure 2.2, a plot of the rate equation for the 13 data points spanning $50^{\circ} \mathrm{C}$ to $183^{\circ} \mathrm{C}$ reported by Mollison and colleagues in 1945 (and which are included in the STP dataset) almost perfectly overlays that section of the regression of the entire STP dataset. The regression of the technical literature data as selected by Hilton (2000) likewise is plotted in Figure 2.2. Some small difference between the STP regression and that of Hilton is visible at

(a) Appendix G of Plys and Schmidt (2006) established the rate equation and rate design and safety factors that are provided in the Sludge Technical Databook (Schmidt 2006). 
higher temperatures. However, even at $300^{\circ} \mathrm{C}$, the rate predicted by the Hilton equation is only $22 \%$ lower than the rate predicted by the STP equation.

The reaction rates and $95 \%$ confidence limits for the STP rate equation over the $15^{\circ} \mathrm{C}$ to $200^{\circ} \mathrm{C}$ temperature range are presented in Table 2.1 with the values at $15^{\circ} \mathrm{C}$ and $20^{\circ} \mathrm{C}$ being rates projected below the lowest tested temperature of $\sim 24^{\circ} \mathrm{C}$.

Table 2.1. Predicted Corrosion Rate Parameters and High/Low Values at the $95 \%$ Confidence Limits for the STP Rate Equation

\begin{tabular}{|c|c|c|c|c|c|c|c|c|c|c|}
\hline \multirow{3}{*}{$\begin{array}{l}\mathbf{T}, \\
{ }^{\circ} \mathbf{C}\end{array}$} & \multirow{3}{*}{$\begin{array}{c}95 \% \\
\text { Conf. } \\
\text { Limit } \\
\text { Factor } \\
\end{array}$} & \multicolumn{9}{|c|}{ Corrosion Parameters with $95 \%$ Confidence Limits } \\
\hline & & \multicolumn{3}{|c|}{ Corrosion Rate, $\mathrm{mg} / \mathrm{cm}^{2} \cdot \mathrm{h}$} & \multicolumn{3}{|c|}{ Corrosion Rate, $\mu \mathrm{m} / \mathrm{h}$} & \multicolumn{3}{|c|}{ Extinction Time, $1 / 4-$ inch, $h^{(a)}$} \\
\hline & & Predicted & High & Low & Predicted & High & Low & Predicted & Low & High \\
\hline 15 & 3.10 & 0.00402 & 0.0125 & 0.00129 & 0.00210 & 0.00653 & 0.000678 & $1.51 \mathrm{E}+06$ & $4.86 \mathrm{E}+05$ & $4.68 \mathrm{E}+06$ \\
\hline 20 & 3.10 & 0.00653 & 0.0202 & 0.00211 & 0.00342 & 0.0106 & 0.00110 & $9.29 \mathrm{E}+05$ & $3.00 \mathrm{E}+05$ & $2.88 \mathrm{E}+06$ \\
\hline 30 & 3.08 & 0.0164 & 0.0507 & 0.00533 & 0.00861 & 0.0266 & 0.00279 & $3.69 \mathrm{E}+05$ & $1.20 \mathrm{E}+05$ & $1.14 \mathrm{E}+06$ \\
\hline 40 & 3.07 & 0.0390 & 0.120 & 0.0127 & 0.0204 & 0.0629 & 0.00665 & $1.55 \mathrm{E}+05$ & $5.05 \mathrm{E}+04$ & $4.77 \mathrm{E}+05$ \\
\hline 50 & 3.07 & 0.0879 & 0.269 & 0.0287 & 0.0460 & 0.141 & 0.0150 & $6.90 \mathrm{E}+04$ & $2.25 \mathrm{E}+04$ & $2.12 \mathrm{E}+05$ \\
\hline 60 & 3.06 & 0.188 & 0.576 & 0.0616 & 0.0986 & 0.302 & 0.0322 & $3.22 \mathrm{E}+04$ & $1.05 \mathrm{E}+04$ & $9.85 \mathrm{E}+04$ \\
\hline 70 & 3.05 & 0.386 & 1.18 & 0.126 & 0.202 & 0.618 & 0.0662 & $1.57 \mathrm{E}+04$ & $5.14 \mathrm{E}+03$ & $4.80 \mathrm{E}+04$ \\
\hline 80 & 3.05 & 0.760 & 2.32 & 0.249 & 0.398 & 1.21 & 0.131 & $7.98 \mathrm{E}+03$ & $2.62 \mathrm{E}+03$ & $2.43 \mathrm{E}+04$ \\
\hline 90 & 3.05 & 1.44 & 4.39 & 0.473 & 0.755 & 2.30 & 0.248 & $4.21 \mathrm{E}+03$ & $1.38 \mathrm{E}+03$ & $1.28 \mathrm{E}+04$ \\
\hline 100 & 3.04 & 2.64 & 8.04 & 0.868 & 1.38 & 4.21 & 0.454 & $2.29 \mathrm{E}+03$ & $7.54 \mathrm{E}+02$ & $6.99 \mathrm{E}+03$ \\
\hline 110 & 3.04 & 4.69 & 14.3 & 1.54 & 2.46 & 7.47 & 0.807 & $1.29 \mathrm{E}+03$ & $4.25 \mathrm{E}+02$ & $3.93 E+03$ \\
\hline 120 & 3.04 & 8.09 & 24.6 & 2.66 & 4.24 & 12.9 & 1.39 & $7.50 \mathrm{E}+02$ & $2.46 \mathrm{E}+02$ & $2.28 \mathrm{E}+03$ \\
\hline 130 & 3.04 & 13.6 & 41.3 & 4.47 & 7.11 & 21.6 & 2.34 & $4.47 \mathrm{E}+02$ & $\mid 1.47 \mathrm{E}+02$ & $1.36 \mathrm{E}+03$ \\
\hline 140 & 3.04 & 22.2 & 67.6 & 7.31 & 11.6 & 35.4 & 3.83 & $2.73 \mathrm{E}+02$ & $8.97 \mathrm{E}+01$ & $8.30 \mathrm{E}+02$ \\
\hline 150 & 3.04 & 35.5 & 108 & 11.7 & 18.6 & 56.6 & 6.12 & $1.71 \mathrm{E}+02$ & $5.61 \mathrm{E}+01$ & $5.19 \mathrm{E}+02$ \\
\hline 160 & 3.04 & 55.6 & 169 & 18.3 & 29.1 & 88.6 & 9.58 & $1.09 \mathrm{E}+02$ & $3.58 \mathrm{E}+01$ & $3.32 \mathrm{E}+02$ \\
\hline 170 & 3.04 & 85.3 & 260 & 28.0 & 44.7 & 136 & 14.7 & $7.11 \mathrm{E}+01$ & $2.34 \mathrm{E}+01$ & $2.16 \mathrm{E}+02$ \\
\hline 180 & 3.04 & 128 & 391 & 42.2 & 67.2 & 205 & 22.1 & $4.72 \mathrm{E}+01$ & $1.55 \mathrm{E}+01$ & $1.44 \mathrm{E}+02$ \\
\hline 190 & 3.05 & 190 & 578 & 62.3 & 99.4 & 303 & 32.6 & $3.19 \mathrm{E}+01$ & $1.05 \mathrm{E}+01$ & $9.73 \mathrm{E}+01$ \\
\hline 200 & 3.05 & 276 & 841 & 90.6 & 145 & 440 & 47.4 & $2.20 \mathrm{E}+01$ & $7.21 \mathrm{E}+00$ & $6.69 \mathrm{E}+01$ \\
\hline
\end{tabular}

(a) One month $=730$ hours; one year $=8766$ hours. The predicted extinction time for a ${ }^{1 / 4}$-inch particle at $20^{\circ} \mathrm{C}$ is $\sim 106$ years.

The corrosion behavior of N Reactor SNF pieces shipped from the KW Basin to the 327 Building for characterization studies was used to estimate uranium metal corrosion rates (Praga 1998). The corrosion rates were based on gas-generation-rate data taken from gauge pressure increases in the closed containers, the known confinement times and basin temperatures $\left(96\right.$ hours at $20.6^{\circ} \mathrm{C}$ or 116 hours at $21.7^{\circ} \mathrm{C}$ ), and the exposed geometric fuel metal surface areas estimated from photo images. The generated gas was presumed to be hydrogen. Some of the vessels exhibited lag times before gas generation, but the explicit lag times were not recorded. Using these data, uranium metal reaction rates at $20.6^{\circ} \mathrm{C}$ were estimated to be 0.060 and $0.00092 \mathrm{mg} / \mathrm{cm}^{2} \cdot \mathrm{h}$, factors of $\sim 8.7$ and $\sim 1.3$ larger than the $0.00069 \mathrm{mg} / \mathrm{cm}^{2} \cdot \mathrm{h}$ rate based on the STP equation. The rates measured at $21.7^{\circ} \mathrm{C}$ were 0.00075 and $0.0097 \mathrm{mg} / \mathrm{cm}^{2} \cdot \mathrm{h}$, which were factors of $\sim 1.0$ and $\sim 12.6$ larger than the $0.00076 \mathrm{mg} / \mathrm{cm}^{2} \cdot \mathrm{h}$ rate based on the STP equation. 
As noted by Praga (1998), the higher observed rates compared with those predicted by the STP rate equation likely are due to the greater surface area of the fractured fuel caused by surface roughness. The collected gas findings from the fuel piece shipment and the demonstrated linearity of the Arrhenius plot from $\sim 24^{\circ} \mathrm{C}$ to $350^{\circ} \mathrm{C}$ based on numerous studies and individual data points give confidence that the STP rate equation can be extrapolated 5 to $10^{\circ} \mathrm{C}$ to uranium metal corrosion at $\sim 15$ to $20^{\circ} \mathrm{C}$ basin temperatures.

\subsection{Uranium Metal Corrosion Rates in Oxic Liquid Water}

Measurements of the corrosion rates of uranium metal in aerated or oxic liquid water are much more limited than those in anoxic water. Experimentally, the decreased experimental frequency results from the difficulty in maintaining constant dissolved oxygen concentration, mostly due to its consumption by reaction with uranium metal and partly due to the decrease in oxygen solubility in water with increased temperature. In addition to its source from air, oxygen may arise from radiolysis. In sludge, oxygen may be consumed by oxidation of $\mathrm{UO}_{2}$, oxidation of metallic iron, and oxidation of organic molecules besides its reaction with uranium metal.

Data for the non-irradiated uranium metal corrosion rate in $36^{\circ} \mathrm{C}$ to $90^{\circ} \mathrm{C}$ aerated waters, irradiated $\mathrm{N}$ Reactor fuel in $25^{\circ} \mathrm{C}$ and $75^{\circ} \mathrm{C}$ aerated and anoxic waters, non-irradiated $\mathrm{N}$ Reactor fuel in $25^{\circ} \mathrm{C}$ aerated and anoxic waters, and blanket fuel from Experimental Breeder Reactor (EBR)-II irradiated to 1\% $\mathrm{Pu}$ (estimated $\sim 30,000 \mathrm{MWD} / \mathrm{MTU}$ [megawatts per day per metric ton of uranium]) in $90^{\circ} \mathrm{C}$ aerated and anoxic waters are plotted in Figure 2.3. The observed rates are compared with the STP survey of rates observed for non-irradiated uranium metal in anoxic liquid water.

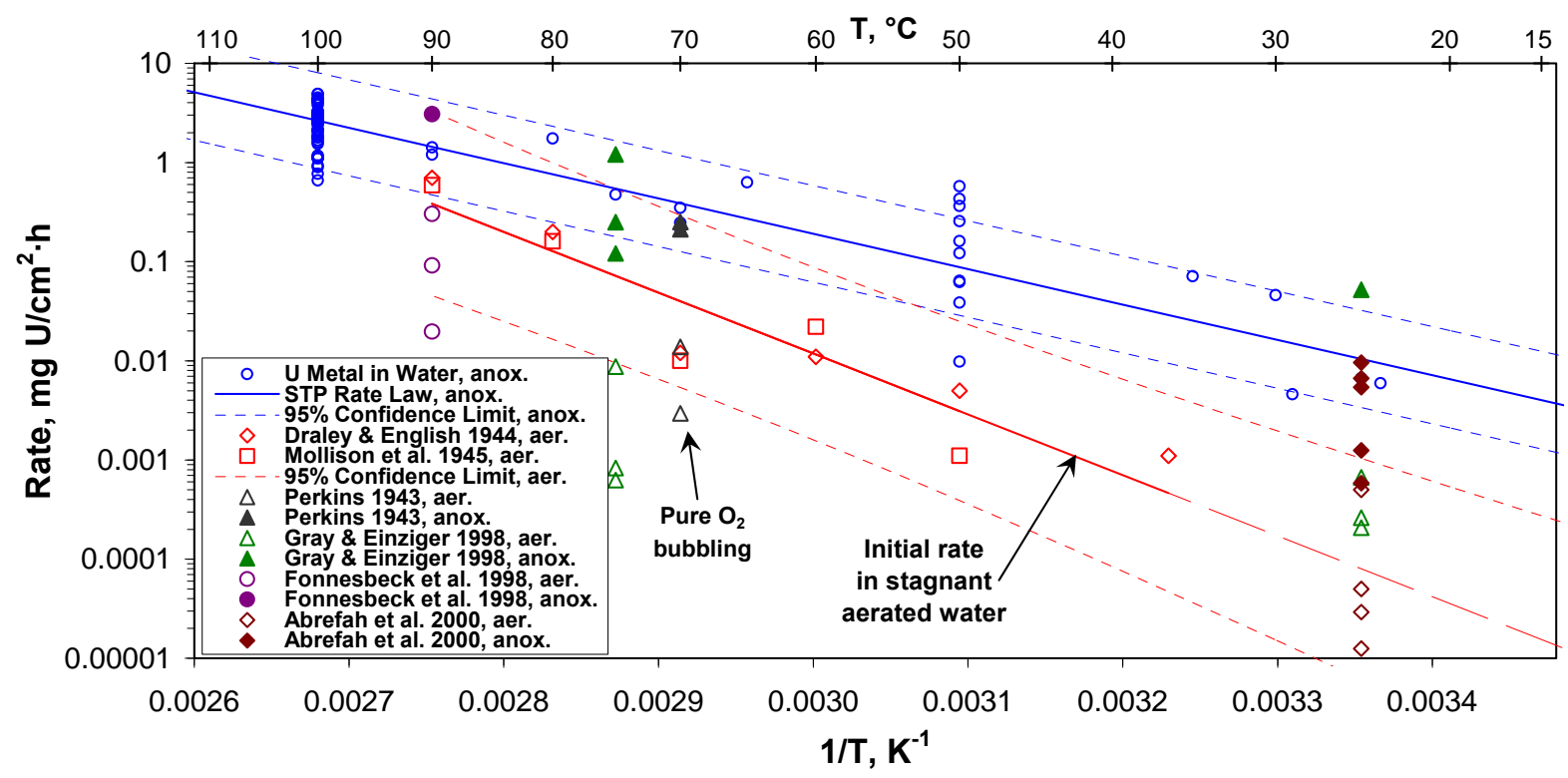

Figure 2.3. Comparison of Uranium Metal Oxidation-Rate Data for Anoxic Water from the Technical Literature with Uranium Metal Oxidation Rate in Aerated Water

The rates observed by Draley and English (1944) and Mollison et al. (1945) were analyzed by linear regression $\left(\mathrm{R}^{2}=0.875\right)$ to provide corrosion-rate expressions in units of areal corrosion and linear penetration. 


$$
\begin{gathered}
\log _{10} \text { rate, } \mathrm{mg} \mathrm{U} / \mathrm{cm}^{2} \cdot \mathrm{hr}=16.48-6134 / \mathrm{T} \\
\log _{10} \text { rate, } \mu \mathrm{m} / \mathrm{hr}=16.20-6134 / \mathrm{T}
\end{gathered}
$$

The slope corresponds to an activation energy, $\mathrm{E}_{\mathrm{a}}$, of $28.1 \mathrm{kcal} / \mathrm{mole}$. The $95 \%$ confidence limit on these rate equations varies plus/minus factors of $\sim 7.4$ (near $66^{\circ} \mathrm{C}$ ) to 9.8 over the examined temperature range of $\sim 37^{\circ} \mathrm{C}$ to $90^{\circ} \mathrm{C}$. The extrapolated uranium metal corrosion rate for $15^{\circ} \mathrm{C}$ oxic water (where the enhancement/de-enhancement factor at the $95 \%$ confidence limit is $\sim 18)$, is $0.0000154 \mathrm{mg} \mathrm{U} / \mathrm{cm}^{2} \cdot \mathrm{h}$. The projected rate at $15^{\circ} \mathrm{C}$ for anoxic water is 260 -times greater than the oxic water rate.

It is generally agreed that the metal surface formed in the presence of dissolved oxygen inhibits the anoxic reaction of uranium metal with water while dissolved oxygen is consumed at least locally by the reaction with uranium. A qualitative demonstration of this behavior was performed in which a flat piece of polished uranium, immersed in water in an open beaker, was partially covered with a curved (concave upward) glass dish. After some time, the metal near the dish edge, where oxygenated water could freely exchange, remained relatively unattacked while the oxygen-starved region near the dish center showed marked corrosion (Waber 1956). Therefore, with time and the consumption of dissolved oxygen, the more rapid anoxic reaction of uranium metal with water begins to occur, producing its much less adherent powdery $\mathrm{UO}_{2}$ corrosion product. As a result, the uranium corrosion rates, even in water continuously open to the air at $50^{\circ} \mathrm{C}$ to $100^{\circ} \mathrm{C}$, increase with time to reach the higher rates established in anoxic water. This behavior is shown in Figure 2.4 (Mollison et al. 1945).

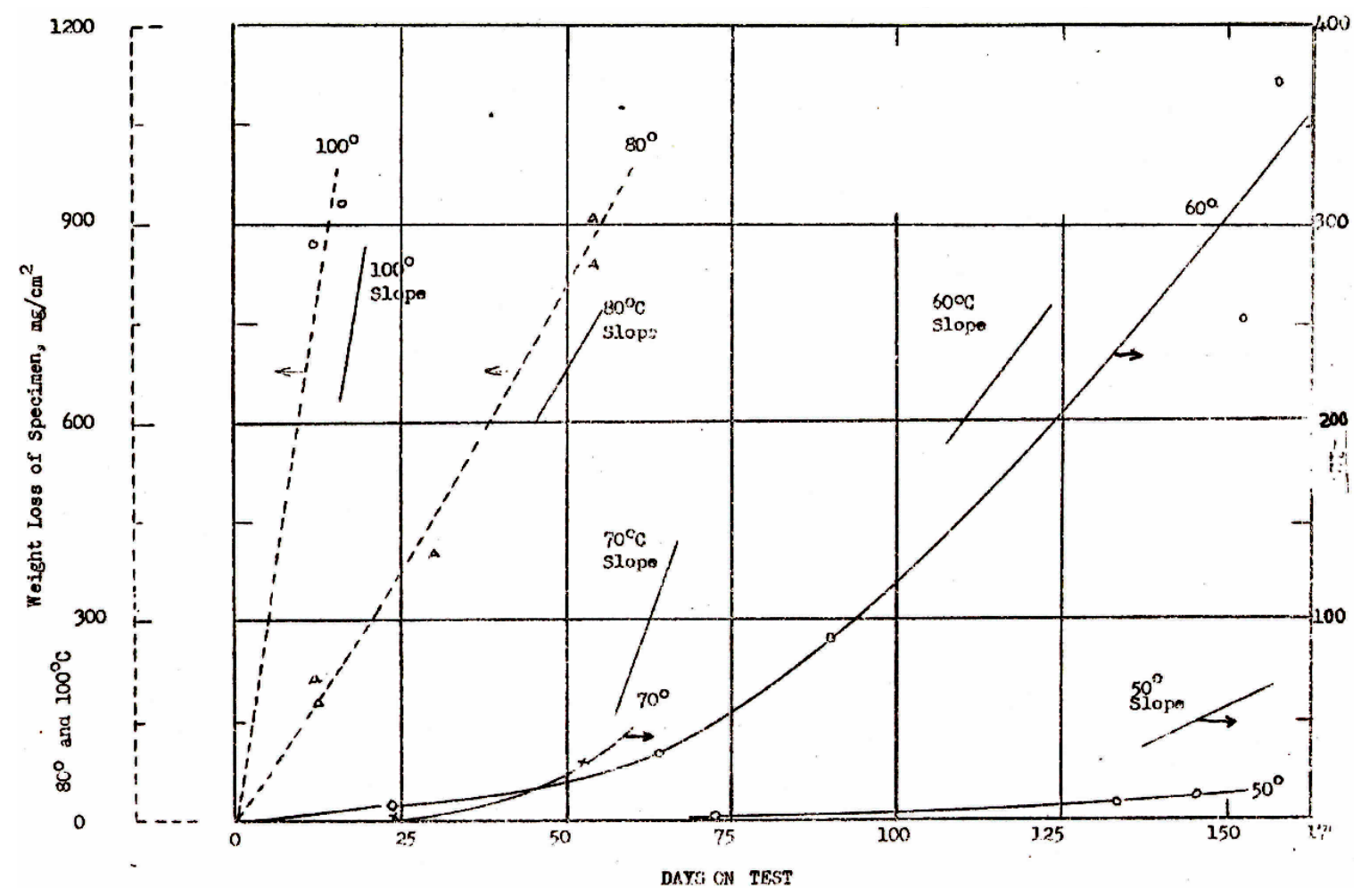

Figure 2.4. Uranium Metal-Corrosion Weight Loss in Aerated Distilled Water as a Function of Temperature and Time (Mollison et al. 1945) 
The time required for the full transition from relatively low uranium metal corrosion rates under oxic conditions to the more rapid rates under anoxic corrosion conditions is difficult to predict but clearly decreases with increasing temperature. As seen in Figure 2.4, the transition to the more rapid anoxic corrosion rates is gradual at temperatures below $80^{\circ} \mathrm{C}$, but is reached almost instantaneously at $80^{\circ} \mathrm{C}$ and $100^{\circ} \mathrm{C}$ in these parallel tests.

The corrosion rates of non-irradiated uranium metal in $70^{\circ} \mathrm{C}$ water under pure oxygen, air, nitrogen, and helium were determined in early testing (Perkins 1943). As seen in Figure 2.3, the rates observed under nitrogen and helium atmospheres were consistent with the rates observed in the STP survey under anoxic water conditions while the rate under air is consistent with those observed by Draley and English (1944) and Mollison et al. (1945) for aerated systems. The rate observed under pure oxygen was about $20 \%$ of the rate observed under air, meaning that the rate was inversely proportional to the oxygen partial pressure and concentration in solution.

Gray and Einziger (1998) investigated the corrosion of irradiated ( 2,200 MWD/MTU; Delegard et al. 2004a) N Reactor fuel pieces in aerated water of $\mathrm{pH} 8$ to 10. The aerated water, which contained either $0.02 \mathrm{M}$ carbonate, $0.002 \mathrm{M}$ carbonate (in a simulated groundwater), or $0.0002 \mathrm{M}$ carbonate, was supplied continuously in a flow-through apparatus at $25^{\circ} \mathrm{C}$ and $75^{\circ} \mathrm{C}$. The corrosion rates were monitored by analyzing uranium concentrations in the effluent solutions. Corrosion rate monitoring by measuring dissolved uranium was made possible by the carbonate, which kept soluble the U(VI) corrosion product arising under aerated conditions. The uranium metal behavior under aerated conditions was dubbed "Stage 1" corrosion. With time, accelerated corrosion was observed for some of the tests. This period of enhanced rate was called "Stage 2" corrosion, and a $\mathrm{UO}_{2}$ corrosion product was observed. During this period, rates were monitored by ${ }^{137} \mathrm{Cs}$ release, taking into account the $\sim 20 \%$ of the ${ }^{137} \mathrm{Cs}$ retained by the solid corrosion product. Monitoring by uranium concentration was not valid because the $\mathrm{UO}_{2}$ product is not soluble even in the presence of carbonate.

As seen in Figure 2.3, the $25^{\circ} \mathrm{C}$ rates for corrosion of irradiated uranium in flowing aerated waters (Gray and Einziger 1998) are consistent with rates obtained by extrapolating the earlier data from non-irradiated uranium corrosion under stagnant aerated conditions (Draley and English 1944; Mollison et al. 1945). However, the $75^{\circ} \mathrm{C}$ rates for irradiated uranium are about 10 to 100 times lower than those found in the prior studies. The lower rates at $75^{\circ} \mathrm{C}$ in the 1998 study could have been because the aerated water was continuously refreshed, bringing additional dissolved oxygen to the system. In the 1940s tests, the water was stagnant, though open to the atmosphere. As noted, several of the tests with irradiated uranium transitioned to anoxic corrosion as shown by large increases in ${ }^{137} \mathrm{Cs}$ fission product releases and solid $\mathrm{UO}_{2}$ corrosion products. The corrosion rates based on ${ }^{137} \mathrm{Cs}$ release under anoxic "Stage 2" conditions at both $25^{\circ} \mathrm{C}$ and $75^{\circ} \mathrm{C}$ are seen to be consistent with those found in the STP survey.

Results of corrosion tests of non-irradiated $\mathrm{N}$ Reactor fuel metal in flowing $25^{\circ} \mathrm{C}$ aerated and nitrogenpurged distilled water, $0.02 \mathrm{M}$ bicarbonate, and simulated groundwater also are shown in Figure 2.3 (Abrefah et al. 2000). The rates in aerated water are about 20 to 100 times lower than rates found when the same tests became anoxic by depletion of dissolved oxygen (the $0.02 \mathrm{M}$ bicarbonate test) or by argon purge (the test with distilled water). The rates observed for the aerated conditions are broadly consistent with the aerated rates extrapolated from the 1940s data and are about 20 to 300 times lower than the STP rate law for anoxic water at $25^{\circ} \mathrm{C}$. It was speculated that one of the tests did not become fully anoxic 
(i.e., still suffered from some oxygen poisoning), although its value is shown in the anoxic data in Figure 2.3. Two of the observations under "Stage 2" anoxic conditions are within the STP 95\% confidence limits, and two lie below these limits.

The corrosion of the highly irradiated EBR-II blanket fuel was tested in closed vessels with initially aerated simulated groundwater and air cover gas (Fonnesbeck et al. 1998). The vessels were opened weekly for sampling, fresh aerated water was added, and the vessels were reclosed. Three such tests were conducted with corrosion rates monitored by ${ }^{137} \mathrm{Cs}$ release. In one of the tests, a steep increase in rate was noted at the 21 - to 28 -day interval accompanied by significant gas pressurization and distinctly greater uranium fuel coupon corrosion. This test was not continued, however, because of sample fracturing. The behavior of the fuel in the 21- to 28-day interval was ascribed to anoxic corrosion and called "Stage 2" in reference to the similar behaviors observed by Gray and Einziger (1998). As seen in Figure 2.3, the corrosion rates found in the tests under aerated conditions with confined air in the vapor space were lower than would be predicted based on the 1940s tests in open vessels (Draley and English 1944; Mollison et al. 1945). The rate under anoxic "Stage 2" conditions was about a factor of two higher than the STP predicted rate, but within the range observed in the surveyed literature.

Although investigations of uranium metal corrosion in oxic liquid water are limited, several investigations of the effect of oxygen on the corrosion of uranium in the presence of water vapor have been conducted. Information gained from these studies can be useful to understand the reaction in oxic liquid water. One of the most insightful studies featured tests conducted from $80^{\circ} \mathrm{C}$ to $110^{\circ} \mathrm{C}$ with varying $\mathrm{O}_{2}$ pressures and $\mathrm{H}_{2} \mathrm{O}$ relative humidities ranging from $\sim 5$ to $100 \%$ (Baker et al. 1966b; see also Orman 1976). The reaction progress was monitored by $\mathrm{H}_{2}, \mathrm{H}_{2} \mathrm{O}$, and $\mathrm{O}_{2}$ gas-phase concentrations. The presence of oxygen was found to decrease the corrosion rate by factors of 30 to 100 compared with the oxygen-free rate. However, the reaction rates were unaffected by relative humidity in the $\sim 5$ and $90 \%$ range and by oxygen pressures in the range $<0.1$ to 100 Torr. Above $90 \%$ relative humidity, surface condensation occurred to achieve conditions analogous to immersion in aerated water. The corrosion rate in this regime was about 1.2 to 1.5 times higher than at non-condensing aerated conditions, and $\mathrm{UO}_{3}$ phases were observed.

The gas analyses showed that during the oxic portion of the reaction, oxygen is consumed, trace amounts of hydrogen are evolved, and no perceptible change in water vapor pressure occurs. Once the gas-phase oxygen is exhausted, the water vapor pressure begins to decrease with an accompanying strong increase in hydrogen pressure. The reaction product at this wide range of intermediate humidity is $\mathrm{UO}_{2.3}, \mathrm{a}$ hyperstoichiometric uraninite phase richer in oxygen than the $\mathrm{UO}_{2+\mathrm{x}}(\mathrm{x}<0.1)$ phase observed for uranium metal corrosion in anoxic liquid water.

Isotopically labeled oxygen gas was used in selected tests. Nearly all of the labeled oxygen reacted to form water vapor with only a small amount of the labeled oxygen appearing in the uranium oxide product. Baker et al. (1966b) interpreted their findings to indicate that the oxidation of uranium metal by oxygenated water vapor is retarded by blockage caused by oxygen being merely chemisorbed on the metal surface and not chemically bound as a uranium oxide. This conclusion was made because the hydrogen radicals that arise by the inhibited water-uranium reaction combine with the oxygen chemisorbed at the metal surface to form water, as indicated by the labeled oxygen tests, with only a fraction of the hydrogen radicals combining to form the observed amounts of hydrogen gas. As the reaction progressed and the oxygen gas became completely consumed, the chemisorbed barrier dissipated to leave the surface vulnerable to the higher rate anoxic reaction of water with uranium metal. Under 
condensing water or with liquid water immersion, oxygen gas diffusion to passivate the uranium metal surface is impeded, allowing somewhat higher rates to occur than those afforded by the complete oxygen surface chemisorption at lower humidities.

The effect of oxygen pressure and temperature on the reaction of uranium metal with water vapor was studied in prior related tests at $65^{\circ} \mathrm{C}$ to $80^{\circ} \mathrm{C}$ (Orman 1963). As in the later experiments by the same laboratory (Baker et al. 1966b), the reaction rate was retarded until the oxygen was consumed at all studied pressures and temperatures. Under otherwise similar conditions (uranium metal surface area, oxygen pressure), the duration of the lower oxygen-poisoned rates increased from 180 hours at $80^{\circ} \mathrm{C}$ to 450 hours at $65^{\circ} \mathrm{C}$.

Uranium metal corrosion tests at $100 \%$ relative humidity in the presence of oxygen were conducted from $25^{\circ} \mathrm{C}$ to $100^{\circ} \mathrm{C}$ in four different studies by the United Kingdom's Atomic Weapons Research

Establishment (Ritchie 1981). The rate law follows an Arrhenius temperature dependence $\left(\mathrm{R}^{2}=0.982\right)$ that roughly parallels the STP rate law for anoxic liquid water but at rates at $20^{\circ} \mathrm{C}$ lower by about a factor of 27. The observed areal and linear penetration rate laws for oxic condensing water vapor derived from these limited data are:

$$
\begin{gathered}
\log _{10} \text { rate, } \mathrm{mg} \mathrm{U} / \mathrm{cm}^{2} \cdot \mathrm{hr}=9.466-3836 / \mathrm{T} \\
\log _{10} \text { rate }, \mu \mathrm{m} / \mathrm{hr}=9.185-3836 / \mathrm{T}
\end{gathered}
$$

Given the inhibiting effect of aeration on uranium corrosion, it might be postulated that the rapid anoxic uranium oxidation mechanism would be quenched by vigorous aeration. In one relevant experience, air sparging was done to KE canister sludge samples with water in graduated cylinders to study sludge settling properties (Makenas et al. 1997). Of the four sludge samples subjected to air lance agitation, two formed gas bubbles both before and after sparging, one formed bubbles after several weeks, and one did not form bubbles. The tests for the two most active sludges were repeated using an inert gas (helium) lance; bubbling again was observed before and after agitation. All tests were performed at $\sim 32^{\circ} \mathrm{C}$ hot-cell temperatures. Gases from the two samples that bubbled most readily were analyzed after the air sparging test, and gases from one of the two samples also were analyzed after the helium sparging. In all cases, high $\mathrm{H}_{2}$ concentrations as well as krypton and xenon fission products were found, confirming that the gas arose from the reaction of uranium metal with water. For at least these two most active KE canister sludge samples, air sparging did not perceptibly inhibit the corrosion reaction.

The corrosion test of non-irradiated N Reactor fuel (Abrefah et al. 2000) was cycled from aerated, to argon-purged (anoxic), and back to aerated feed water conditions. About 4 days of running with argonpurged water were needed to establish anoxic conditions as shown by the enhanced corrosion rate. Less than 1 day was required to reach aerated conditions (lower uranium corrosion rate) once the air sparge replaced the argon sparge in the feed water. The carbonate and oxidizing conditions introduced in the air sparge may have helped dissolve the $\mathrm{UO}_{2}$ product from the prior anoxic corrosion as hexavalent uranium to contribute to the relatively high aerated rate that was observed for this test. Nevertheless, the cycling of aerated to anoxic and back to aerated water conditions in this test were reflected in the observed lowhigh-low uranium corrosion rates. 
Attempts have been made to model oxygen diffusion into water from air, its creation by radiolysis, and its consumption by reactions with uranium metal, $\mathrm{UO}_{2}$, and potentially other sludge phases to attempt to determine the susceptibility of sludge systems to transition to, or remain under, oxic conditions (Shelor et al. 2004). However, such models have not been validated by testing.

As shown by these studies, oxygen inhibits the reaction of uranium metal with both water vapor and liquid water. The more rapid anoxic reaction can follow a period of lower, but increasing, oxic rates. The times to this transition decrease with increased temperature. The timing of the transitions likely is affected by many factors. Besides temperature, potential influences on the timing of the oxic $\rightarrow$ anoxic rate transition in sludge include the concentration or surface area of uranium metal, the aeration rate, the condition of the semi-protective uranium metal surface-oxide layer (affected, for example, by abrasion in sludge transport and processing), the presence of crevices or occlusions on the uranium metal surface that can become locally anoxic, the generation of oxygen, hydrogen, or hydrogen peroxide by water radiolysis, and the presence of oxygen and hydrogen scavengers or consumers (e.g., $\mathrm{UO}_{2}$ to consume oxygen and form $\mathrm{UO}_{3} \cdot 2 \mathrm{H}_{2} \mathrm{O}$ ). As noted by Hilton (2000, p. 22):

While the oxygen dependence of the $\mathrm{U} / \mathrm{H}_{2} \mathrm{O}$ reaction at initial times can be rationalized, more research is necessary to understand the low temperature transition occurring at long times from $\mathrm{U} / \mathrm{O}-\mathrm{H}_{2} \mathrm{O}$ rates to anoxic water rates. 


\subsection{STP Testing-Uranium Metal Corrosion Rate, Concentration, and Particle Size Determination}

Over the past 10 years, the STP has conducted testing to investigate the uranium metal corrosion rate, concentration, and particle size in simulated and actual K Basin sludge. Results from this testing, including comparison of corrosion rates to the STP rate law, are summarized in this section.

\subsection{Correspondence of Non-Irradiated Uranium Metal Corrosion Rates in Water and in Simulated Sludge with Predicted Rates}

Non-irradiated uranium metal corrosion has been studied for the K Basins Project (Delegard et al. 2004b). The tests were conducted using near spherical uranium metal beads of known particle-size distribution. Tests were run both with and without a simple accompanying simulated $\mathrm{K}$ Basin sludge composed of $\mathrm{UO}_{2}$ powder and $\mathrm{SiO}_{2}$ sand. The progress of the reaction for the metal was monitored by measuring the rate of $\mathrm{H}_{2}$ gas production, and the tests were conducted until the uranium metal was completely extinct.

The apparatus used in the measurements with the uranium metal beads and in other gas generation measurements for the $\mathrm{K}$ Basin sludge projects is shown in Figure 3.1. The reaction vessel and its contents are diagrammed at the left and the gas measurement system on the right. A similar apparatus has been used to accurately measure the rates of gas-generating reactions in radioactive tank waste (Bryan et al. 1996).

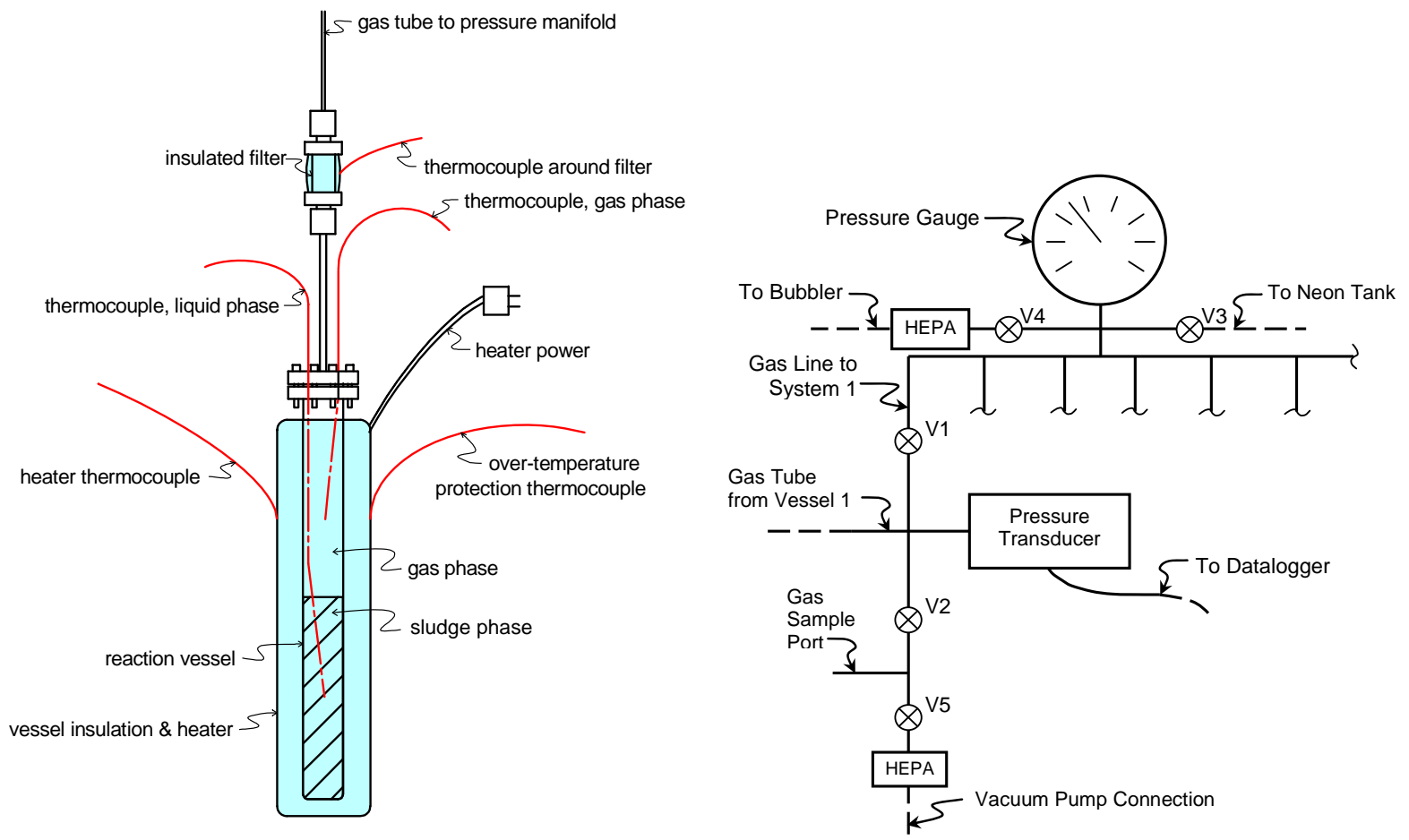

Figure 3.1. Gas Generation Test Apparatus 
The entire surface of the reaction system exposed to the test material and gas is stainless steel, except for a gold-plated copper gasket sealing the flange at the top of the reaction vessel. Each vessel is wrapped in heating tape and insulated to achieve the targeted test temperature. Two thermocouples are attached to the external body, one for feedback temperature control and one for over-temperature protection. Two thermocouples are inserted through the flange. The thermocouple centered in the lower half of the vessel monitors the temperature of the sludge phase; the one centered in the upper half monitors the gas-phase temperature within the reaction vessel. The reaction vessels are connected by a thin $(0.0058-\mathrm{cm}$ inside diameter) stainless steel tube to the gas manifold. A $2-\mu \mathrm{m}$ pore size stainless steel filter is used to protect the tubing and manifold from contamination. A thermocouple is attached to this filter as well. Each reaction vessel has a separate pressure transducer on the gas manifold line. Temperatures and pressures for each vessel are recorded every 10 seconds and the data averaged every 20 minutes and saved. Temperature and pressure data are also manually logged once each working day.

The reaction vessels are sealed, connected to the manifold system, and purged with neon gas to remove air, achieve anoxic conditions, and provide a cover gas of known composition. Neon is used rather than argon (a cheaper inert gas) so that potential air contamination, which includes $\sim 1 \%$ argon, can be monitored. The vessels are heated to the target conditions by applying power to the heat tapes. Temperatures and gas pressures are monitored continuously, and the temperature is controlled by a feedback system (thermostat). Gas samples are collected as desired over the test duration and analyzed by mass spectrometry.

The observed rates of reaction in the uranium metal bead test series are plotted in Arrhenius coordinates in Figure 3.2. Also plotted for reference are the STP rate law, the $95 \%$ confidence limits in the rate law, and the contributing data points used in deriving the rate law. It is seen that the rates for the tests with the non-irradiated uranium metal beads lie within the $95 \%$ confidence limits for the STP rate law but show somewhat lower rates (approximately a factor of two) for those tests conducted with accompanying simulated sludge.

\subsection{Correspondence of Irradiated Uranium Metal Corrosion Rates in Water and in Sludge with Predicted Rates}

The reaction rate of irradiated uranium metal $\mathrm{N}$ Reactor fuel in anoxic liquid water has been studied for the K Basins Project (Schmidt et al. 2003). In these tests, crushed and sieved fuel particles of various particle-size distributions were reacted in closed vessels both with and without accompanying K Basin sludge. The apparatus used in this testing was the same, except for the specific test vessels, as that described in Figure 3.1 and the accompanying paragraphs. The rates of reaction were determined by measuring the quantities and rates of fission-product gas $(\mathrm{Kr}$ and $\mathrm{Xe}$ ) release occurring by the reaction of the metal. Hydrogen generation rates also were recorded. Gas samples were collected several times over the test period. Most tests were run to complete extinction of the uranium metal. The effects of irradiation on corrosion in anoxic liquid water are manifest in both the intrinsic limited corrosion rate of the surface area and on metal fragmentation. 


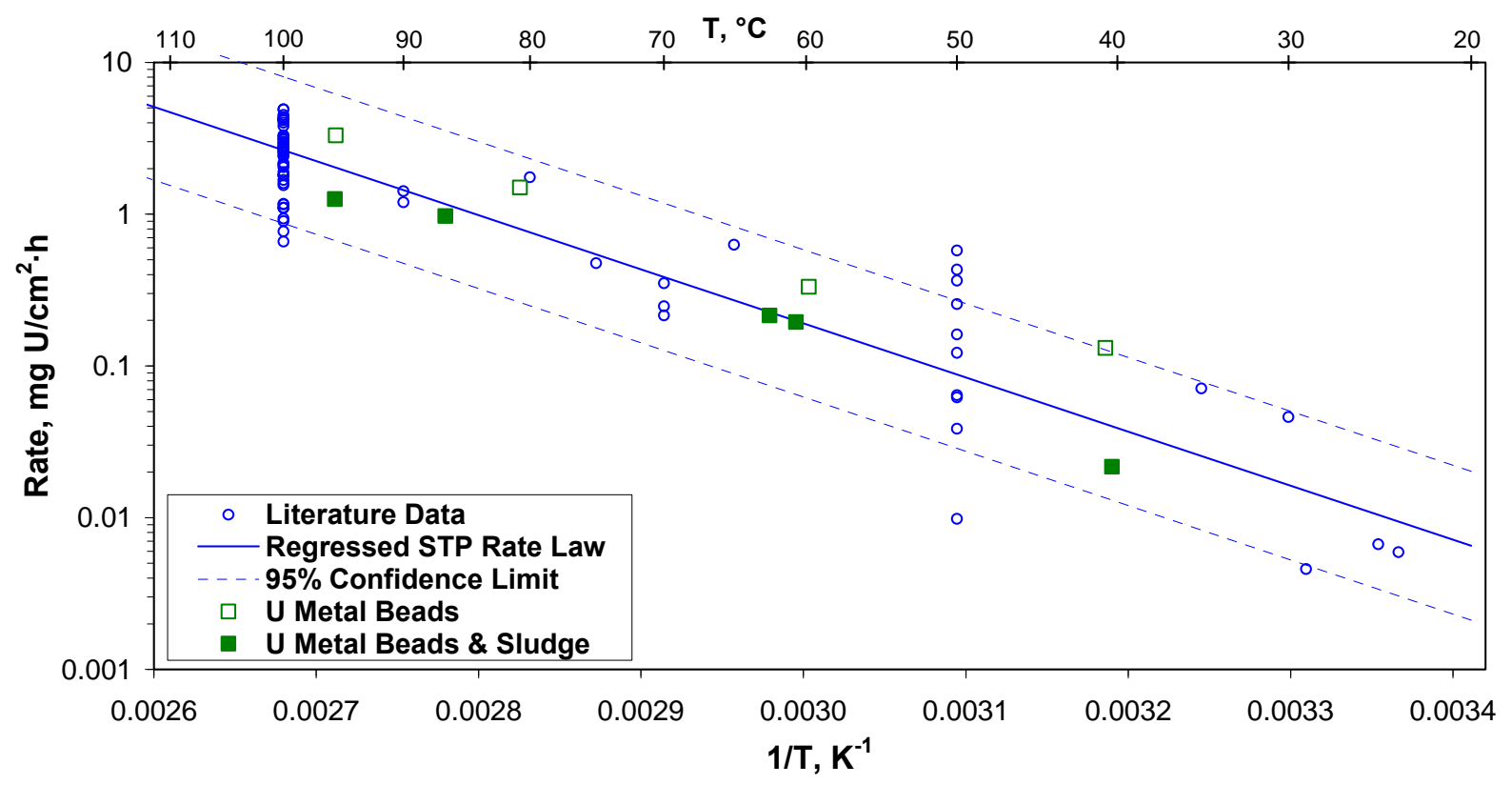

Figure 3.2. Comparison of Uranium Metal Oxidation Rate Data from the Technical Literature with Data from Tests of Non-Irradiated Uranium Metal Beads with and Without Simulated Sludge Based on $\mathrm{H}_{2}$ Generation (Delegard et al. 2004b)

Higher confidence in observing corrosion rates is obtained by using rates based on the chemically inert $\mathrm{Kr}$ and Xe fission product gas release rather than $\mathrm{H}_{2}$ generation because of potential $\mathrm{H}_{2}$ sequestration as $\mathrm{UH}_{3}$ in the corroding uranium metal. Of the two fission product gases, $\mathrm{Xe}$ is about eight times more abundant than $\mathrm{Kr}$ and does not suffer from interference from hydrocarbon isobars (at about 83 to 88 atomic mass units). Therefore, the Xe data are the best for accurately monitoring the uranium metal corrosion rate and are used in considering the K Basins Project findings (Schmidt et al. 2003).

The observed rates of reaction in the test series with and without added sludge are plotted in Arrhenius coordinates based on the Xe release rate data and are compared with the STP rate law, the data used to construct the rate law, and the rate-law error bars with a 95\% confidence level (Figure 3.3). The rates observed for the crushed irradiated N Reactor fuel without sludge range from factors of 1 to 10 times lower and are about a factor of 3 lower, overall, than predicted based on the surveyed technical literature based on non-irradiated uranium corrosion. The effect of sludge overburden is not evident in these data, as presented, from varied tests. However, sludge overburden is shown to lower rates in side-by-side tests as described by Schmidt et al. (2003). 


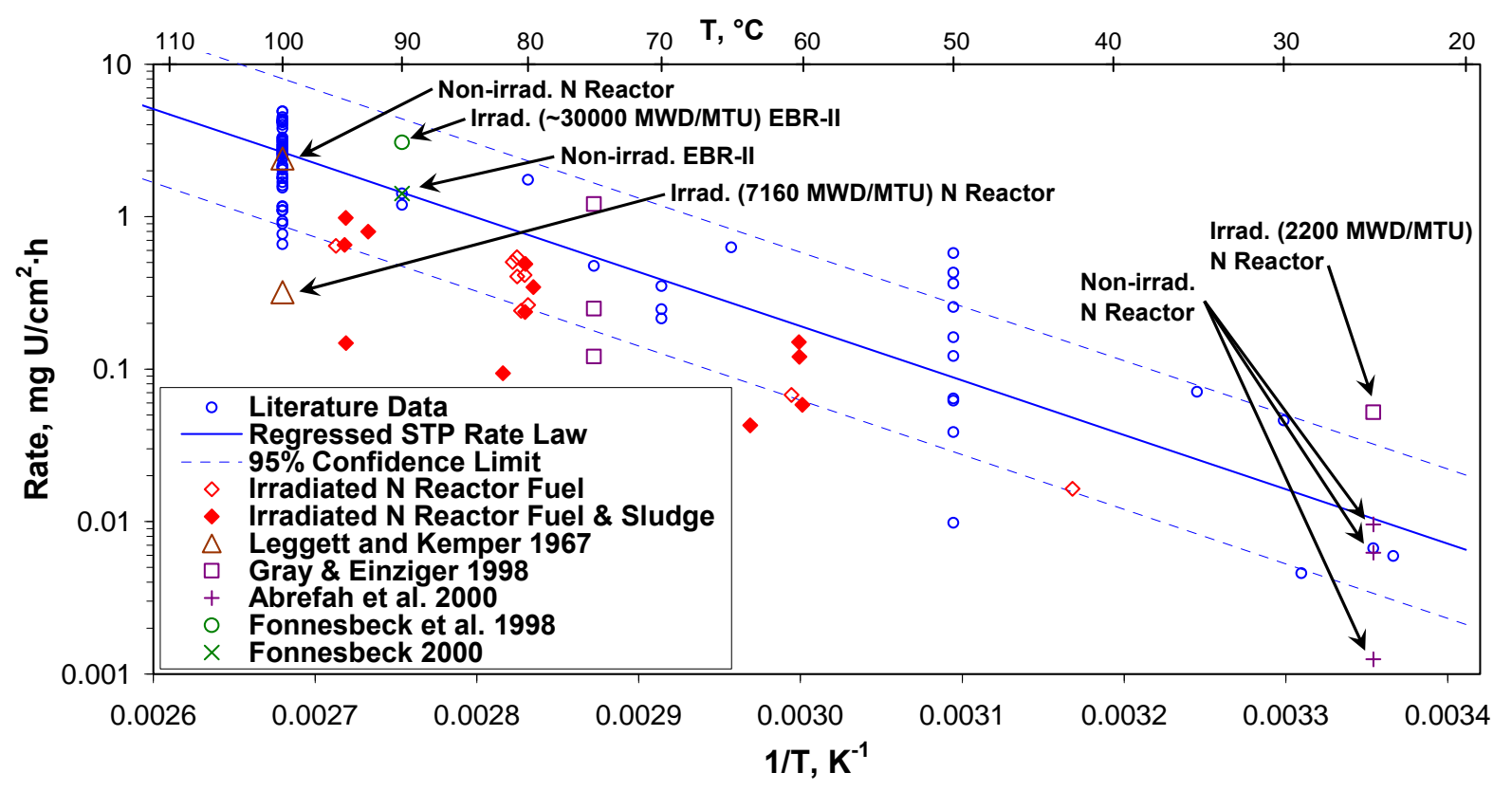

Figure 3.3. Comparison of Anoxic Uranium Metal Oxidation-Rate Data from the Technical Literature with Data from Tests of Irradiated Uranium with and Without K Basin Sludge Based on Xe Release (Schmidt et al. 2003)

The effect of irradiation on the $\mathrm{N}$ Reactor uranium metal-fuel corrosion rate also may be estimated by examining the data of Leggett and Kemper (1967) and Leggett (1967) as presented in Figure 3.3. In these tests, transverse slices of Mark I N Reactor inner fuel elements $(1.27 \mathrm{~cm}$ thick, $3.15 \mathrm{~cm}$ diameter, and cylinders with 1.17 -cm-diameter circular holes $)$ were corroded in boiling $\left(100^{\circ} \mathrm{C}\right)$ water. ${ }^{\text {(a) }}$ One slice had been irradiated to 7,160 MWD/MTU, and one slice was not irradiated. The initial corrosion rate after 28 hours of testing (plotted in Figure 3.3) was about 7.5-times lower for the irradiated item than the rate for the non-irradiated control sample. While the corrosion rates remained relatively constant for the nonirradiated sample as testing continued to the full 98 hours, the corrosion rates steadily increased for the irradiated sample and were approaching the rate observed for the non-irradiated item.

The low initial corrosion rate of the irradiated fuel was attributed by Leggett and Kemper (1967) and Leggett (1967) to the "alloying" caused by the presence of fission product atoms (about 0.42 atom\%), including zirconium ( $\sim 900 \mathrm{ppm})$ and molybdenum $(\sim 750 \mathrm{ppm})$. The subsequent increase in corrosion rates observed for the irradiated fuel was caused by the significant fragmentation that occurred as the corrosion testing progressed. The irradiated fuel slice cracked and broke into a number of pieces as the corrosion testing proceeded while the non-irradiated fuel slice remained intact. No similar observations of increased corrosion rate with time or fuel fragment crumbling were observed in the more recent tests of irradiated N Reactor fuel particle corrosion (Schmidt et al. 2003), which were conducted with much smaller particles (largest $\sim 0.7 \mathrm{~cm}$ ).

The observations for 2,200 MWD/MTU irradiated N Reactor fuel under anoxic conditions (Gray and Einziger 1998), shown in Figure 3.3, are scattered within the rate range expected based on the STP rate

(a) The sludge in the K Basins largely arose from fuel irradiated to about $2900 \mathrm{MWD} / \mathrm{MTU}$. 
law. The rate at $25^{\circ} \mathrm{C}$ for irradiated $\mathrm{N}$ Reactor fuel is about a factor of four higher than the STP rate law. Similar tests on non-irradiated $\mathrm{N}$ Reactor fuel at $25^{\circ} \mathrm{C}$ (Abrefah et al. 2000) are at or lower than the rate forecast by the STP rate law. The $90^{\circ} \mathrm{C}$ rate datum for uranium metal blanket fuel irradiated to $\sim 30,000 \mathrm{MWD} / \mathrm{MTU}$ (Fonnesbeck et al. 1998) also is shown in Figure 3.3 and likewise is consistent with the STP rate. Comparable corrosion-rate measurements of non-irradiated EBR-II fuel metal in anoxic liquid water by hydrogen gas generation were conducted at the same $90^{\circ} \mathrm{C}$ temperature by the same laboratory (Fonnesbeck 2000, 2003). As seen in Figure 3.3, the corrosion rate for non-irradiated EBR-II fuel metal is about half of the rate for the comparable irradiated EBR-II metal.

Overall, the paired findings for the irradiated and non-irradiated $\mathrm{N}$ Reactor fuel at $25^{\circ} \mathrm{C}$ (Gray and Einziger 1998 and Abrefah et al. 2000, respectively) and irradiated and non-irradiated EBR-II fuel at $90^{\circ} \mathrm{C}$ (Fonnesbeck et al. 1998 and Fonnesbeck 2000, 2003, respectively) show irradiation to increase rates. However, the effects of irradiated fuel crumbling or increased surface area were not investigated.

The effects of irradiation on the rate of uranium metal corrosion by anoxic liquid water have been measured in other studies. In single parallel tests, irradiation at $\sim 1,000 \mathrm{MWD} / \mathrm{MTU}$ was found to have a negligible effect on the uranium metal corrosion rate (non-irradiated rate $2.92 \mathrm{mg} / \mathrm{cm}^{2} \cdot \mathrm{h}$; irradiated rate $3.13 \mathrm{mg} / \mathrm{cm}^{2} \cdot \mathrm{h}$; Kittel et al. 1956). The corrosion rate of uranium irradiated to 1,100 to 9,850 MWD/ MTU was found to be enhanced when compared with the rate of non-irradiated uranium under otherwise equal conditions (Tyfield 1988). The enhanced rate was attributed entirely to the increased surface area created by swelling of the fuel caused by radiation exposure.

The conclusions of a review, stated below (Hilton 2000, p. 42), are that the effects of irradiation on corrosion rate in oxygen and water vapor are slight for fuels having low exposure and associated swelling (such as the K Basin fuel generally irradiated to less than 3,000 MWD/MTU in the N Reactor):

The effects of irradiation on uranium metal oxidation are summarized as follows. Irradiation does not increase the intrinsic oxidation rate of uranium metal. The apparent rate (normalized to geometric surface area) increases with irradiation-induced swelling. The enhancement factor due to irradiation is defined as an exponential function of swelling and is attributed to the associated increase in surface area. The oxidation rate of metal fuel irradiated to low burnup, which has negligible swelling, is expected to be similar to that of unirradiated $U$ metal. Consistent with this, unirradiated uranium and irradiated KW SNF (which has a low burnup and negligible swelling) have essentially the same reaction rates in oxygen and water vapor environments, within the variability of the literature data. The similarity between oxidation rates of KW SNF and U metal is also consistent with dissolution rates of irradiated uranium metal fuel reported by Gray and Einziger at PNNL and Fonnesbeck at Argonne National Laboratory-West (ANL-W).

\subsection{Crumbling of Uranium Metal During Corrosion}

Crumbling of uranium metal during corrosion in water has been observed in many studies, including those of Leggett and Kemper (1967) and Schmidt et al. (2003). The crumbling phenomenon, also called fragmentation, discontinuous failure, matrix breakup, or breakaway corrosion, is discussed in more detail in Appendix G of Plys and Schmidt (2006) where the observations of fragmentation phenomena are 
summarized and, where possible, the residual particle size (post crumbling terminal size) upon fragmentation is estimated.

In consideration of the $\mathrm{N}$ Reactor fuel studies, terminal particle sizes ranged from $\sim 400$ to $5,000 \mu \mathrm{m}$ with average particle diameters ranging from about 800 to $3,500 \mu \mathrm{m}$. The Sauter mean diameter, the particle diameter that yields the same overall reactive surface area per unit volume as the entire particle size distribution, is 3,250 $\mu \mathrm{m}$ ( $\sim 1 / 8$ inch) for irradiated N Reactor fuel upon crumbling (Plys and Schmidt 2006 interpretation of data of Abrefah and Sell 1999). However, the smallest diameter particle that Abrefah and Sell (1999) were able to count was $\sim 400 \mu \mathrm{m}$. Therefore, conservative assumptions were made by Plys and Schmidt (2005) to estimate the fraction of total particle volume composed of particles less than $400 \mu \mathrm{m}$ to derive design and safety basis particle-size distributions. These estimates for the volume fraction of particles less than $400 \mu \mathrm{m}$ were $0.37 \mathrm{vol} \%$ for the design basis and $2 \mathrm{vol} \%$ for the safety basis. From these distributions, design and safety basis reactive particle diameters for fuel piece sludge were established at $2,300 \mu \mathrm{m}$ and $1,500 \mu \mathrm{m}$, respectively.

The observed terminal particle sizes suggest that further crumbling of irradiated uranium metal found in sludge (where the upper particle size is $6,350 \mu \mathrm{m}$ ) is unlikely. If further crumbling of a $6,350-\mu \mathrm{m}$ particle were to occur, the crumbling would cease at particles no smaller than $\sim 400 \mu \mathrm{m}$. Because the total surface area of a collection of particles arising from a single particle is inversely proportional to their respective diameters, dividing a $6,350-\mu \mathrm{m}$ particle to a collection of $400-\mu \mathrm{m}$ particles would increase the exposed surface area by a factor of $(6,350 / 400 \cong) \sim 16$. It is more likely that a $6,350-\mu \mathrm{m}$ particle would crumble to the observed Sauter mean diameter of $3,250 \mu \mathrm{m}$, increasing the surface area by about a factor of two.

\subsection{Determination of Uranium Metal Concentration in K Basin Sludge}

The presence of uranium metal in K Basin sludge is of concern in its storage, treatment, and disposal. Accordingly, determining the presence and quantity of uranium metal in K Basin sludge was a leading goal in sludge characterization studies (see, for example, Makenas et al. 1996). X-ray diffractometry (XRD) was one of the tools tried to determine if uranium metal was present. Although various uranium oxides (e.g., $\mathrm{UO}_{2}, \mathrm{U}_{4} \mathrm{O}_{9}, \mathrm{U}_{3} \mathrm{O}_{8}, \mathrm{UO}_{3} \cdot 2 \mathrm{H}_{2} \mathrm{O}, \mathrm{UO}_{4} \cdot 2 \mathrm{H}_{2} \mathrm{O}$ ), more complex oxidized uranium compounds [e.g., becquerelite, a calcium-bearing $\mathrm{U}(\mathrm{VI})$ mineral], and even $\mathrm{UH}_{3}$ were found as well as non-uranium phases, no uranium metal was identified by XRD (Makenas et al. 1996, 1997, 1998, and 1999). In retrospect, this probably was partly due to the low uranium metal concentrations present in the sludge and more fundamentally due to the shielding to X-rays caused by the overlying dense uranium oxide on the metal.

The first substantive evidence for the presence of uranium metal in sludge was found in the K East canister sludge analysis campaign (Appendix B of Makenas et al. 1997). The evidence included observation of gas bubbles (which also had been observed in sludge and fuel movement activities in the $\mathrm{K}$ Basins), gas pressurization in closed shipping vessels, the formation of gas pockets in settled sludge, and, most compellingly, a quantitative analyses of $\mathrm{H}_{2}, \mathrm{Kr}$, and $\mathrm{Xe}$ in the evolved gases as well as methane, ethane, and other hydrocarbons (from the reaction of uranium carbide in the fuel with water). Later characterization of K West canister sludge (Makenas et al. 1998) provided similar evidence to show that most $\mathrm{KE}$ and $\mathrm{KW}$ canister sludge samples generated gas. 
The concentrations of uranium metal in $\mathrm{K}$ Basin sludge have been measured by a reaction calorimetric technique and by a gas generation/release technique. A third technique, which relies on selective dissolution of oxidized uranium compounds away from uranium metal, has been developed into a routine procedure.

\subsubsection{Uranium Metal Concentration by Reaction Calorimetry}

Initial estimates of the concentrations of uranium metal in $\mathrm{K}$ Basin sludge were attempted through reaction calorimetry (Bredt et al. 1999; Bredt et al. 2000; Appendix B of Plys and Schmidt 2006). In this technique, samples of sludge were reacted with concentrated nitric acid $\left(\mathrm{HNO}_{3}\right)$ and the elevation in temperature measured. The temperature rise reflects the heating caused by the dilution of the water present in the sludge, the dissolution of aluminum hydroxide as $\mathrm{Al}(\mathrm{OH})_{3}$, the dissolution of iron hydroxide as $\mathrm{FeOOH}$, the reaction of $\mathrm{UO}_{2}$ with $\mathrm{HNO}_{3}$ to form uranyl nitrate $\left[\mathrm{UO}_{2}\left(\mathrm{NO}_{3}\right)_{2}\right]$ solution, and the reaction of uranium metal with $\mathrm{HNO}_{3}$ to form $\mathrm{UO}_{2}\left(\mathrm{NO}_{3}\right)_{2}$ solution. The contributions to the observed temperature rise caused by these reactions can be estimated based on the known concentrations of water, aluminum, iron, and total uranium $\left(\mathrm{UO}_{2}\right.$ plus uranium metal) and their known enthalpies (heats) of dilution and reaction. Because the reaction of uranium metal with $\mathrm{HNO}_{3}$ is about 10 times more energetic per mole of uranium than the reaction of $\mathrm{UO}_{2}$ with $\mathrm{HNO}_{3}$, the relative contributions of $\mathrm{UO}_{2}$ and uranium metal to the reaction heat can be determined algebraically.

The uranium metal concentrations in composite sludge samples KC-2/3 P250, KC-4 P250, and KC-5 P250 and in single-pull sludge samples FE-1, FE-3, FE-5, and FE-6 were estimated by evaluating sludge compositions and observed total reaction enthalpies. All tested sludges were found to have zero metal content except KC-2/3 P250 (9.4 wt $\%$, dry basis, U metal or $5.1 \mathrm{wt} \% \mathrm{U}$ metal on a settled sludge basis), KC-5 (5.6 wt\% U metal, dry basis, or $2.4 \mathrm{wt} \%$, settled sludge basis), and FE-5 (3.2 wt \% U metal dry basis; $1.5 \%$ settled sludge basis). However, the assumptions that all iron is present as $\mathrm{FeOOH}$ and all aluminum is present as $\mathrm{Al}(\mathrm{OH})_{3}$, the large uncertainties in their extents of dissolution, and the errors in obtaining representative samples of these heterogeneous sludges (particularly in their water content), led to significant uncertainties in these uranium metal-concentration estimates. The high uncertainty also precluded estimates of uranium metal concentrations below about $2 \mathrm{wt} \%$ in settled sludge.

\subsubsection{Uranium Metal Concentration by Gas Generation and Release}

Based on the observation of hydrogen and fission product gases in the sludge, testing was proposed and executed to measure gas-generating reactions in $\mathrm{K}$ Basin sludge. The same test apparatus as described in Figure 3.1 was used in this testing. Three sets of gas generation testing were performed. The objective of the first set of testing was to determine the reactivity of the KE floor and canister sludge collected using a consolidated sampling technique and to determine the uranium metal concentrations (Delegard et al. 2000). The effects of sludge particle size and temperature on reactivity also were examined. The objective of the second set of testing was to measure uranium metal concentrations in KE floor, pit, and canister sludge. Size-fractionated and agitated versus non-agitated KE canister sludge also were tested as well as floor and pit sludge from areas in the KE Basin that had not previously been sampled (Bryan et al. 2004). The objective of the third test series was to determine uranium metal concentration in $\mathrm{K}$ East Basin North Loadout Pit sludge and gas generation from sludge waste forms (Mellinger et al. 2004).

The quantities of uranium metal present in the sludge were determined by correlations with the observed quantities of $\mathrm{H}_{2}$ produced (from reaction with water) and the small amounts of $\mathrm{O}_{2}$ and $\mathrm{N}_{2}$ from trace air 
contamination that were consumed. The estimates were made based on the assumption that uranium was the only reactant with water to form $\mathrm{H}_{2}$ or the only reactant with $\mathrm{O}_{2}$ and $\mathrm{N}_{2}$. However, as previously noted, the product $\mathrm{H}_{2}$ or consumed $\mathrm{O}_{2}$ and $\mathrm{N}_{2}$ are neither unique nor quantitative indicators of uranium metal reaction. Thus, $\mathrm{H}_{2}$ might also arise from radiolysis or, for example, by corrosion of iron metal. Conversely, $\mathrm{H}_{2}$ can react with uranium metal or other metals to form hydrides or perhaps reduce oxidized uranium species. The reduction of dissolved hexavalent uranium $\left(\mathrm{UO}_{2}{ }^{2+}\right)$ by $\mathrm{H}_{2}$ has been studied (Ekeroth et al. 2004 and references therein):

$$
\mathrm{UO}_{2}^{2+}+\mathrm{H}_{2} \rightarrow \mathrm{UO}_{2}+2 \mathrm{H}^{+}
$$

The consumption of $\mathrm{H}_{2}$ by reaction with ferric hydroxide $\left[\mathrm{Fe}(\mathrm{OH})_{3}\right.$, present from the corrosion of mild steel hardware in the basins] to form magnetite, $\mathrm{Fe}_{3} \mathrm{O}_{4}$, also is thermodynamically possible:

$$
\mathrm{H}_{2}+6 \mathrm{Fe}(\mathrm{OH})_{3} \rightarrow \mathrm{Fe}_{3} \mathrm{O}_{4}+10 \mathrm{H}_{2} \mathrm{O}
$$

Similarly, $\mathrm{N}_{2}$ and particularly $\mathrm{O}_{2}$ may be consumed by other reactions. One prominent example is the reaction of $\mathrm{UO}_{2}$ (which is known to be present in most sludge samples) with $\mathrm{O}_{2}$ and water to produce $\mathrm{UO}_{3} \cdot 2 \mathrm{H}_{2} \mathrm{O}$ (Sinkov et al. 2008):

$$
\mathrm{UO}_{2}+0.5 \mathrm{O}_{2}+2 \mathrm{H}_{2} \mathrm{O} \rightarrow \mathrm{UO}_{3} \cdot 2 \mathrm{H}_{2} \mathrm{O}
$$

Under the same test conditions, the quantities of uranium present in the sludge also were determined, independently, by correlation with the quantities of $\mathrm{Kr}$ and $\mathrm{Xe}$ fission product gas released. To do this, the burn-up of the fuel producing the uranium metal particles in the sludge must be known. A fuel burnup of 2,900 MWD/MTU is typical of the fuel that was present in the K Basins. Based on the 2,900 MWD/MTU value, the ORIGEN reactor code run for N Reactor fuel predicts $47.2 \mu \mathrm{g} \mathrm{Kr} / \mathrm{gram}$ uranium $(0.0132 \mathrm{~mole} \% \mathrm{Kr} / \mathrm{mole} \mathrm{U})$ and $602 \mu \mathrm{g} \mathrm{Xe/gram} \mathrm{uranium} \mathrm{(0.106} \mathrm{mole \%} \mathrm{Xe/mole} \mathrm{U).} \mathrm{The} \mathrm{burn-}$ up determined by fully reacting uranium metal from a metal-rich composite sludge sample retrieved from canisters holding moderately and highly corroded fuel in the KE Basin showed 2,800 MWD/MTU burnup, in close agreement with the nominal burn-up (Delegard et al. 2000). The burn-up found for the crushed irradiated fuel pieces ranged from about 2,600 to 3,100 MWD/MTU (Schmidt et al. 2003).

The impacts of the reactions with the non- $\mathrm{U}$ metal sludge materials become increasingly significant influences in estimating $U$ metal concentrations as $U$ metal concentrations decrease. The quantities of uranium metal present in sludge samples have been estimated based on these individual reactions and their summations in the characterization testing for sludge gas generation (Delegard et al. 2000, Bryan et al. 2004, and Mellinger et al. 2004).

The results of the uranium metal-concentration evaluations determined by $\mathrm{H}_{2}$ production, by the sum of $\mathrm{H}_{2}$ production and $\mathrm{O}_{2}$ and $\mathrm{N}_{2}$ consumption, and by Xe release are compared in Table 3.1. The ratios of the uranium concentrations determined by $\mathrm{H}_{2}$ production and the sum of $\mathrm{H}_{2}$ production and $\mathrm{O}_{2}$ and $\mathrm{N}_{2}$ consumption to the concentrations determined by Xe release in the last two columns show how well the results correspond. 
All but four of the samples were reacted to complete extinction of uranium metal by extended heating at $95^{\circ} \mathrm{C}$. The remaining four $(\mathrm{KC}-2 / 3 \mathrm{P} 250 \mathrm{~L}, \mathrm{KC}-4 \mathrm{~L}, \mathrm{KC}-4 \mathrm{~L}$ Dup, and $\mathrm{KC}-5 \mathrm{~L})$ were run in $800-\mathrm{mL}$ vessels and maintained at the hot cell temperature $\left(\sim 32^{\circ} \mathrm{C}\right)$ for the entire test duration.

Because Xe can only arise from uranium metal and does not react with other sludge components as $\mathrm{H}_{2}$, $\mathrm{O}_{2}$, and $\mathrm{N}_{2}$ potentially can do, the most reliable uranium concentration data are those obtained by Xe release. It is seen in Table 3.1 that the uranium metal concentrations deduced by $\mathrm{H}_{2}$ production are generally lower than those found by Xe release, especially for sludges having low uranium metal concentrations. Even the inclusion of $\mathrm{N}_{2}$ and $\mathrm{O}_{2}$ consumption with the $\mathrm{H}_{2}$ production was not sufficient, in most cases, to account for enough uranium metal to match that measured by Xe release. The relationships between the quantities of uranium metal determined by Xe release and the quantities determined by $\mathrm{H}_{2}$ generation or the combination of $\mathrm{H}_{2}$ generation and $\mathrm{O}_{2}$ plus $\mathrm{N}_{2}$ consumption are shown in Figure 3.4. The lowest uranium metal concentrations, as determined by Xe release, are about $0.004 \mathrm{wt} \%$ in the settled sludge.

\subsubsection{Uranium Metal Concentration by Selective Dissolution}

An alternative technique to determine uranium metal concentration in sludge is suggested by recent observations that the dissolution rates of uranium oxides in $\mathrm{Na}_{2} \mathrm{SO}_{4}$-bearing $\mathrm{H}_{3} \mathrm{PO}_{4}$ are vastly greater than those of uranium metal in the same medium (Sinkov et al. 2008). Because of the large dissolution rate difference, a selective dissolution of oxidized uranium away from the uranium metal may be achieved. The residual uranium metal then can be dissolved by a subsequent $\mathrm{HNO}_{3}$ treatment and the dissolved uranium metal concentrations analyzed by established uranium analytical methods.

The approach is to first contact the sludge with $\mathrm{Na}_{2} \mathrm{SO}_{4}$-bearing $\mathrm{H}_{3} \mathrm{PO}_{4}$ at $\sim 80^{\circ} \mathrm{C}$. Based on tests with $\mathrm{UO}_{2}$ agglomerates, this treatment is expected to dissolve the oxidized uranium compounds (e.g., uraninite, metaschoepite, becquerelite, soddyite $)^{(\mathrm{a})}$ within two hours but will not appreciably attack uranium metal based on the observation that $500-\mu \mathrm{m}$ uranium metal particles required about 11 days to dissolve in $\mathrm{Na}_{2} \mathrm{SO}_{4}$-bearing concentrated $\mathrm{H}_{3} \mathrm{PO}_{4}$ at $130^{\circ} \mathrm{C}$. The $\mathrm{H}_{3} \mathrm{PO}_{4}$ solution with dissolved uranium compounds then is removed from the residual sludge solids and may be retained for uranium analysis to determine the concentration of oxidized uranium in the sludge. The solids heel is rinsed thoroughly with dilute roomtemperature nitric acid $\left(\mathrm{HNO}_{3}\right)$ to remove any entrained uranium-bearing liquid and the rinses are discarded. The residual uranium metal with other solids that are not dissolved by $\mathrm{H}_{3} \mathrm{PO}_{4}$ (e.g., sand, ion exchange media, Zircaloy cladding, Grafoil gasketing material) then is treated with hot strong $\mathrm{HNO}_{3}$. The uranium metal dissolution rate in near boiling $10 \mathrm{M} \mathrm{HNO}_{3}$ is about $500 \mu \mathrm{m} /$ hour. After several hours of heating, the uranium metal is fully dissolved and the concentrated $\mathrm{HNO}_{3}$ solution is cooled and collected for uranium concentration analysis.

(a) Becquerelite $\left[\mathrm{Ca}\left(\mathrm{UO}_{2}\right)_{6} \mathrm{O}_{4}(\mathrm{OH})_{6}\left(\mathrm{H}_{2} \mathrm{O}\right)_{8}\right]$ and soddyite $\left[\left(\mathrm{UO}_{2}\right)_{2} \mathrm{SiO}_{4} \cdot 2 \mathrm{H}_{2} \mathrm{O}\right]$ have been observed in sludge and hydrothermal sludge products (Delegard et al. 2007). Minor amounts of other oxidized (non-metal) uranium compounds also may be present in sludge. 
Table 3.1. Uranium Metal Concentrations in K Basin Sludge Based on Gas Generation Testing

\begin{tabular}{|c|c|c|c|c|c|c|c|c|c|}
\hline \multirow{2}{*}{\multicolumn{2}{|c|}{\begin{tabular}{||c|} 
Sludge Description \\
\end{tabular}}} & \multicolumn{2}{|c|}{ Settled Sludge Sample } & \multirow{2}{*}{$\begin{array}{c}\text { Test } \\
\text { Temp., }{ }^{\circ} \mathrm{C}\end{array}$} & \multicolumn{3}{|c|}{ Wt\% U Metal, Settled Sludge Basis, by } & \multicolumn{2}{|c|}{ Wt\% U Metal Ratio } \\
\hline & & Sample ID & Weight, $\mathrm{g}$ & & $\mathbf{X e}$ & $\mathrm{H}_{2}$ Only & $\mathrm{H}_{2}+\mathrm{O}_{2}+\mathrm{N}_{2}$ & $\mathbf{H}_{2} / \mathbf{X e}^{(a)}$ & $\mathrm{H}_{2}+\mathrm{O}_{2}+\mathrm{N}_{2} / \mathrm{Xe}^{(\mathrm{b})}$ \\
\hline \multicolumn{10}{|c|}{ KE Canister Sludge Consolidated Samples - Delegard et al. 2000} \\
\hline \multirow{4}{*}{\multicolumn{2}{|c|}{$\begin{array}{l}\text { Canister sludge from moderately and highly damaged } \\
\text { fuel; P (plus) and } \mathrm{M} \text { (minus) } 250 \mu \mathrm{m} \text { particle size }\end{array}$}} & KC-2/3 M250 & $\mathbf{1 7 . 5 6}$ & 80,95 & 0.194 & 0.00249 & 0.0485 & 0.013 & 0.25 \\
\hline & & KC-2/3 P250 - 40 & 23.69 & 40,95 & 7.41 & 7.65 & 7.66 & 1.03 & 1.03 \\
\hline & & KC-2/3 P250 - 60 & 18.66 & 60,95 & 6.62 & 7.83 & 8.04 & 1.18 & 1.21 \\
\hline & & KC-2/3 P250 - 80 & 13.71 & 80,95 & 6.63 & 6.34 & 6.36 & 0.96 & 0.96 \\
\hline \multirow{2}{*}{\multicolumn{2}{|c|}{$\begin{array}{l}\text { Floor sludge from between slotted canister barrels; } \\
\text { plus and minus } 250 \mu \mathrm{m}\end{array}$}} & KC-4 M250 & 15.14 & 80,95 & 0.00562 & 0.00932 & 0.0524 & 1.7 & 9.3 \\
\hline & & KC-4 P250 & 7.82 & 80,95 & 0.00368 & 0.0146 & 0.145 & 4.0 & 39 \\
\hline \multirow{2}{*}{\multicolumn{2}{|c|}{$\begin{array}{l}\text { Floor sludge from deep areas away from highly } \\
\text { damaged fuel }\end{array}$}} & KC-5 M250 & 13.86 & 80,95 & 0.00483 & 0.00893 & 0.0150 & 1.8 & 3.1 \\
\hline & & KC-5 P250 & 16.23 & 80,95 & 0.0625 & 0.0292 & 0.0451 & 0.47 & 0.72 \\
\hline \multirow{4}{*}{\multicolumn{2}{|c|}{$\begin{array}{l}\text { See above descriptions; large }(800 \mathrm{ml}) \text { test vessels; } \\
\text { KC-4-L, KC-4-L Dup, and KC-5-L run } 5271 \text { hours; } \\
\text { KC-2/3 P250 L run 10,140 hours; none run to } \\
\text { extinction }\end{array}$}} & KC-2/3 P250 L ${ }^{(c)}$ & 65.98 & $\sim 32$ & 0.0196 & 0.00797 & 0.110 & 0.41 & 5.6 \\
\hline & & \begin{tabular}{|l|} 
KC-4 L \\
\end{tabular} & 421.51 & $\sim 32$ & 0.00598 & 0.00167 & 0.00339 & 0.28 & 0.57 \\
\hline & & KC-4 L Dup & 378.25 & $\sim 32$ & 0.00725 & 0.00127 & 0.00468 & 0.18 & 0.65 \\
\hline & & KC-5 L & 439.45 & $\sim 32$ & 0.00918 & 0.000753 & 0.00349 & 0.08 & 0.38 \\
\hline \multicolumn{10}{|c|}{ KE Canister Sludge Consolidated Samples - Bryan et al. 2004} \\
\hline \multirow{4}{*}{$\begin{array}{l}\text { Canister sludge from } \\
\text { highly damaged fuel }\end{array}$} & Unmixed KC-1 & KC-1 Un & 23.75 & 60,95 & 0.0852 & 0.000201 & 0.0120 & 0.0024 & 0.14 \\
\hline & Mixed KC-1 & KC-1 Mix & 25.61 & 60,95 & 0.468 & 0.00174 & 0.00877 & 0.0037 & 0.019 \\
\hline & KC-1, plus $500 \mu \mathrm{m}$ & KC-1 P500 & 14.15 & 80,95 & 3.77 & 0.373 & 0.390 & 0.099 & 0.103 \\
\hline & KC-1, minus $500 \mu \mathrm{m}$ & KC-1 M500 & 22.30 & 80,95 & 0.145 & 0.000665 & 0.00657 & 0.0046 & 0.045 \\
\hline \multicolumn{10}{|c|}{ Single-Pull Core KE Floor and Pit Sludge Samples - Bryan et al. 2004} \\
\hline \multicolumn{2}{|l|}{ Main Floor (FE-1) } & FE-1 & 27.00 & 90,95 & 0.0215 & 0.00650 & 0.0151 & 0.30 & 0.70 \\
\hline \multicolumn{2}{|c|}{ North Loadout Pit (FE-3) } & FE-3 & 21.22 & 90,95 & $<0.0088$ & 0.000313 & 0.0013 & - & - \\
\hline \multicolumn{2}{|l|}{ Weasel Pit (FE-5) } & FE-5 & 19.93 & 90,95 & 0.0272 & 0.00102 & 0.0168 & 0.038 & 0.62 \\
\hline \multicolumn{2}{|c|}{$\begin{array}{l}\text { Dummy Elevator and Tech View Pit } \\
(63 \mathrm{wt} \% \text { FE-4 }+37 \mathrm{wt} \% \text { FE-6) }\end{array}$} & FE-4/6 & $\begin{array}{c}15.87 \\
(10.00 / 5.87) \\
\end{array}$ & 90,95 & 0.00519 & 0.00195 & 0.0136 & 0.38 & 2.6 \\
\hline \multicolumn{10}{|c|}{ Other Tests - Bryan et al. 2004} \\
\hline \multicolumn{2}{|c|}{ Organic ion exchange resin } & KC-6 (whole) & 19.10 & 90,95 & $<0.010$ & 0.0118 & 0.0255 & - & - \\
\hline \multicolumn{2}{|c|}{1996 KE canister sludge } & $96-06$ & 19.51 & 80,95 & 0.990 & 0.00134 & 0.00325 & 0.0014 & 0.0033 \\
\hline \multicolumn{10}{|c|}{ KE North Loadout Pit - Mellinger et al. 2004} \\
\hline \multirow{2}{*}{\multicolumn{2}{|c|}{ KE North Loadout Pit }} & NLOP-U1 & 57.06 & 95 & $<0.018$ & 0.0108 & $0.0360(\mathrm{~d})$ & - & - \\
\hline & & NLOP-U2 & 54.47 & 95 & $<0.018$ & 0.0163 & $0.0273(\mathrm{~d})$ & - & - \\
\hline \multicolumn{10}{|c|}{$\begin{array}{l}\text { (a) } \mathrm{Wt} \% \mathrm{U} \text { metal as determined by } \mathrm{H}_{2} \text { generation divided by wt } \% \mathrm{U} \text { metal as determined by Xe } \\
\text { (b) } \mathrm{Wt} \% \mathrm{U} \text { metal as determined by } \mathrm{H}_{2} \text { generation plus } \mathrm{O}_{2} \text { and } \mathrm{N}_{2} \text { consumption divided by wt } \% \\
\text { (c) Started as described in Delegard et al. (2000); final data reported by Schmidt et al. (2003). } \\
\text { (d) Based on } \mathrm{H}_{2} \text { and } \mathrm{O}_{2} \text { reactions only. }\end{array}$} \\
\hline
\end{tabular}




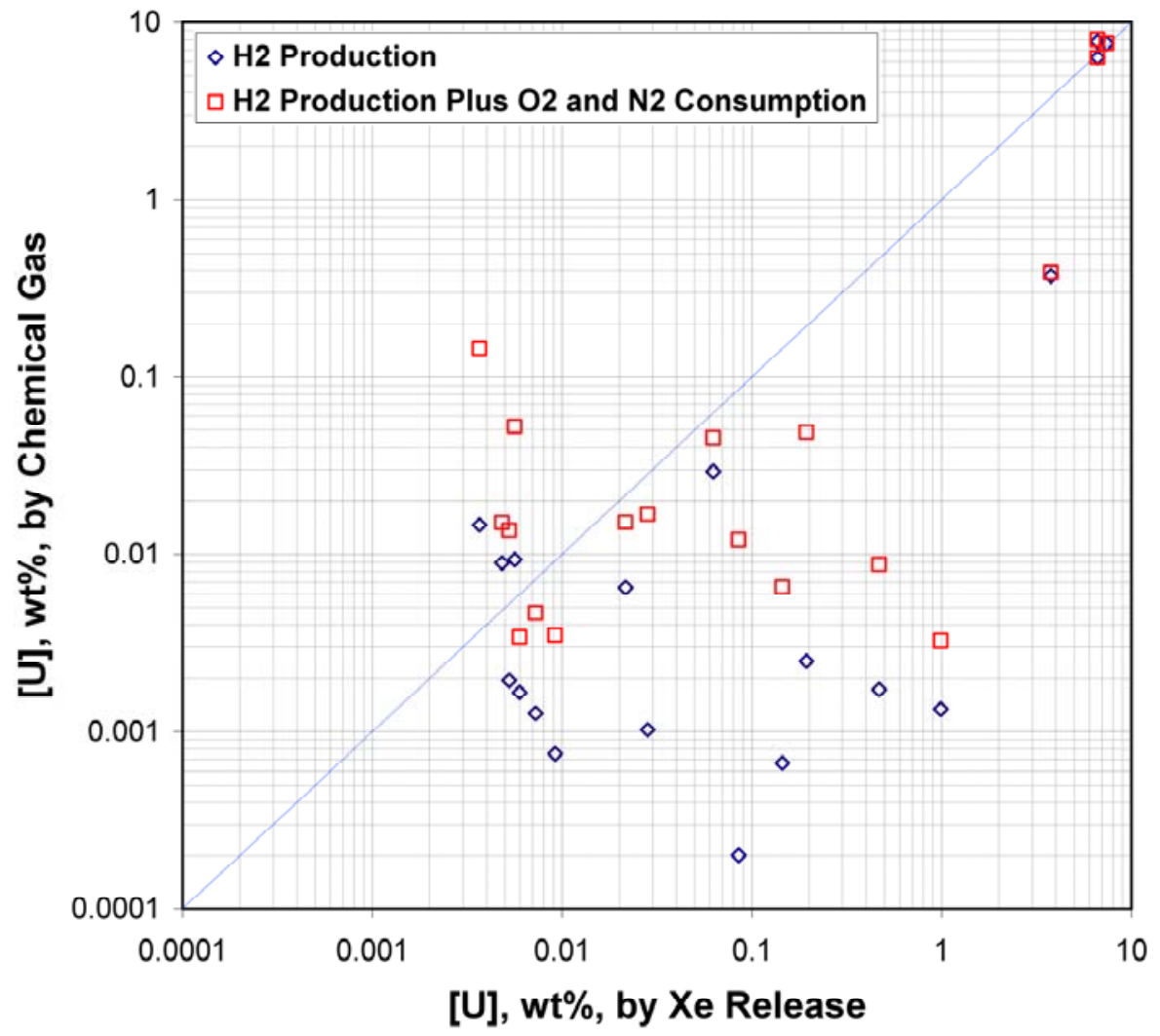

Figure 3.4. Uranium Concentrations in Settled K Basin Sludge as Determined by Chemical Gas Compared with Xe Fission Product Gas Release (Chemical Gas is $\mathrm{H}_{2}$ Generation and Combined $\mathrm{H}_{2}$ Generation Plus $\mathrm{O}_{2}$ and $\mathrm{N}_{2}$ Consumption)

Uranium metal recoveries in tests with simulated and genuine sludge containing known amounts of added uranium metal beads (Delegard et al. 2008) ${ }^{(\mathrm{a})}$ were excellent and allowed this digestion method to become formalized as a routine analytical procedure. ${ }^{(b)}$ The detection limit for this technique is on the order of $0.004-w t \%$ uranium metal in settled sludge. The results of the testing with genuine sludge spiked with uranium metal beads are shown in Figure 3.5.

The selective dissolution technique thus appears to have sensitivity similar to the technique based on Xe gas release. The selective dissolution technique also is performed more rapidly (within 1 to 2 weeks compared with $\sim 3$ months for the gas-release testing) and does not require knowledge or assumptions of the parent fuel burn-up as does the gas-release technique. As shown in the following section, with multiple gas samples, uranium metal particle size can be obtained based on the Xe release rates. In contrast, with selective dissolution, no information on uranium metal particle size in the sample is

(a) CH Delegard, SI Sinkov, and AJ Schmidt. 2008. Uranium Metal Analysis via Selective Dissolution - Summary of Initial Results. Letter report 53451-RPT03, PNNL-17626 (limited distribution), Pacific Northwest National Laboratory, Richland, WA.

(b) SA Jones. 2008. Sample Preparation for Determination of Uranium Metal Concentrations in Sludge. RPGCMC-107, Pacific Northwest National Laboratory, Richland, WA. 
acquired unless the sludge samples are sieved, and selective dissolution is performed on the sizefractionated sub-samples.

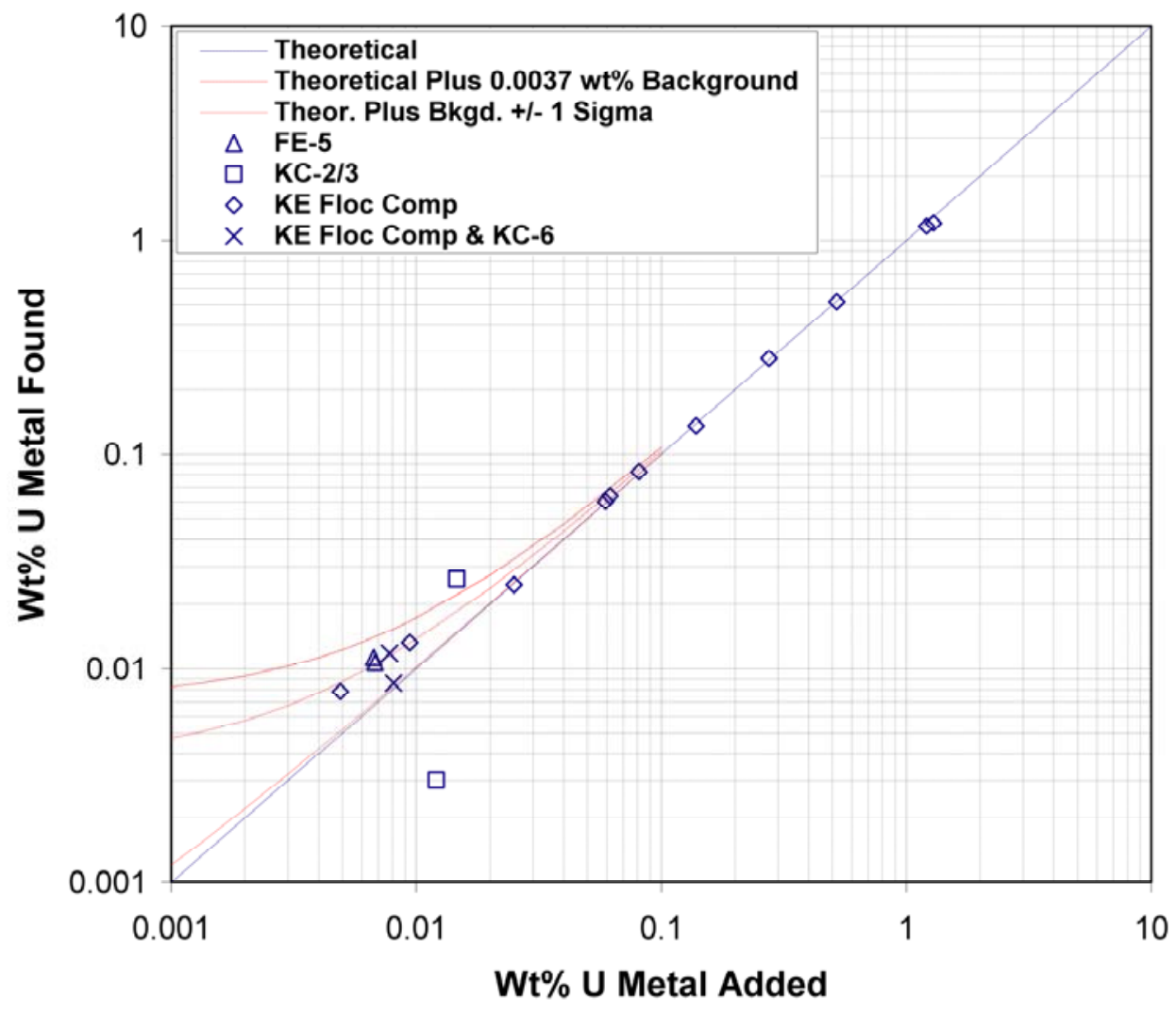

Figure 3.5. Uranium Metal-Concentration Analysis by Selective Dissolution

\subsection{Modeling Corrosion Rates in K Basin Sludge by Gas Generation Analysis to Determine Uranium Metal Particle-Size Distribution}

The uranium metal particle-size distribution may be estimated based on reaction rate laws derived from the technical literature (e.g., the STP rate law) and analyses of the rates that gases are generated $\left(\mathrm{H}_{2}\right)$, consumed $\left(\mathrm{O}_{2}\right.$ and $\left.\mathrm{N}_{2}\right)$, or released $(\mathrm{Kr}$ and $\mathrm{Xe})$ over the duration of the $\mathrm{U}$ metal reaction. At the most fundamental level, the size of the largest $U$ metal particle in sludge may be estimated by the time required for gas generation to cease by anoxic reaction with water based on the known linear penetration rate at the given reaction temperature. For example, if 400 hours are required for gas generation to cease after reaction at $90^{\circ} \mathrm{C}$ and the linear penetration rate is $0.755 \mu \mathrm{m} /$ hour (as shown in Table 2.1), the depth of penetration is ( 400 hours $\times 0.755 \mu \mathrm{m} /$ hour $=$ ) $302 \mu \mathrm{m}$. Assuming spherical particle geometry, the particle diameter is $604 \mu \mathrm{m}$. However, unless the gas composition also is analyzed, this approach is compromised for many $\mathrm{K}$ Basin sludges, which also can produce significant quantities of carbon dioxide gas, $\mathrm{CO}_{2}$, during hydrothermal reaction.

The sludge sample $\mathrm{KC}-2 / 3 \mathrm{P} 250$ underwent detailed gas generation study by reaction in anoxic liquid water at $40^{\circ} \mathrm{C}, 60^{\circ} \mathrm{C}$, and $80^{\circ} \mathrm{C}$ for extended time periods (Delegard et al. 2000). The tests at $60^{\circ} \mathrm{C}$ and $80^{\circ} \mathrm{C}$ were run virtually to completion, but temperatures were boosted to $95^{\circ} \mathrm{C}$ to verify complete reaction 
of the uranium metal. The test at $40^{\circ} \mathrm{C}$ had only consumed about half of the contained uranium metal at the end of about 3,574 hours of heating when it, too, was boosted to $95^{\circ} \mathrm{C}$ to complete the reaction. The complete extinction of uranium metal by further reaction at $95^{\circ} \mathrm{C}$ in all tests was indicated by no further gas pressure increase. Seven gas samplings and analyses were performed for the test run at $40^{\circ} \mathrm{C}$, eight at $60^{\circ} \mathrm{C}$, ten at $80^{\circ} \mathrm{C}$, and five at the $95^{\circ} \mathrm{C}$ interval run at the end of the test begun at $40^{\circ} \mathrm{C}$. By reacting to extinction, the ratio of the amount of $\mathrm{H}_{2}$ produced by corrosion of uranium metal to the amount of Xe released also could be determined.

The results of these studies are shown in Figure 3.6. In each case, the initial $\mathrm{H}_{2}$ generation is seen to lag the Xe release. The lag is greater at lower reaction temperatures, but the gap closes as the reaction approaches completion. The lag in $\mathrm{H}_{2}$ distribution to the gas phase is consistent with the known uptake of $\mathrm{H}_{2}$ into uranium metal as $\mathrm{UH}_{3}$ in its role as a reaction intermediate. This observation also gives further credence to using Xe release as a more accurate measure of the reaction progress, particularly at the initial stages of reaction where $\mathrm{H}_{2}$ uptake as $\mathrm{UH}_{3}$ is greatest.

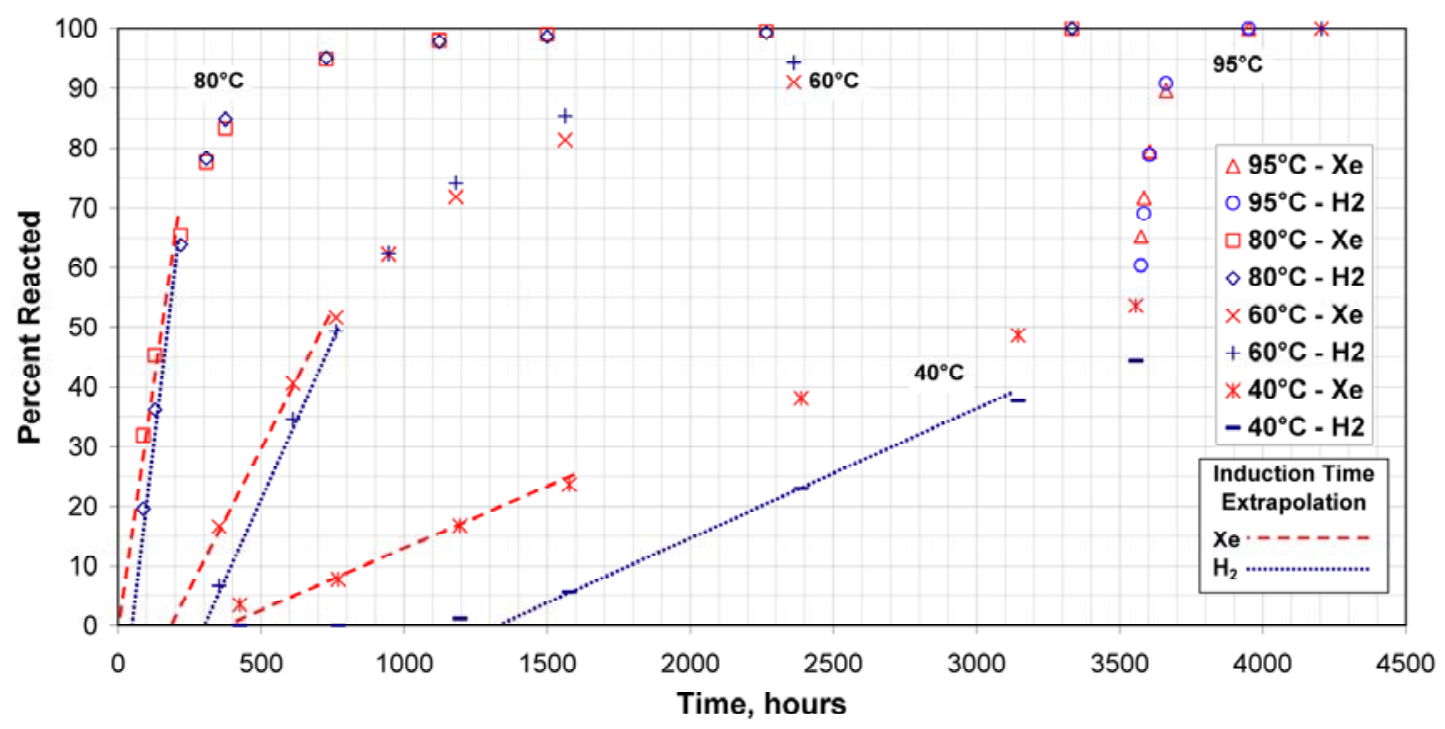

Figure 3.6. Progress of the Uranium Metal-Corrosion Reaction in KC-2/3 P250 Sludge as Measured by $\mathrm{H}_{2}$ Generation and Xe Release

The gas-measurement data also show that variable time intervals were required before the uranium metalcorrosion reaction began. The time intervals (reaction induction times) varied depending on which gas was used to monitor uranium corrosion with the induction time lower as the reaction temperature increased. For a given reaction temperature, the induction times based on Xe were lower than those based on $\mathrm{H}_{2}$. The induction times can be estimated, as shown in Figure 3.6, by extrapolating the inflections of the reaction curves (at $40^{\circ} \mathrm{C}$; the first two data points were used for the $60^{\circ} \mathrm{C}$ and $80^{\circ} \mathrm{C}$ tests) to zero percent reacted (i.e., the $\mathrm{x}$-axis). The uranium-corrosion reaction begins essentially instantaneously at $80^{\circ} \mathrm{C}$ as measured by Xe release but required about 27 hours based on $\mathrm{H}_{2}$ generation.

As shown in Table 3.1, a fourth test, $\mathrm{KC}-2 / 3 \mathrm{P} 250 \mathrm{~L}$, also was run at $\sim 32^{\circ} \mathrm{C}$ (hot cell temperature) with the same sludge. This test used an $\sim 800$ - $\mathrm{mL}$ vessel rather than the $\sim 60-\mathrm{mL}$ vessel used in the other tests done at higher temperatures. Despite extended monitoring of the gas pressure over an $\sim 14$-month interval and analyses of seven gas samples over this span, the total amount of uranium metal corrosion amounted 
to $<0.3 \%$ based on Xe release and $\sim 0.1 \%$ based on $\mathrm{H}_{2}$ generation. The combined analytical results clearly show that the KC-2/3 P250 L test did not overcome the induction time, likely caused through inhibition by atmospheric oxygen as described in Section 2.4 , needed to achieve the rapid hydride-mediated corrosion. ${ }^{\text {(a) }}$ The induction times for all tests conducted with the KC-2/3 P250 sludge are summarized in Table 3.2.

Table 3.2. Induction Times for Uranium Metal Corrosion in KC-2/3 P 250 Sludge as Measured by $\mathrm{H}_{2}$ Generation and Xe Release

\begin{tabular}{|c|c|c|}
\hline \hline \multirow{2}{*}{$\begin{array}{c}\text { Temperature, } \\
{ }^{\mathbf{}} \mathbf{C}\end{array}$} & \multicolumn{2}{|c|}{ Induction Time, hours } \\
\cline { 2 - 3 } & ${\mathbf{B y ~} \mathbf{H}_{\mathbf{2}}}_{\mathbf{B}}$ & $\mathbf{B y} \mathbf{X e}$ \\
\hline$\sim 32$ & $>10,140$ & $>10,140$ \\
\hline 40 & 1,340 & 400 \\
\hline 60 & 205 & 170 \\
\hline 80 & 26.9 & -7 \\
\hline
\end{tabular}

The nominal particle size of the uranium metal in sludge may be determined based on the rate of $\mathrm{H}_{2}$ generation or, better, the rate of Xe release. The kinetics of the reaction of a spherical or cubic particle (or collection of equal-sized spherical or cubic particles) may be expressed analytically for reactions whose rates are proportional to the instantaneous surface area of the solid being consumed by reaction (Delegard et al. 2000). The "shrinking core" model rate law for such equant solids (i.e., shapes of approximately equal dimension in the $x-y-z$ axes) is given by the following equation:

$$
(1-\mathrm{f})^{1 / 3}=1-\frac{\mathrm{kt}}{\mathrm{r}_{0} \rho}=1-\frac{\mathrm{k}^{\prime} \mathrm{t}}{\mathrm{r}_{0}}
$$

in which $f$ is the fraction of uranium metal reacted at time $t, r_{0}$ is the initial particle radius in $\mu \mathrm{m}, \rho$ is the uranium metal density in $\mu \mathrm{g} / \mu \mathrm{m}^{3}\left(1.91 \times 10^{-5} \mu \mathrm{g} / \mu \mathrm{m}^{3}\right)$, and $\mathrm{k}$ is the areal reaction rate expressed in $\mu \mathrm{g} / \mu \mathrm{m}^{2}$.hour. Dividing the areal reaction rate, $\mathrm{k}$, by $\rho$ gives the linear penetration rate in $\mu \mathrm{m} /$ hour. A plot of $(1-\mathrm{f})^{1 / 3}$ versus time (in hours) thus has a slope of $\mathrm{k}^{1} / \mathrm{r}_{0}\left(\right.$ or $\left.\mathrm{k} / \mathrm{r}_{0} \rho\right)$ and intercept on the vertical axis of 1 .

The Xe release data for the tests at $40^{\circ} \mathrm{C}, 60^{\circ} \mathrm{C}$, and $80^{\circ} \mathrm{C}$ were plotted in $(1-\mathrm{f})^{1 / 3}$-versus-time coordinates with the reaction times adjusted to account for the variable induction times as determined by Xe release (Table 3.2). The data for the completion of the $40^{\circ} \mathrm{C}$ test at $95^{\circ} \mathrm{C}$ also were plotted in this manner. The plots, shown in Figure 3.7, also present regressions of the initial linear data found until about $50 \%$ to $70 \%$ of the uranium has reacted. Deviations from linearity occur beyond this time, reflecting the persistence of larger uranium metal particles.

The initial radii of the nominally spherical particles whose corrosion is modeled by the straight lines may be calculated based on the slopes of those plots; i.e., $r=k^{\prime} /$ slope where $k^{\prime}$ is the linear penetration corrosion rate at the temperature of interest. The STP corrosion rates may be used to estimate the particle radii. The slope, corrosion rate, and calculated radii data are summarized in Table 3.3. It is seen that the

(a) On the other hand, anoxic conditions as shown by hydrogen gas generation can be re-established quickly even for uranium metal-rich sludge that has been aerated as found during settling tests for metal-rich KE Basin canister sludge (Makenas et al. 1997). 
uranium metal particle size estimated at each of the four tested temperatures vary around an average of $566 \mu \mathrm{m}$, plus or minus $5 \%$, at one standard deviation.

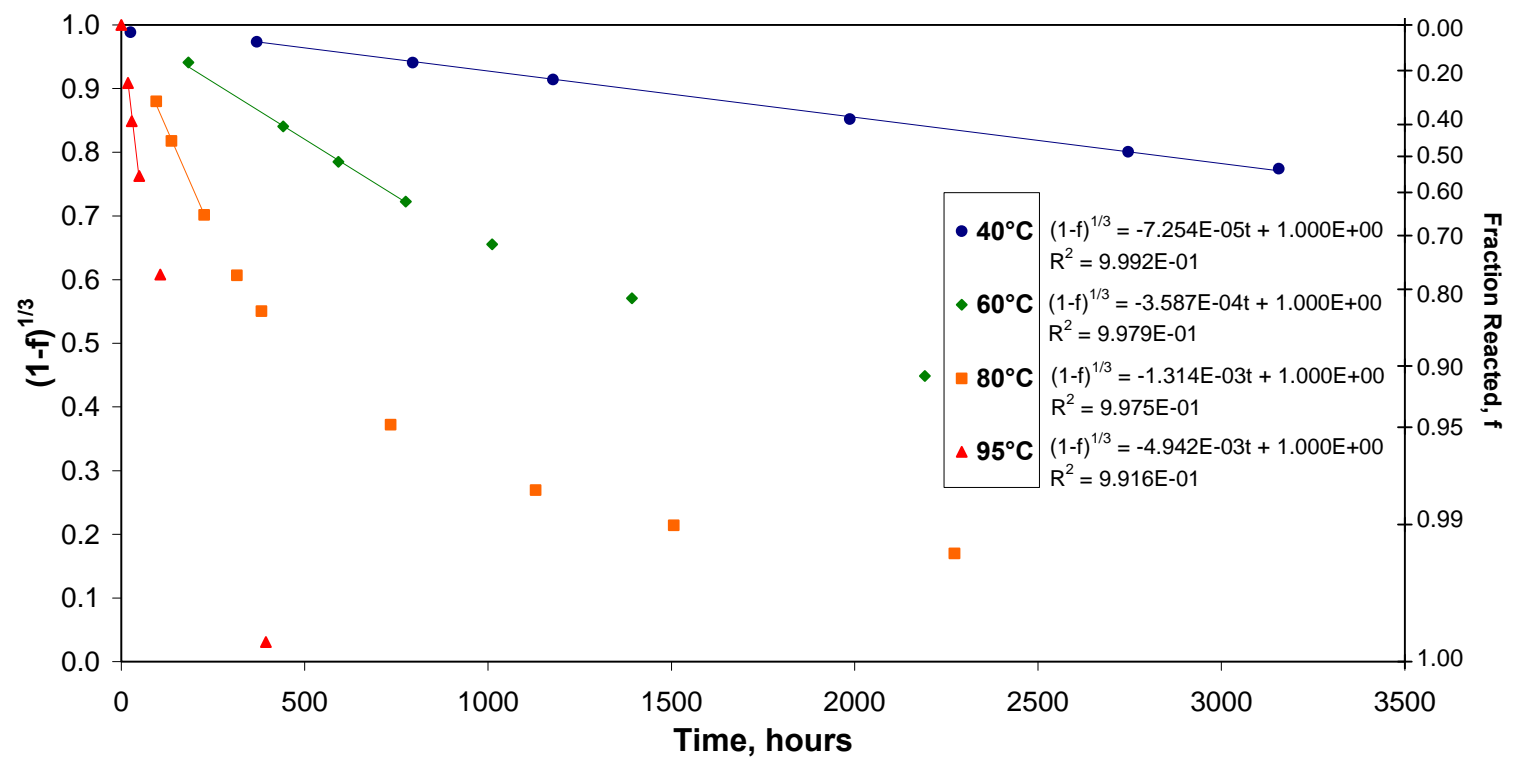

Figure 3.7. Rate of Uranium Oxidation by Water Expressed by the Shrinking Core Model

Table 3.3. Uranium Metal-Particle Size Calculation for KC-2/3 P250 Sludge

\begin{tabular}{|c|c|c|c|c|c|}
\hline $\begin{array}{l}\text { Temp., } \\
{ }^{\circ} \mathrm{C}\end{array}$ & Slope, $\mathbf{h}^{-1}$ & $\begin{array}{l}\text { Rate, } \\
\mu \mathrm{m} / \mathrm{h}\end{array}$ & $\begin{array}{c}\text { Radius, } \\
\mu \mathrm{m}\end{array}$ & $\begin{array}{c}\text { Diameter, } \\
\mu \mathrm{m}\end{array}$ & $\begin{array}{l}\text { Adj. Dia., } \\
\mu \mathrm{m}\end{array}$ \\
\hline 40 & $-7.254 \mathrm{E}-05$ & 0.0204 & 282 & 564 & 564 \\
\hline 60 & $-3.587 \mathrm{E}-04$ & 0.0986 & 275 & 550 & 550 \\
\hline 80 & $-1.314 \mathrm{E}-03$ & 0.398 & 303 & 606 & 606 \\
\hline 95 & $-4.942 \mathrm{E}-03$ & 1.026 & 208 & 415 & $544^{\text {(a) }}$ \\
\hline \multirow{2}{*}{\multicolumn{4}{|c|}{$\begin{array}{l}\text { (a) Diameter increased by the amount corroded at } \\
40^{\circ} \mathrm{C}(=2 \times 0.0204 \mu \mathrm{m} / \mathrm{h} \times 3156 \mathrm{~h}) \text {. }\end{array}$}} & Average & 566 \\
\hline & & & & Std. Dev. & 28 \\
\hline
\end{tabular}

The uranium metal particle size of $566 \mu \mathrm{m}$ models the behavior of about $1 / 2$ to $2 / 3$ of the total uranium metal. However, significant tailing of the shrinking core plot at extended reaction times indicates that larger particles exist.

A better understanding of the apparent uranium metal particle-size distribution may be obtained by creating such a distribution over a range of particle-size bins and comparing the predicted behavior with the observed behavior. This was done with the Xe release data from the $40^{\circ} \mathrm{C}$ (continued to $95^{\circ} \mathrm{C}$ ), $60^{\circ} \mathrm{C}$, and $80^{\circ} \mathrm{C}$ experiments, the STP rate data at those temperatures, the selection of diameter size bins at 300 , $400,525,600,800,1,000,1,500,2,500$, and 3,500 $\mu \mathrm{m}$, and trial-and-error assignment of uranium metal weight fractions at the selected bin sizes. A spreadsheet model was prepared to advance the corrosion of the uranium metal over time increments and compare the total corrosion with the observed progress as manifest by Xe release. As shown in Figure 3.8, the uranium metal particle-size distribution shown in Table 3.4 gave a satisfactory fit of all of the observed Xe release data. 
Table 3.4. Initial Uranium Metal Particle-Size Distribution

\begin{tabular}{|c|c|}
\hline Diameter, $\boldsymbol{\mu m}$ & Wt. Fraction \\
\hline 300 & 0.02 \\
\hline 400 & 0.18 \\
\hline 525 & 0.34 \\
\hline 600 & 0.26 \\
\hline 800 & 0.09 \\
\hline 1000 & 0.04 \\
\hline 1500 & 0.03 \\
\hline 2500 & 0.025 \\
\hline 3500 & 0.015 \\
\hline
\end{tabular}

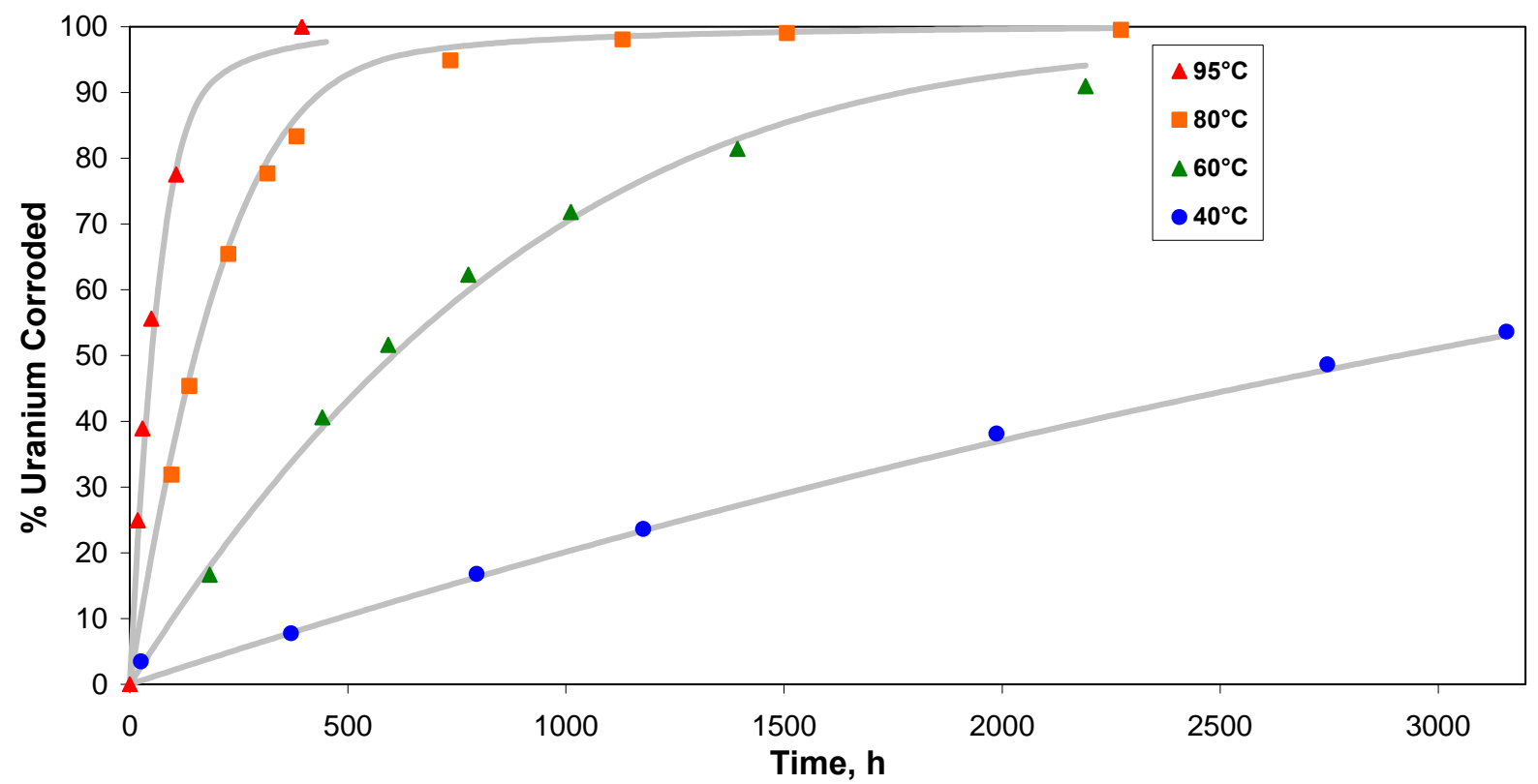

Figure 3.8. Model Shrinking Core Corrosion of Uranium Metal Versus Corrosion Observed Based on Xe Release Data

The Sauter mean diameter of the starting uranium metal size distribution shown in Table 3.4 is $560 \mu \mathrm{m}$, closely matching the $566-\mu \mathrm{m}$ shrinking core model outcome shown in Table 3.3.

Under the $15^{\circ} \mathrm{C}$ anoxic storage conditions in the $\mathrm{K}$ Basins, the linear penetration rate is $0.00210 \mu \mathrm{m} /$ hour (Table 2.1). If these anoxic conditions providing maximum corrosion rate continued, the uranium metal particle diameter would decrease $36.8 \mu \mathrm{m}$ annually such that the nominally 560 - $\mu \mathrm{m}$-diameter uranium metal particles obtained in 1999 would be $\sim 230 \mu \mathrm{m}$ in diameter 9 years later in 2008. In addition, new particles were introduced to the sludge by the irradiated fuel storage and washing, which occurred through 2004, while oxic conditions (created by basin operations, including hose-in-hose transfer) may be inhibiting corrosion as noted in Section 2.4. If oxic conditions have existed since 1999, the initial $560-\mu \mathrm{m}$-diameter particles would decrease $\sim 0.14 \mu \mathrm{m}$ annually (i.e., 260 times lower rate than under 
anoxic conditions), and the present particle size would be $\sim 559 \mu \mathrm{m}$. Overall, uranium metal in the containerized sludge certainly still exists although its size distribution in 2008 is impossible to predict. 


\subsection{Uranium Metal Oxidation in Grouted Simulated Sludge}

Grouting has been proposed as a method to treat K Basin sludge in anticipation of its offsite disposal. The goals of grouting are to fix drainable liquid and potentially inhibit the reaction of water with uranium metal, thus limiting the rate of $\mathrm{H}_{2}$ generation. Grouting tests with simulated sludges have been performed at British Nuclear Fuels, Limited (BNFL) and at Pacific Northwest National Laboratory (PNNL). Results of these tests are summarized in this section.

\subsection{BNFL Grouting Studies}

BNFL in the United Kingdom has investigated the immobilization of active metals (e.g., uranium, magnesium as Magnox cladding, and aluminum) in cementitious matrices. Results of grout solidification tests of uranium metal performed previously by BNFL were compiled in a summary report for Fluor Hanford (Godfrey et al. 2004). Eighteen tests were conducted in these studies using uranium metal "pennies" about $28 \mathrm{~mm}$ in diameter and $10 \mathrm{~mm}$ thick cut from natural uranium metal cylindrical bars. Thirty-two such pennies, about 3,300 grams total weight, were suspended on a cradle of plastic netting within a 25-liter test container, and the selected grout formulation was poured over the pennies through a ball valve at the top of the thermostatted gas-tight container. Two tests also were conducted with 20 -cm-long bars of the same diameter.

The grouts were composed of varying ratios of blast furnace slag and ordinary Portland cement (Type I, Type II, or Type I/II as known in the United States). The weight ratios of water to cement former (blast furnace slag plus cement) ranged from about $0.4: 1$ to $0.31: 1$, which is drier than the $\sim 0.5: 1$ ratios used in most grouts. The vessels were purged and then backfilled with nitrogen cover gas, and heat was applied. Each test was conducted at fixed nominal temperatures of $25^{\circ} \mathrm{C}, 40^{\circ} \mathrm{C}, 50^{\circ} \mathrm{C}$, or $60^{\circ} \mathrm{C}$. Reaction rates were monitored by ideal-gas-law techniques.

Subsequent related work for K Basin sludge treatment was performed under contract to Fluor Hanford (Godfrey and Brogdon 2004; data updated and report revised by Butcher et al. 2004). ${ }^{\text {(a) }}$ The goal of the later testing was to minimize the rate of uranium corrosion by adjusting the grout composition. These later tests also were performed using natural uranium metal pennies about $28 \mathrm{~mm}$ in diameter but $12 \mathrm{~mm}$ thick. Thirty pennies, about 3,500 to 4,500 grams total weight, were suspended on a cradle of plastic netting within a 25-liter test container, and the selected grout formulation (including the sludge simulant

(a) A European patent and U.S. patent application evidently arose out of the latter work (Godfrey et al. 2005). The approaches given in the patent and application are the same as advanced when the BNFL work was done for Fluor Hanford:

- Use inorganic peroxides to bleed oxygen gas into the grout and avoid the faster corrosion rates under anoxic conditions.

- Use cenospheres (small hollow beads, usually from fly ash) to retain oxygenated air in the grout and maintain oxic conditions (note that cenospheres also are used to produce light weight cements).

- Use dry grout formulations, with the aid of superplasticizers, to tie up the water that causes the uranium metal corrosion by the cement hydration reactions.

In addition, air-entraining agents also were proposed in the patent to improve oxygen contact with the uranium metal to retard the more rapid anoxic corrosion. 
of sand, hematite powder, and stainless steel grit) was poured over the pennies. The grout compositions were based on ordinary Portland cement with blast furnace slag or pulverized fuel ash (but not both) added as part of the cement formers. Single tests with cenospheres (spheres from fly ash with gas voids) and barium peroxide were run to test the effects of these agents that potentially can deliver oxygen to the system and thus impose the slower oxic reaction of water with uranium metal. Ten tests were run in total. The tested water-to-cement former weight ratios for eight tests were $\sim 0.21: 1$. Single tests at $\sim 0.28: 1$ and $0.31: 1$ weight ratios also were run. These ratios are drier (less water), overall, than the ratios reported in the prior BNFL work (Godfrey et al. 2004).

The test vessels were closed, purged with argon, and pressurized with argon to verify gas tightness. The grouts were cured about 4 to 6 days before the temperatures were elevated to about $60^{\circ} \mathrm{C}$. After varying induction times were overcome, steady reaction rates could be monitored by ideal-gas-law techniques. Many of the tests then were run at steady temperatures of about $20^{\circ} \mathrm{C}, 25^{\circ} \mathrm{C}$, and $40^{\circ} \mathrm{C}$ for extended periods to gather rate data at those temperatures. All tests were terminated after 125 days of reaction.

Using the prior data and the results of the testing conducted for FH, BNFL developed two uranium metal corrosion-rate expressions for grout. The first rate expression is based on the prior studies for normal grout formulations for applications where a maximum uranium corrosion rate is desired. The second rate expression, based on the drier grout formulations, is for applications where the minimum uranium corrosion rate is desired over the $\sim 20^{\circ} \mathrm{C}$ to $60^{\circ} \mathrm{C}$ range of applicability.

\subsection{PNNL Grouting Studies}

Grout-type solidification matrices have been evaluated by PNNL for their potential to fix drainable liquid and to inhibit the reaction of water with uranium metal in simulated K Basin sludge (Delegard et al. 2004b). The tests done by PNNL examined four grout formulations based on Portland cement and two formulations based on a magnesium phosphate cement called Tectonite ${ }^{\mathrm{TM}} .^{(\mathrm{a})}$

Four Portland cement grout compositions were tested in attempts to limit uranium metal reaction by limiting its access to water. The first formulation, proposed by BNFL researchers, was based on 20 -wt $\%$ ordinary Portland cement and 80 -wt $\%$ blast furnace slag with an added superplasticizer. The amount of water necessary for the wet grout slurry to be mixable can be decreased with the superplasticizer. A nominal starting point for mixable grout slurries has a water:cement former weight ratio of about 0.5:1. The test with the BNFL grout formula was conducted using a $\sim 0.20: 1$ weight ratio of water to cement former and was just mixable by hand.

Because bentonite decreases hydraulic permeability and increases the plasticity of wet grout mixtures, it, too, may decrease the rate of uranium corrosion in the present application by limiting water transport and availability to the uranium metal surface. A mixture of bentonite and Portland cement therefore was tested in which the bentonite was about $8 \%$ of the cement weight.

A masonry cement grout (Portland cement, calcium sulfate, calcium carbonate) was used in past Hanford operations to solidify uranium metal scrap (chips, turnings, fines) arising from $\mathrm{N}$ Reactor fuel fabrication. The cement-treated uranium metal scrap was shipped to Fernald, Ohio, for recovery of the contained

(a) Tectonics International, Warm Springs, OR. 
uranium (Weakley 1980). A grout of the formulation used for the uranium scrap was tested in the PNNL grouting studies. Also tested was Cast Stone (Portland cement, blast furnace slag, and fly ash), a grout formulation used in other Hanford waste immobilization applications.

Formulations using the magnesium phosphate cement, Tectonite, were tested based on the perceived potential of a matrix that could chemically combine all of the sludge water as a magnesium phosphate compound hydrate and thus prevent the water from interacting with uranium metal to form hydrogen gas. Magnesium potassium phosphate hexahydrate (i.e., $\mathrm{MgKPO}_{4} \cdot 6 \mathrm{H}_{2} \mathrm{O}$ ) is typical of magnesium phosphate cements and has been proposed for plutonium waste microencapsulation and for mixed waste treatment (Wagh et al. 1999; 2001). Magnesium potassium phosphate forms according to the reaction:

$$
\mathrm{MgO}+\mathrm{KH}_{2} \mathrm{PO}_{4}+5 \mathrm{H}_{2} \mathrm{O} \rightarrow \mathrm{MgKPO}_{4} \cdot 6 \mathrm{H}_{2} \mathrm{O}
$$

Two Tectonite formulations, one using the proprietary Tectonite alone and the second adding bentonite clay (Tectonite-Bentonite), were tested. Both were sub-stoichiometric in water according to the formation of the corresponding hexahydrate compound.

The compositions of the grouted simulated sludge test articles are shown in Table 4.1. All preparations, except the Weakley test, were made with the greatest quantities of dry grout formers that could be used and still be mixable by hand. The simulated sludge used in all tests contained $\mathrm{UO}_{2}$, silica $\left(\mathrm{SiO}_{2}\right)$ sand, uranium metal beads, and water. The test articles were cast into $41-\mathrm{mm}$-diameter right circular cylinders, allowed to cure for at least 4 days, loaded into pressure vessels, and then underwent testing using the gasgeneration test apparatus shown in Figure 3.1 and associated techniques. The testing in all cases began at $\sim 60^{\circ} \mathrm{C}$ until the induction time was overcome and a steady reaction rate, as shown by gas pressurization, was observed. The test temperatures then were raised to $\sim 80^{\circ} \mathrm{C}$ and $95^{\circ} \mathrm{C}$ before being decreased to $40^{\circ} \mathrm{C}$. Rate data were gathered at all tested temperatures to develop rate equations in Arrhenius coordinates. All tests were run to complete consumption in uranium metal at $95^{\circ} \mathrm{C}$. Analyses of the gas space compositions were done by mass spectrometry.

Table 4.1. Grouted Simulated Sludge Test Matrix

\begin{tabular}{|c|c|c|c|c|c|c|}
\hline \multirow[b]{2}{*}{ Test Name } & \multicolumn{4}{|c|}{ Sludge Component Mass, $\mathbf{g}^{(\mathbf{a})}$} & \multirow[b]{2}{*}{ Grout Component Mass } & \multirow{2}{*}{$\begin{array}{l}\text { Water: Cement } \\
\text { Former Wt. Ratio }\end{array}$} \\
\hline & $\mathbf{U}$ & $\mathbf{U O}_{2}$ & $\mathrm{SiO}_{2}$ & $\mathrm{H}_{2} \mathrm{O}$ & & \\
\hline \multicolumn{7}{|c|}{ Portland Cement Grouts } \\
\hline BNFL & 1.507 & 21.329 & 2.339 & 30.379 & $\begin{array}{l}25.682 \text { g Type I/II Portland cement; } 102.692 \text { g Grade } \\
120 \text { ground granulated blast furnace slag; } 1.402 \mathrm{~g} \\
\text { ADVA Cast } 500 \text { superplasticizer }\end{array}$ & 0.20 \\
\hline Bentonite & 1.458 & 21.294 & 2.319 & 30.187 & 61.211 g Type I/II Portland cement; 5.011 g bentonite & 0.38 \\
\hline Weakley & 1.523 & 21.305 & 2.335 & 30.230 & $\begin{array}{l}27.318 \mathrm{~g} \text { Type I/II Portland cement; } 25.630 \mathrm{~g} \mathrm{CaCO}_{3} \\
1.613 \mathrm{~g} \mathrm{CaSO}_{4} \cdot 2 \mathrm{H}_{2} \mathrm{O}\end{array}$ & 0.46 \\
\hline Cast Stone & 1.532 & 21.322 & 2.291 & 30.058 & $\begin{array}{l}100.850 \mathrm{~g} \text { Cast Stone dry mix }(10 \mathrm{wt} \% \text { Type } \mathrm{I} / \mathrm{II} \\
\text { Portland cement, } 46 \mathrm{wt} \% \text { grade } 120 \text { ground granulated } \\
\text { blast furnace slag, } 44 \mathrm{wt} \% \text { Class } \mathrm{F} \text { fly ash) }\end{array}$ & 0.25 \\
\hline \multicolumn{7}{|c|}{ Magnesium Phosphate Grouts } \\
\hline Tectonite & 1.571 & 21.263 & 2.312 & 30.089 & $187.550 \mathrm{~g}$ Tectonite neat; $6.038 \mathrm{~g}$ set retarder & 0.13 \\
\hline $\begin{array}{l}\text { Tectonite- } \\
\text { Bentonite }\end{array}$ & 1.491 & 21.273 & 2.309 & 30.010 & $\begin{array}{l}157.999 \mathrm{~g} \text { Tectonite neat; } 5.080 \mathrm{~g} \text { set retarder; } \\
15.841 \mathrm{~g} \text { bentonite }\end{array}$ & 0.14 \\
\hline
\end{tabular}




\subsection{Results of BNFL and PNNL Testing}

The results obtained from the BNFL and PNNL testing of grouted simulated sludge containing uranium metal are presented in Arrhenius coordinates in Figure 4.1 (with PNNL test results presented as a group) and Figure 4.2 (with individual PNNL grout formulations identified). The data are identical in both figures. The results in both figures are compared with the STP rate law and contributing literature data.

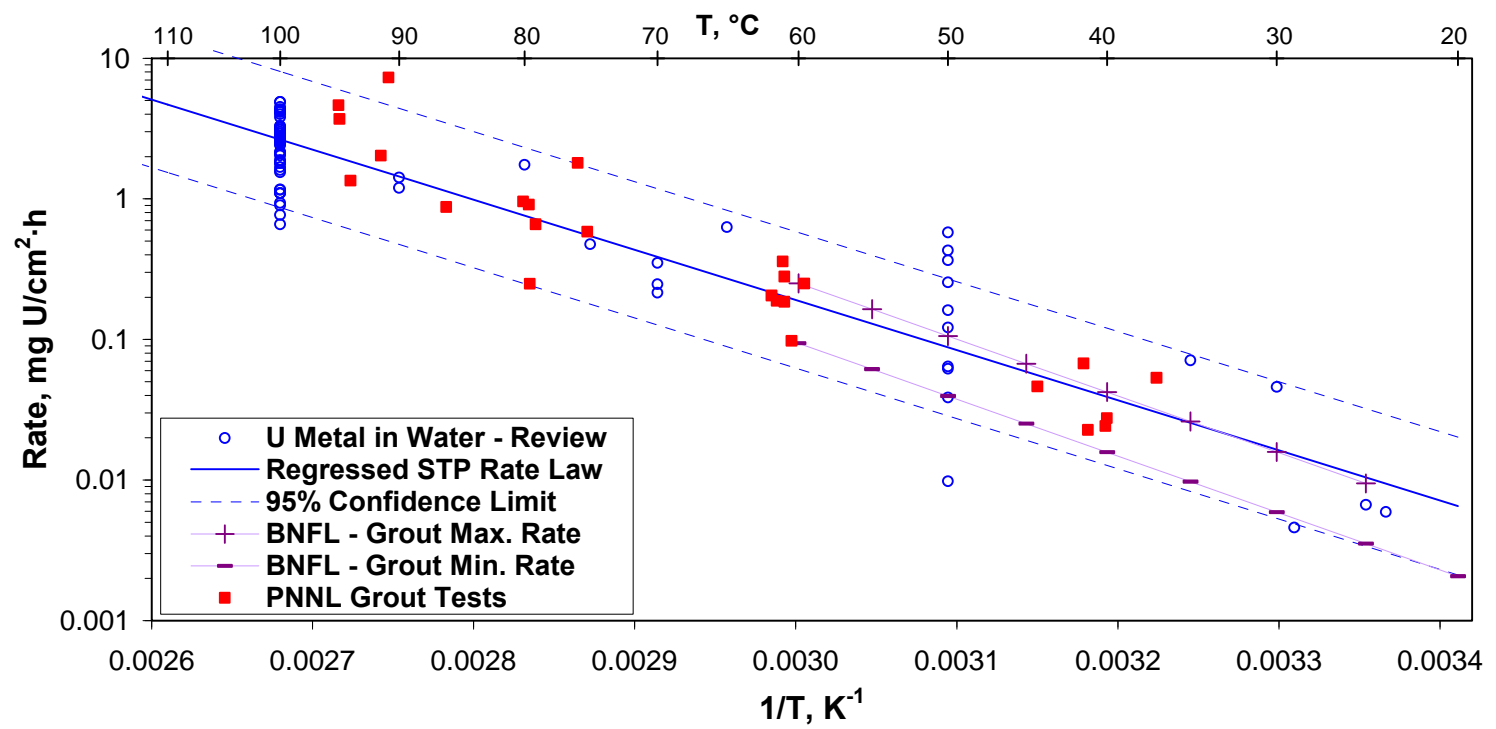

Figure 4.1. Comparison of Uranium Metal Oxidation-Rate Data from the Technical Literature with BNFL Maximum Rate Grouts (Godfrey et al. 2004), BNFL Minimum Rate Grouts (Butcher et al. 2004), and PNNL Grouts (Delegard et al. 2004b) Based on $\mathrm{H}_{2}$ Generation

The individual test data were not tabulated in the BNFL reports. Instead, Arrhenius plots of the data were provided, and regressions of the rate data were provided as rate equations. The plots of these regression lines are shown in Figure 4.1 and Figure 4.2. The trace labeled "Grout Max. Rate" arises from the work reported by Godfrey et al. (2004) for grout of typical water content and is seen to be near the STP rate law for uranium metal in anoxic water. This grout rate law also is given by Butcher et al. (2004), who commend its use for grout formulations that maximize the corrosion rate. The trace labeled "Grout Min. Rate" summarizes the observations of the tests conducted with drier grouts formulated to minimize the corrosion rate. The difference between these two rate curves is a factor of $\sim 2.7$; i.e., the "Grout Max. Rate" is about 2.7 times the "Grout Min. Rate." Although the uranium metal corrosion rates for both BNFL curves still lie within the $95 \%$ confidence limit established in the STP rate review for bare metal in anoxic water, the range of individual rate data points for the BNFL studies, particularly the "Grout Min. Rate," may vary outside the $95 \%$ confidence limits for the STP rate law.

The PNNL tests showed some variation in uranium oxidation rate with grout composition. However, all but one of the 25 observed rates were within the $95 \%$ confidence limit derived for the STP rate law for uranium metal in anoxic water. The driest grouts (i.e., BNFL grout for the Portland cement grouts and Tectonite for the magnesium phosphate grouts) did not provide the lowest reaction rates. The lowest 
rates, observed for the Portland cement grout containing bentonite (Figure 4.2), were about a factor of two lower than the nominal rate for metal alone.

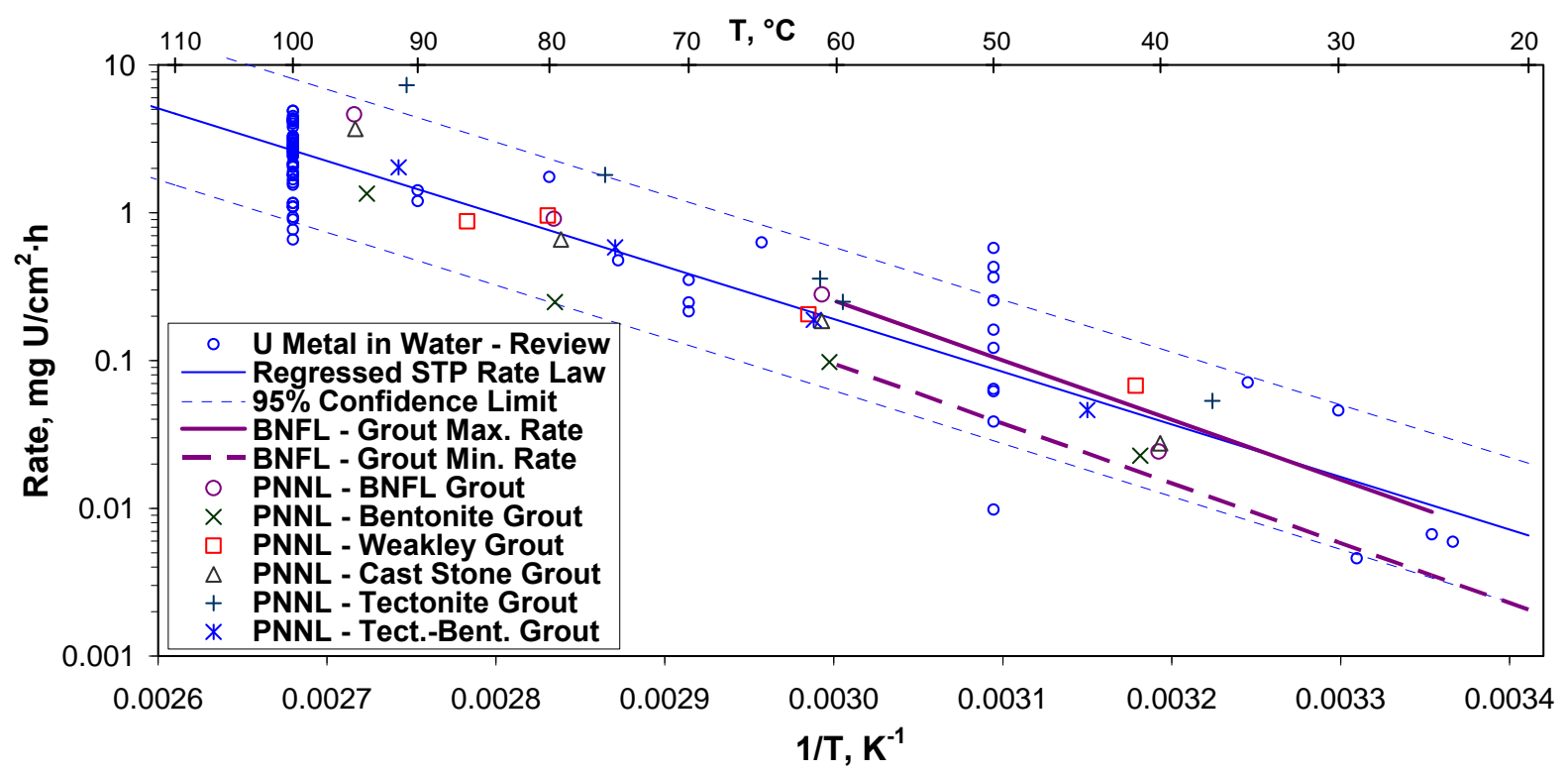

Figure 4.2. Comparison of Uranium Metal Oxidation-Rate Data from the Technical Literature with Data from BNFL Tests of Grouted Uranium Metal Pennies and Cylinders (Maximum Rates; Godfrey et al. 2004), BNFL Tests of Grouted Uranium Metal Pennies in Dry Blends (Minimum Rates; Butcher et al. 2004), and PNNL Tests of Grouted Uranium Metal Beads in Simulated Sludge (Delegard et al. 2004b) Based on $\mathrm{H}_{2}$ Generation

The gas generation testing showed that water, either present as liquid or vapor, was not sufficiently sequestered or chemically bound by the grouts to prevent reaction with the uranium metal. As is known by prior studies, under anoxic conditions, uranium metal corrosion proceeds at essentially the same rate whether immersed in water or simply present in saturated water vapor (Hilton 2000, p. 21):

Uranium corrosion in immersed water obeys linear kinetics at temperatures below $300^{\circ} \mathrm{C}$ and proceeds at a rate similar to the water vapor reaction at saturation pressure. Due to the rate similarity, the same mechanism probably controls water immersion oxidation as well as water vapor oxidation.

Water absorbed on the uranium metal and uranium oxide on the metal surface evidently was sufficient to allow the uranium metal-corrosion reaction to continue relatively unabated. The grouts, if anything, may only help decrease the uranium metal corrosion rate by altering the metal/oxide surface or perhaps diminish the rate by decreasing the water vapor pressure. However, none of the grouts was a powerful enough desiccant to significantly diminish water accessibility from the vapor phase and thus decrease the uranium metal-corrosion reaction rate. 


\subsection{Conclusions}

The corrosion of uranium metal in anoxic liquid water is of concern in $\mathrm{K}$ Basin sludge storage, treatment, and disposal. The reaction is highly exothermic and produces hydrogen gas. A survey of the technical literature was conducted to determine the corrosion rate of uranium metal in anoxic liquid water as a function of temperature. The survey identified 128 rate data points from 32 separate studies. The rate data from tests run from $\sim 24^{\circ} \mathrm{C}$ to $350^{\circ} \mathrm{C}$ ranged over a factor of four million, following an Arrhenius rate law. The data were regressed, and a rate law was derived for use by the STP with a $95 \%$ confidence level of about a factor of three.

Uranium corrosion is inhibited in oxic or aerated water with rates lower by factors of $\sim 10$ to 1,000 , depending on the study, compared with the rates under anoxic conditions. With time, the corrosion under oxic conditions can be supplanted by the more rapid anoxic rates as dissolved oxygen becomes depleted. The influences of aeration and diffusion of atmospheric oxygen to the water, radiolytic production of oxygen, and oxygen consumption by reactions with $\mathrm{UO}_{2}$ as well as uranium metal can dynamically alter the oxygen concentrations available to the uranium metal corrosion system. Restoring oxic conditions to systems under anoxic control may or may not lead to lower aerated rates as observations of both alternatives have been made. The degree of corrosion rate inhibition caused by aeration and the duration of the rate inhibition, if it occurs at all, is not predictable.

The corrosion rates of non-irradiated uranium metal with and without simulated sludge and irradiated metallic N Reactor fuel particles with and without $\mathrm{K}$ Basin sludge were measured at temperatures ranging from about $40^{\circ} \mathrm{C}$ to $95^{\circ} \mathrm{C}$ using an apparatus to monitor the gas pressure, volume, and temperature. These rates were found to correspond well with the rates observed in the technical literature for uranium metal in anoxic water. The corrosion rates for $\mathrm{N}$ Reactor fuel irradiated to $\sim 2,800 \mathrm{MWD} / \mathrm{MTU}$ found in testing for the STP, although scattered, overall were lower than the regression line by a factor of about three. Other studies in the technical literature on the effect of irradiation at the level of the $\mathrm{N}$ Reactor fuel show some rate increase with the increase being attributed to increased surface area caused by fuel swelling or fragmentation.

The concentrations of uranium metal in $\mathrm{K}$ Basin sludge were determined using the same gas-generation test apparatus. The uranium metal concentration data were found to be more reliable when based on the release of fission product gases (krypton and, with more sensitivity, xenon) than when based on hydrogen generation. Complete distribution of hydrogen to the gas phase did not necessarily occur, particularly for low uranium metal concentrations. Evidence for sequestration of hydrogen to uranium metal hydride also was observed. Uranium metal concentrations as low as about $0.004 \mathrm{wt} \%$ were observed by xenon gas release measurements. Another technique developed for measuring uranium concentration, based on the selective dissolution of oxidized uranium compounds away from uranium metal, shows a similar detection limit and is more rapid.

The size of irradiated uranium metal particles in sludge can be determined by analyzing the rate of gas generation or release. Simple completion of gas generation might be used to determine the extinction of uranium metal, provided gas analyses are done to confirm the expected hydrogen generation or xenon gas release. However, more sensitive and definitive particle sizes and size distributions can be obtained by 
multiple gas samplings and analyses for released xenon gas. A self-consistent uranium metal particle-size distribution for canister sludge KC-2/3 P250 was found with a Sauter mean diameter of about $560 \mu \mathrm{m}$.

Tests of the effects of grouting on the rate of hydrogen generation from simulated K Basin sludge have been described by two independent laboratories. Normal grouts show corrosion rates near those observed for bare uranium metal in anoxic water. A factor of 2 to 3 decrease in corrosion rate is observed by BNFL for dry grouts (compared with normal grouts) or, in PNNL tests, for Portland cement with bentonite.

The non-irradiated and irradiated uranium metal corrosion-rate data in anoxic water, simulated and genuine sludge, and in grout matrices are summarized in Figure 5.1. Nearly all rate data lie within the $95 \%$ confidence level of the rates observed for non-irradiated metal in anoxic liquid water used to produce the STP rate law. However, in side-by-side testing, uranium metal with sludge corrodes at marginally lower rates than uranium metal without sludge. Irradiated uranium corrodes at rates generally lower than comparable non-irradiated uranium. According to BNFL studies, "dry" grout formulations corrode at rates about 2.7 times lower than normal "wet" grout formulations.

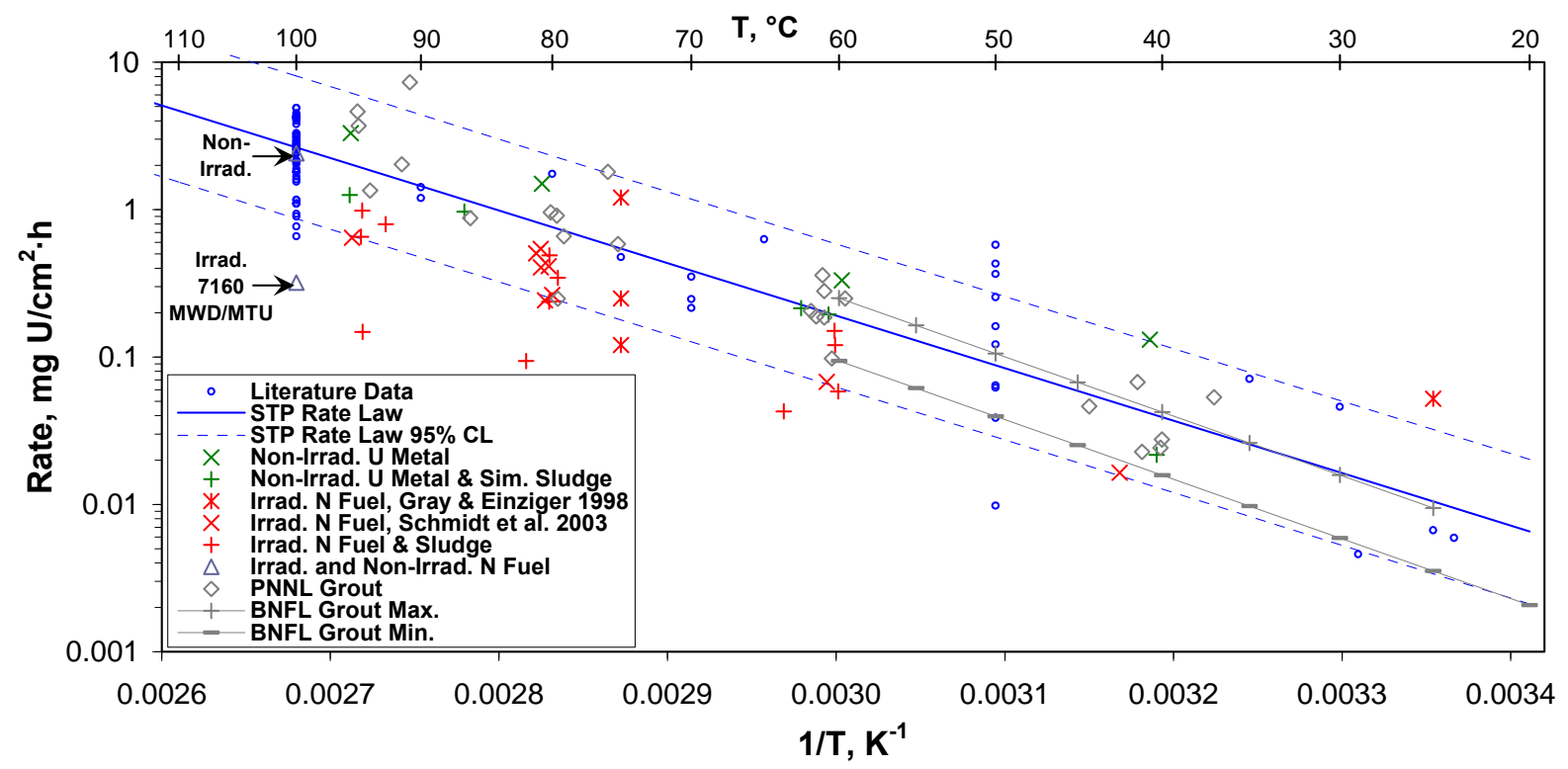

Figure 5.1. Summary of Non-Irradiated and Irradiated Uranium Metal Corrosion-Rate Data in Anoxic Water, Sludge, and Grout Matrices 


\subsection{References}

Abrefah J, and RL Sell. 1999. Oxidation of K-West Basin Spent Nuclear Fuel in Moist Helium Atmosphere. PNNL-12167, Pacific Northwest National Laboratory, Richland, WA.

Abrefah J, WJ Gray, and CV Shelton-Davis. 2000. Dissolution Rate of Unirradiated N-Reactor Fuel. PNNL-SA-33740, Pacific Northwest National Laboratory, Richland, WA.

Baker M McD, LN Less, and S Orman. 1966a. "Uranium + Water Reaction, Part 1. - Kinetics, Products and Mechanism." Transactions of the Faraday Society 62:2513-2524.

Baker M McD, LN Less, and S Orman. 1966b. "Uranium + Water Reaction, Part 2. - Effect of Oxygen and Other Gases," Transactions of the Faraday Society 62:2525-2530.

Bechtel SAIC. 2004. DSNF and Other Waste Form Degradation Abstraction. ANL-WIS-MD-000004, REV 04. DOC.20041201.0007, Bechtel SAIC Company, LLC, Las Vegas, NV. Available at: http://www.ocrwm.doe.gov/documents/amr/43458 osti/43458.pdf.

Bredt PR, CH Delegard, AJ Schmidt, and KL Silvers. 1999. Testing and Analysis of Consolidated Sludge Sample from 105K East Basin Floor and Canisters. PNNL-13341, Pacific Northwest National Laboratory, Richland, WA. Available at: http://www.pnl.gov/main/publications/external/technical_reports/PNNL-13341.pdf.

Bredt PR, CH Delegard, AJ Schmidt, KL Silvers, BM Thornton, and SR Gano. 2000. Particle Size (Sieving) and Enthalpy (Acid Calorimetry) Analysis of Single-Pull K East Basin Floor and Pit Sludges. PNNL-13373, Pacific Northwest National Laboratory, Richland, WA. Available at: http://www.pnl.gov/main/publications/external/technical_reports/PNNL-13373.pdf.

Bryan SA, CH Delegard, AJ Schmidt, RL Sell, KL Silvers, SR Gano, and BM Thornton. 2004. Gas Generation from K East Basin Sludges - Series II Testing. PNNL-13446, Rev. 1, Pacific Northwest National Laboratory, Richland, WA. Available at: http://www.pnl.gov/main/publications/external/technical_reports/PNNL-13446Rev1.pdf.

Bryan SA, LR Pederson, CM King, SV Forbes, and RL Sell. 1996. Gas Generation from Tank 241-SY103 Waste. PNL-10798, Pacific Northwest National Laboratory, Richland, WA.

Buck BJ, AL Brock, WH Johnson, and AL Ulery. 2004. "Corrosion of Depleted Uranium in an Arid Environment: Soil-Geomorphology, SEM/EDS, XRD, and Electron Microprobe Analyses." Soil \& Sediment Contamination 13:545-561.

Butcher EJ, IH Godfrey, and M Brogden. 2004. Final Report on the Minimisation of Uranium Corrosion When Treating Hanford KE and KW Basin Wastes Using Cementation. NSTS (04) 5438, Issue 01, British Nuclear Fuels Limited, Inc., Richland, WA. 
Delegard CH, SA Bryan, AJ Schmidt, PR Bredt, CM King, RL Sell, LL Burger, and KL Silvers. 2000. Gas Generation from K East Basin Sludges - Series I Testing. PNNL-13320, Pacific Northwest National Laboratory, Richland, WA.

Delegard CH, AJ Schmidt, and JW Chenault. 2004a. Mechanical Properties of K Basin Sludge Constituents and Their Surrogates. PNNL-14947, Pacific Northwest National Laboratory, Richland, WA. Available at: http://www.pnl.gov/main/publications/external/technical reports/PNNL-14947.pdf.

Delegard CH, AJ Schmidt, RL Sell, SI Sinkov, SA Bryan, SR Gano, and BM Thornton. 2004b. Final Report - Gas Generation Testing of Uranium Metal in Simulated K Basin Sludge and in Grouted Sludge Waste Forms. PNNL-14811, Pacific Northwest National Laboratory, Richland, WA. Available at: http://www.pnl.gov/main/publications/external/technical_reports/PNNL-14811.pdf.

Delegard CH, AJ Schmidt, and BM Thornton. 2007. Hydrothermal Testing of K Basin Sludge and N Reactor Fuel at Sludge Treatment Project Operating Conditions. PNNL-16496, Pacific Northwest National Laboratory, Richland, WA.

Delegard CH, SI Sinkov, AJ Schmidt, and JW Chenault. 2008. Uranium Metal Analysis via Selective Dissolution. PNNL-17800, Pacific Northwest National Laboratory, Richland, WA.

Draley JE, and GC English. 1944. Corrosion Research-Uranium and Alloys. CT-1943, University of Chicago, Chicago, IL.

Ekeroth E, M Jonsson, TE Eriksen, K Ljungqvist, S Kovács, and I Puigdomenech. 2004. "Reduction of $\mathrm{UO}_{2}{ }^{2+}$ by $\mathrm{H}_{2} . "$ Journal of Nuclear Materials 334:35-39.

Fonnesbeck JE, JR Krsul, and SG Johnson. 1998. "EBR-II Blanket Fuel Leaching Test Using Simulated J-13 Well Water." In: Proceedings of Third Topical Meeting on DOE Spent Nuclear Fuel and Fissile Materials, Vol. 2, September 1998, American Nuclear Society, Charleston, SC.

Fonnesbeck JE. 2000. Quantitative Analysis of Hydrogen Gas Formed by Aqueous Corrosion of Metallic Uranium. ANL-00/19, Argonne National Laboratory, Idaho Falls, ID.

Fonnesbeck JE. 2003. "Quantisation of Hydrogen Gas Formed by Aqueous Corrosion of Metallic Uranium.” Corrosion Engineering, Science and Technology 38(1):51-56.

Godfrey IH, EJ Butcher, and JL Parr. 2005. Encapsulation of Hazardous Waste Materials, European Patent EP1741109 and US Patent Application 10/599,897 (2007). Available at:

http://www.wipo.int/pctdb/en/wo.jsp?wo $=2005101426$ and

http://appft1.uspto.gov/netacgi/nph-

Parser?Sect $1=$ PTO2\&Sect $2=$ HITOFF $\& p=1 \& u=\% 2$ Fnetahtml $\% 2 F P T O \% 2 F$ search-

bool.html\&r=1\&f=G\&l=50\&col=AND\&d=PG01\&s1=10\%2F599897\&OS=10/599897\&RS=10/599897

Godfrey IH and M Brogden. 2004. Minimisation of Uranium Corrosion When Treating Hanford KE and KW Basin Wastes Using Cementation. NSTS (04) 4993, Issue 2, British Nuclear Fuels Limited, Inc., Richland, WA. 
Godfrey IH, M Brogden, and S Curwen. 2004. BNFL Historical Data on the Corrosion of Uranium in BFS/OPC Cement in Support of Treating Hanford KE and KW Basin Wastes Using Cementation. NSTS (04) 4992, Issue 2, British Nuclear Fuels Limited, Inc., Richland, WA.

Gray WJ, and RE Einziger. 1998. Initial Results from Dissolution Rate Testing of N Reactor Spent Fuel Over a Range of Potential Geologic Repository Aqueous Condition. DOE/SNF/REP-022, PNNL-11894, Pacific Northwest National Laboratory, Richland, WA.

Hilton, BA. 2000. Review of Oxidation Rates of DOE Spent Nuclear Fuel Part 1: Metallic Fuel. ANL-00/24, Argonne National Laboratory, Idaho Falls, ID. Available at: http://www.osti.gov/bridge/product.biblio.jsp?osti id=775264.

Kaminski MD, NM Dimitrijevic, CJ Mertz, and MM Goldberg. 2005. "Colloids from the Aqueous Corrosion of Uranium Nuclear Fuel.” Journal of Nuclear Materials 347:77-87.

Kaminski MD. 2001. Batch Tests with Unirradiated Uranium Metal Fuel Program Report. ANL-01/33. Argonne National Laboratory, Argonne, IL.

Katz JJ, and GT Seaborg. 1957. The Chemistry of the Actinide Elements. Methuen and Co., London, United Kingdom.

Kittel JH, S Greenberg, SH Paine, and JE Draley. 1956. "Effects of Irradiation on Some CorrosionResistant Fuel Alloys.” Nuclear Science and Engineering 2:431-449.

Leggett RD, and RS Kemper. 1967. Status of Metallic Uranium Fuel Technology. BNWL-CC-1444 Part 2, pp. C.151-156, Battelle-Northwest, Richland, WA.

Leggett RD. 1967. Twenty-Fifth High Temperature Fuels Meeting Preliminary Data-Metal Fuels. BNWL-CC-1384, Battelle-Northwest, Richland, WA.

Makenas BJ, TL Welsh, PR Bredt, GR Golcar, AJ Schmidt, KL Silvers, JM Tingey, AH Zacher, and RB Baker. 1999. Analysis of Internal Sludge and Cladding Coatings from N-Reactor Fuel Stored in Hanford K Basins. HNF-3589, Rev. 0, Fluor Daniel Hanford, Inc., Richland, WA.

Makenas BJ, TL Welsh, RB Baker, GR Golcar, PR Bredt, AJ Schmidt, and JM Tingey. 1998. Analysis of Sludge from Hanford K West Basin Canisters. HNF-1728, Rev. 0, Fluor Daniel Hanford, Richland, WA.

Makenas BJ, TL Welsh, RB Baker, EW Hoppe, AJ Schmidt, J Abrefah, JM Tingey, PR Bredt, and GR Golcar. 1997. Analysis of Sludge from Hanford K East Basin Canisters. HNF-SP-1201, Rev. 0, Duke Engineering \& Services Hanford, Inc., Richland, WA.

Makenas BJ, TL Welsh, RB Baker, DR Hansen, and GR Golcar. 1996. Analysis of Sludge from Hanford K East Basin Floor and Weasel Pit. WHC-SP-1182, Rev. 0, Westinghouse Hanford Company, Richland, WA. 
Mellinger GE, CH Delegard, AJ Schmidt, and GJ Sevigny. 2004. Evaluation and Recommendation of Waste Form and Packaging for Disposition of the K East Basin North Loadout Pit Sludge. PNNL-14741, Pacific Northwest National Laboratory, Richland, WA. Available at: http://www.pnl.gov/main/publications/external/technical_reports/PNNL-14741.pdf.

Mollison WA, GC English, and F Nelson. 1945. Corrosion of Uranium in Distilled Water. CT-3055, University of Chicago, Chicago, IL.

Orman S. 1963. "The Effect of Certain Gases on the Rate of Oxidation of Uranium by Water Vapour." Chemistry and Industry (42):1692-1693.

Orman S. 1976. "Oxidation of Uranium and Uranium Alloys," chapter 7, pages 815-834, of Physical Metallurgy of Uranium Alloys. In: Proceedings of the Third Army Materials Technology Conference, JJ Burke, DA Colling, AE Gorum, and J Greenspan, editors, Brook Hill Publishing Co., Chestnut Hill, MA.

Perkins KT. 1943. Oxidation Rates of Tuballoy Metal. CT-1008, University of Chicago, Chicago, IL. Figure 38, page 380, and citation 52, page 851, of WD Wilkinson. 1962. Uranium Metallurgy, Interscience Publishers, New York, NY.

Plys MG, and AJ Schmidt. 2005. Supporting Basis for SNF Project Technical Databook. SNF-7765, Rev. 3B, Fluor Hanford, Richland, WA.

Plys MG, and AJ Schmidt. 2006. Supporting Basis for SNF Project Technical Databook. SNF-7765, Rev. 3C, Fluor Hanford, Richland, WA. For uranium metal reaction rate data, see Appendix G, "Updated Evaluation of Uranium Metal Reaction Rates in Oxygen-Free Liquid Water."

Praga AN. 1998. MCO Loading and Cask Loadout Technical Manual. HNF-2169, Rev. 0, DE\&S Hanford, Inc., Richland, WA.

Ritchie AG. 1981. "A Review of the Rates of Reaction of Uranium with Oxygen and Water Vapour at Temperatures Up to $300^{\circ} \mathrm{C}$." Journal of Nuclear Materials 102:170-182.

Schmidt AJ. 2006. Spent Nuclear Fuel Project Databook, Volume 2, Sludge. HNF-SD-SNF-TI-015, Rev. 13, Fluor Hanford, Inc., Richland, WA.

Schmidt AJ, CH Delegard, SA Bryan, MR Elmore, RL Sell, KL Silvers, SR Gano, and BM Thornton. 2003. Gas Generation from K East Basin Sludges and Irradiated Metallic Uranium Fuel Particles Series III Testing. PNNL-14346, Pacific Northwest National Laboratory, Richland, WA. Available at: http://www.pnl.gov/main/publications/external/technical_reports/PNNL-14346.pdf.

Shelor JL, MG Plys, M Epstein, JP Sloughter, J Abrefah, CH Delegard, and AJ Schmidt. 2004. Gas Behavior in Large Diameter Containers (LDCs) During and Following Loading with 105K East North Loadout Pit Sludge. SNF-22059, Fluor Hanford Co., Richland, WA. 
Sinkov SI, CH Delegard, and AJ Schmidt. 2008. Preparation and Characterization of Uranium Oxides in Support of the K Basin Sludge Treatment Project. PNNL-17678, Pacific Northwest National Laboratory, Richland, WA.

Trimble DJ. 1998. Reaction Rate Constant for Uranium in Water and Water Vapor. HNF-2853, Rev. 0, Duke Engineering \& Services Hanford, Inc., Richland, WA.

Tyfield SP. 1988. "Corrosion of Reactor Grade Uranium in Aqueous Solutions Relevant to Storage and Transport." Nuclear Energy 27(2):91-98.

Waber JT. 1956. A Review of the Corrosion Behavior of Uranium, LA-2035, Los Alamos National Laboratory, Los Alamos, NM.

Wagh AS, R Strain, SY Jeong, D Reed, T Krause, and D Singh. 1999. "Stabilization of Rocky Flats PuContaminated Ash Within Chemically Bonded Phosphate Ceramics." Journal of Nuclear Materials 265:295-307.

Wagh AS, D Singh, and S-Y Jeong. 2001. "Chemically Bonded Phosphate Ceramics for Stabilization and Solidification of Mixed Waste." Chapter 6.3 in Hazardous and Radioactive Waste Treatment Technologies Handbook, CH Oh, editor. CRC Press, Boca Raton, FL.

Wagman DD, WH Evans, VB Parker, RH Schumm, I Halow, SM Bailey, KL Churney, and RL Nuttall. 1982. "The NBS Tables of Chemical Thermodynamic Properties - Selected Values for Inorganic and $\mathrm{C}_{1}$ and $\mathrm{C}_{2}$ Organic Substances in SI Units." Journal of Physical and Chemical Reference Data 11 (Supplement 2).

Weakley EA. 1980. Interim Report on Concreted Uranium Fines and Chips Billet Curing Tests: A Basis for Resuming Shipment of Concreted Uranium Scrap Billets. UNI-1454, United Nuclear, Richland, WA. 